University of Rhode Island

DigitalCommons@URI

Open Access Dissertations

1962

\title{
Factors Affecting Anthocyanin Synthesis and Morphogenesis in the Hypocotyl of Impatiens Balsamina L.
}

\author{
Allan Windsor Arnold \\ University of Rhode Island
}

Follow this and additional works at: https://digitalcommons.uri.edu/oa_diss

\section{Recommended Citation}

Arnold, Allan Windsor, "Factors Affecting Anthocyanin Synthesis and Morphogenesis in the Hypocotyl of Impatiens Balsamina L." (1962). Open Access Dissertations. Paper 795.

https://digitalcommons.uri.edu/oa_diss/795

This Dissertation is brought to you for free and open access by DigitalCommons@URI. It has been accepted for inclusion in Open Access Dissertations by an authorized administrator of DigitalCommons@URI. For more information, please contact digitalcommons-group@uri.edu. 
FACTORS. AFFECTING ANTHOCYANIN SYNTHESIS

A N D

MORPHOGENESIS IN THE HYPOCOTYL OF

IMPATIENS BAISAMINA I.

BY

AITAN WINDSOR ARNOLD

A THESIS SUBMITTED IN PARTIAL FULFILLMENT OF THE REQUIREMENTS FOR THE DEGREE OF

DOGTOR OF PHIIOSOPHY

IN

BOTANY

ONIVERSITY OF RHODE ISLAND

1962 
Copyright by

Allan Windsor Arnold

1964

, 
DOCTOR OF PHIIOSOPHY THESIS

$\mathrm{OF}$

ATILAN WINDSOR ARNOLD

Approved:

Thesis Cormittee:

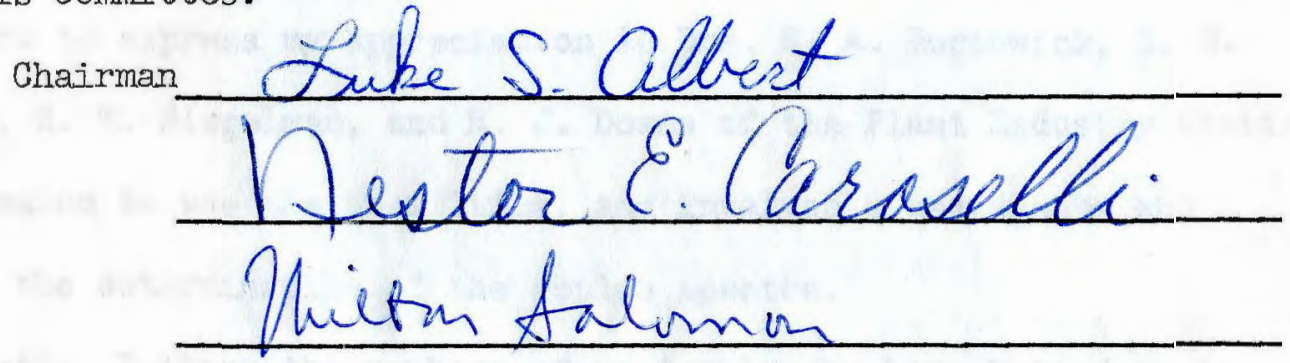

Dean of the Graduate sehool Ee Hauture

UNIVERSITY OF RHODE ISLAND

1962 
My thanks and appreciation are extended to Dr. Ralph E. Alston for his suggestions and advice in initiating this study. I thank also my major professor, Dr. Luke S. Albert, for his continued interest and constructive criticism. Drs. Nestor F. Caroselli and Milton Salomon are thanked for their careful reading of the manuscript and helpful suggestions in its preparation.

I am deeply indebted to the members of the Pioneering Research group of the Plant Industry Station, Beltsville, Maryland. In particular, I want to express my appreciation to Drs. H. A. Borthwick, S. B. Hendricks, H. W. Siegelman, and R. J. Downs of the Plant Industry Station, for permission to use the facilities, and invaluable assistance and advice in the determination of the action spectra.

Lastly, I thank the members of my family who have helped me in any way, especially my wife Pradence whose spirit and endurance contributed greatly to the over-all endeavor. 
General Scope of the Problem . . . . . . . . . 1

I. Anatomy of the hypocotyl ........... I

2. Chemical factors affecting anthocyanin formation and morphogenesis........... 2

3. Responses of the hypocotyl to light . . . . 2

II. IITERATURE REVIEW ................. . . 4

Hypocotyl Anatomy . . . . . . . . . . . . . 4

Chemical Factors Affecting Anthocyanin Formation and Morphogenesis .................. 7

I. Sugars . . . . . . . . . . . . . 7

2. Auxins: Naphthalene acetic acid (NAA), Indole acetic acid (IAA) ........ 8

3. Antiauxins: Triiodobenzoic acid (TIBA) . . . 12

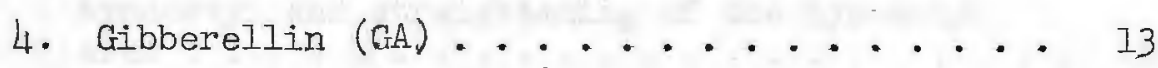

5. Purine analogues: Benzimidazole ( $\mathrm{Bz})$, Azaguanine (Aza) . . . . . . . . . I4

The Action of light on Plants . . . . . . . . . I6

I. The photoperiodic mechanism . . . . . . I6

2. High energy photoreactions........ . 23

III. MATERIAIS AND METHODS . . . . . . . . . . 26

Plant Material .............. 26

Hypocotyl Anatomy . . . . . . . . . . 26 
CHAPTER

Chemical Factors Affecting Anthocyanin

Formation and Morphogenesis . . . . . . . . . .

Responses of the Hypocotyl to Light . . . . . . . . . 34

IV.

RFSULTS

41

Hypocotyl Anatomy ................... 41

Respiration Studies ............. 63

Chemical Factors Affecting Anthocyanin

Formation and Morphogenesis ............ 63

1. Sugars ................. 66

2. Compounds affecting morphogenesis . . . . . 68

3. Purine analogues (benzinidazole and azaguamins) and riboflavin ......... 81

4. The interaction of selected chemical factors. . 85

Responses of the Hypocotyl to Light . . . . . . . . 91

1. Action spectra for anthocyanin synthesis.... . 91

2. Action spectra for elongation of the hypocotyl and straightening of the hypocotyl

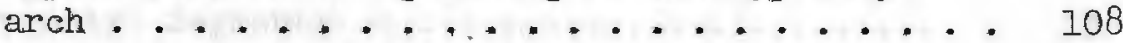

V. DISGUSSION ....................... 121

VI. SUMMARY ..................... 1.... 144

Anatomy and Respiration Rates of the Hypocotyl $* . . \quad 1 \mu_{4}$

Chemical Factors Affecting Anthocyanin Formation and Horphogenesis...................1145

Responses of the Hypocotyl to Light . . . . . . . . 146

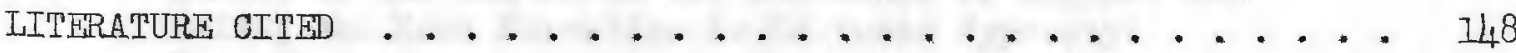


TABJ,E

PAGE

I. Formula for FAA Killing and Preserving Fluid .....

II. Constituents of White's Medium ............

III. Energy Delivered and Wave Iength at Maximum Transmittance of Interference Filters . . . . . . . .

IV. Energy Delivered and Wave Length at Maximum Transmittance of Interference Filters Used in Filongation and Arch Straightening Experiments .........

V. Mitotic Figures Found in Segment \#I of 10 Day Old Dark Grown Hypo cotyls .............

VI. Average Cell Lengths in Microns Along the Axis of the Hypocotyl

VII. Incidence of Anthocyanin Pigment and Epidermal Hairs, and Number of Roots on Segmented Hypocotyls . . . . .

VIII. Relative Amounts of Anthocyanin Formed per Hypocotyl

Segment in 10 Days ............

IX. Effect of Different Levels of NAA on the Incidence of Anthocyanin and Hairs, and the Formation of Roots on Cultured Hypocotyl Segments ...........

X. Effect of GA and TIBA on the Incidence of Anthocyanin and Hairs, and the Formation of Roots on cultured Hypo cotyl Segments ..............

XI. Effect of Different Levels of NAA on Total Anthocyanin Formed in Hypocotyl Segments . . . . . . . . .

XII. Effect of GA and TIBA on Total Anthocyanin Formed in Hypocotyl Segments.............

XIII. Effect of Aza and $\mathrm{Bz}$ on the Incidence of Pigment and Hairs, and Root Formation in Gultured Hypocotyl Segments ................

XIV. Effect of Aza and Bz on Total Anthocyanin Formed in Cultured Hypocotyl Segments .......... 
TABLE

PAGE

XV. Effect of $3 \times 10^{-4}$ Molar Rb on Hypocatyl Segments Cultured in the Dark . . . . . . . . . . . . .

XVI. Interactions of Selected Chemical Factors on the

Incidence of Anthocyanin and Hairs, and Root Formation

in Cultured Eypocatyl Segments . . . . . . . . . . .

XVII. Interactions of Selected Chemical Factors on Total

Anthocyanin Formed in Cultured Hypocotyl Segments . . .

XVIII. Relative Amounts of Anthocyanin Formed Under Different

Fluorescent light Regimes . . . . . . . . . . . . 97

XIX. Influence of a 16 Howr Preinduction Period of

Irradiation on the Relative Amounts of

Anthocyanin Formed in Hypocotyls Treated with

High Level Fluorescent, Red and Far-Red Light

XX. The Effect of Different Ievels of Fluorescent Light

on the Relative Amounts of Anthocyanin Formed in

Impatiens Hypocotyls ..................

XXI. The Action Spectram for Anthocyanin Synthesis in the

Hypocotyl of Impatiens Balsamina I. . . . . . . . . . 106

XXII. Action Maxima for the Photoreversibility of

Anthocyanin Synthesis in the Hypocotyl of

Impatiens Balsamina L.

XXIII. Rate of Flongation of Impatiens Sẹdings Grown

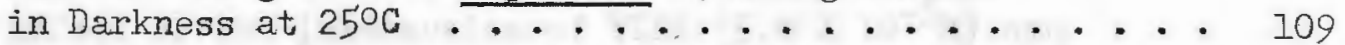

XXIV. Fffect of Red, Far-Red and Fluorescent light on

Hypocotyl Elongation.................

XXV. Effect of Different Levels of Fluorescent Light on the

Inhibition of Elongation of the Impatiens Hypocotyl . .

XXVI. Action Spectrum for the Inhibition of Elongation of the

Hypocotyl of Impatiens Balsamina I.

XXVII. Action Spectrum for the Strajghtening of the

Hypocotyl Arch of Impatiens Balsamina I. 
1. Respiration Rates of $5 \mathrm{~mm}$ Hypocotyl Segments of Impatiens Balsamina I...............

2. Rate of Oxygen Consumption of $2 \mathrm{~mm}$ Segments from the Terminal Fnd of the Hypocotyl ..........

3. Effect of NAA on the Rate of Appearance of Anthocyanin Pigments in Segment 2 of the Hypocotyl ...

4. Effect of NAA on the Rate of Appearance of Anthocyanin Pigments in Segment 9 of the Hypocotyl . .

5. Fffect of NAA Concentration of the Total Amount of Anthocyanin Formed per Hypcotyl in 10 days of Culture .................

6. Eiffect of NAA on the Quantitative Distribution of Anthocyanin Pigments Along the Axis of the Hypocotyl . .

7. Effect of NAA on the Number of Roots Formed Along the Hypocotyl Axis ..............

8. Effect of $5.0 \times 10^{-5} \mathrm{M}$ TIBA on the Quantitative Distribution of Anthöcyanin Pigments Along the Axis of the Hypocotyl . . . . . . . . . . . .

9. Effect of the Interaction of TIBA $\left(5.0 \times 10^{-5}\right.$ N) and NAA (5.0 X $10^{-6}$ M) on the Quantitative Distribution of Anthocyanin $\bar{P}$ igments along the Axis of the

Hypocotyl . . . . . . . . . . . . .

10. Effect of the Interaction of TIBA $\left(5.0 \times 10^{-5} \mathrm{M}\right)$ and NAA (5.0 \ $10^{-6}$ 整 on the Number and Distribution of Roots Along the Axis of the Hypocotyl ........

11. Effect of the Interaction of TIBA $\left(5.0 \times 10^{-5}\right.$ M) and NAA (5.0 I 10-6A) on the Formation of Fpidermal

Hairs Along the Axis of the Hypocotyl . . . . . .

12. Effect of the Interaction of $\mathrm{Bz}\left(3.0 \times 10^{-3} \mathrm{M}\right)$ and NAA (5.0 X 10-6M) on the Formation of Anthocyanin Pigments Along the Axis of the Hypocotyl . . . . . . 
FIGURE

PAGE

13. Effect of the Interaction of $\mathrm{Bz}\left(3.0 \times 10^{-3} \mathrm{M}\right)$ and NAA ( $\left.5.0 \times 10^{-6} \mathrm{M}\right)$ on the Quantitative Distribution of Anthocyanin Pigmentg Along the Axis of the Hypocotyl . . . . . . . . . . . . .

14. Effect of the Interaction of $\mathrm{Bz}\left(3.0 \times 10^{-3} \mathrm{M}\right)$ and

NAA (5.0 X $\left.10^{-6} \mathrm{M}\right)$ on the Formation of Epidermal Hairs Along the Axis of the Hypocotyl . . . . . . . .

15. Effect of the Interaction of $\mathrm{Bz}\left(3.0 \times 10^{-3} \mathrm{M}\right)$ and NAA ( $5.0 \times 10^{-6} \mathrm{M}$ ) on the Formation of Roots Along the Axis of the Hypocotyl . . . . . . . . . . . .

16. The Influence of a 16 Hour Preinduction Period of Irradiation at $250 \mathrm{ft}$. cd. on the Relative Anounts of Anthocyanin Formed in Hypocotyls Treated with High Level Fluorescent, Red and Far-Red Light . . . . .

17. Effect of Different Levels of Fluorescent Light on the Relative Amounts of Anthocyanin Formed in Impatiens Hypocotyls . . . . . . . . . . . . . .

18. Effect of Fluorescent Light to $100 \mathrm{ft}$. cd. on the Relative Amounts of Anthocyanin Formed in Impatiens Hypocotyls ....................

19. Effect of Fluorescent Iight Above $200 \mathrm{ft}$. cd. on the Relative Amounts of Anthocyanins Formed in Impatiens Hypocotyls . . . . . . . . . . . . . . .

20. Action Spectrum for Anthocyanin Synthesis in the Hypocotyl of Impatiens Balsamina I. . . . . . . . .

21. The Rate of Elongation of Impatiens Seedlings Grown

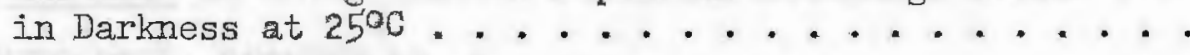

22. Effect of Different Levels of Fluorescent Iight on the Inhibition of Flongation of the Impatiens Hypocotyl .. . . . . . . . . . . . . . .

23. Action Spectrum for the Inhibition of Elongation of the Hypocotyl of Impatiens Balsamina L. . . . . . . .

24. Action Spectrum for the Straightening of the Hypocotyl Arch of Impatiens Balsamina I. . . . . . . . 
PLATE

PAGE

I. SEEDLING OF IMPATIENS BALSAMINA . . . . . . . . . . 48

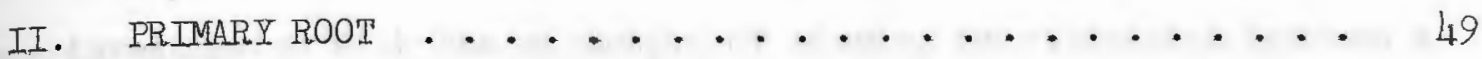

III. HYPOCOTYL: AREA OF ROOT ORIGIN . . . . . . . . . . . 50

IV. HYPOCOTYL: AREA OF ROOT ORIGIN . . . . . . . . . . . 51

V. HYPOCOTYL: LOWER LIMIT . . . . . . . . . . . . . 52

VI. HYPOCOTYL: EARIY TRANSITION . . . . . . . . . . . 53

VII. HYPOCOTYL: DEVELOPMENT OF PITH . . . . . . . . . . 54

VIII. HYPOCOTYL: DIVERGEMGE OF VASCULAR TISSUE TO FORM "TRIAD"

IX. FINAL FORMATION OF COTYLEDON TRACES . . . . . . . . . . 56

X. LONGITUDINAI SECTION OF INNER SIIE OF HYPOCOTYL ARCH

SHOWING COMPACT EPIDERMTS AND HYPODERMIS . . * . . . . 57

XI. HYPOCOTYL: CROSS SECTION IN REGION OF HYPOCOTYL ARCH SHOWING MATURE HYPODERMS GELLS . . . . . . . . . . 58

XII. HYPOCOTYL SEGMENT NO. 7 LONGITUDINAL SECTION: EARIY ROOT PRIMORDIA . . . . . . . . . . . . . . . 59

XIII. THE ORGANTZATION OF THE COTYLEDON TRACES OF IMPATIENS BAISAMTNA I. . . . . . . . . . . . . . . 61

XIV. HYPOCOTYL: SEGMENT NO. I. . . . . . . . . . . 62 


\section{A B S T R A T}

Physiological factors and conditions accompanying anthocyanin synthesis and morphogenesis in the hypocotyl of Impatiens balsamina I. were investigated with the objective of showing relationships between a biochemical process (anthocyanin synthesis) and morphogenetic events (the formation of epidermal hairs and roots, elongation of the hypocotyl, straightening of the hypocotyl arch), which may yield information on the paysiologioal control of growth and development. The scope of the problem includes a study (I) of the hypocotyl anatomy, (2) of the effects of chemical agents on the development of anthocyanins, roots, and epidermal hairs in cultured hypocotyl segments and (3) of the photocontrol of anthocyanin synthesis, hypocotyl elongation, and the straightening of the hypocatyl arch by specific regions of the visible speetrum.

Hypocotyl anatomy was studied by preparing sections from preserved 5 and 10-day-old etiolated seedlings by the paraffin technique and hand sections of fresh tissue from 15-day-old light grown seedlings. Freehand drawings were made of the paraffin sections. A gradient of differentiation from meristematic at the cotyledon end (the pseudomeristem) to mature primary tissues at the base of the hypocotyl is described. The longation of the hypocotyl arose from cell division in the pseudomeristem and cell elongation in the region just below the hypocotyl arch. The hypocotyl arch is formed through differential elongation. Nearly all anthocyanin synthesis occurs in a highly differentiated hypodermal cell 
layer.

An axial gradient of respiration for the hypocotyl was determined by measuring the rates of oxygen consurption of segments of the hypocotyl in a Warburg respirometer. The maximum rates of respiration occurred in the region of the psetadomeristem when expressed on a fresh weight basis and in the region of cell elongation on a per cell basis.

To study the effects of chemical agents, 7-daymold etiolated myocotyls grown under sterile conditions were cut into 10 segments and cultured on an agar medium supplemented with the following chemieals either singly or in combinations: (1) sugars - sucrose and glucose, (2) growth substances - Naphthalene acetic acid (NAA), Triiodobenzoic acid (MIBA) and Gibberellic acid (GA), (3) compounds known to effect anthocyanin synthesis - Azaguanine (Aza), Benzimidazole (Bz) and Riboflavin (Rb). Periodic observations on growth (root and haje formation) and anthocyanin synthesis in the hypocotyl segments were made over a period of 10 days. Glucose supported better anthocyanin synthesis than sucrose, while sucrose supported better growth of the hypocotyl segments. Results from experiments using the growth substances and the purine analogues (Aza and Bz) indicate that growth and anthocyanin synthesis are closely integrated and that their coordination is dependent on an unaltered purine metabolism. Evidence is presented that endogenous adxin levels can simultaneously influence root and hair formation, and the quantitative distribution of anthocyanins along the axis of the hypocotyl. Rb inhibited anthocyanin synthesis generally and inhibited root and hair formation in segment 1 . The high energy action spectra for anthocyanin synthesis, inhibition of hypocotyl elongation, and straightening of the hypocotyl arch 
were determined using monochromatic light sources. All three responses of the hypocotyl were shown to be photoreversibly controlled by the low energy phytochrome reaction through the use of filtered fluorescent and incandescent light. Action maxima for the high energy reaction were found at $425 \mathrm{mu}$ for anthocyanin synthesis and hypocotyl elongation and at $4 \mathrm{ll}$ mu for the straightening of the hypocotyl arch. The similarity of the action spectra indicate that a single photoreceptor was active in all three responses. It is suggested that the high energy photoreceptor is phytochrome itself and a model photomorphogenic system is proposed. 


\section{General Scope of the Problem}

The research problem reported in this thesis is an investigation of the physiological factors and conditions accompanying morphogenesis in the hypocotyl of Impatiens balsamina $I$. This is a study in morphogenesis, but the approach is more than purely descriptive. It is an effort to establish a physiological basis for observed morphogenetical responses along the axis of the hypocotyl which represents a gradient of tissue differentiation from meristematic to highly specialized tissue zones.

In a broad sense, the scope of the problem includes the study of the anatomy of the hypocotyl, the morophogenetical and physiological responses of cultured segments, and the responses of the hypocotyl to Iight. More specifically each of the three major portions of the work are designed to contribute to the major objective and may be best presented separately with their specific problems and objectives as follows:

1. Anatomy of the hypocotyl - A major aspect of this work was the observation and interpretation of morphogenetical responses of the hypocotyl. Therefore a knowledge of the basic internal structure of the experimental material was necessary. This problem consisted of the study of the patterns of the major tissue zones. In particular, attention was given to the distribution and activity of meristematic areas, and the ontogeny of the hypocotyl axis. 
2. Chemical factors affecting anthocyanin formation and morphogenesis - The primary objective in this case was to establish a system of tissue culture under standard conditions upon which periodic observations were made and used as a norm. The morphogenetical responses followed were the production of roots and epidermal hairs. The physiological response measured was the production of anthocyanin pigments in the hypocotyl segments. By altering this system with chemicals that are known to effect growth and development, with chemical agents known to effect anthocyanin formation, a correlation may be made by observing both types of responses under all treatments. The Impatiens hypocotyl provides a system for the study of the physiology of anthocyanin synthesis while anthocyanin itself represents a labile overt physiological indicator which is associated with morphogenetical responses.

3. Responses of the hypocotyl to light - Action spectra for anthocyanin synthesis and inhibition of hypocotyl elongation in the visible portion of the spectrum were obtained. The action on these responses of the red - far-red photoreversible system i.e. the pigment phytochrome was also studied. This portion of the work complements the main objective of the comparative study of the morphological response of elongation and the physiological response of anthocyanin synthesis.

This research problem developed from a rather extensive genetic and physiological study of flavonoid pigments in Impatiens balsamina. Previous studies have involved the inheritance of flower and stem color (48), chemical changes affected by genes controling pigmentation (4), quantitative effects of specific genes (75), leucoanthocyanin synthesis in the Impatiens 
hypocotyl $(2,3)$, and a morphogenetic-physiological study of anthocyanin synthesis in cultured petals of Impatiens (94). 


\section{H A P ER I I}

\section{I.I T E R A T U E R E V I E W}

\section{Hypocotyl Anatomy}

Considerable research on the plant axis has involved the anatomy and ontogeny of the stem and root, while the hypocotyl has received relatively little attention.

Esau (56) describes the vascular pattern of a dicotyledon hypocotyl (Beta vulgaris), but provides few references to other hypocotyl studies. Thomas (150) argues in favor of the phylogenetic significance of the vascular patterns of selected seedlings from Ranales, Rhoedales, and Rosales. other early investigations (45, 46, 151) consider the vasculation and theoretical concept of the transition region, but they are not detailed studies of the entire hypocotyl anatomy. From a morphogenetical and Mhasiological standpoint these early studies contain very little pertinent information.

More recent work on the dicot axis concerning elongation and root formation, although limited, providas useful information. In a series of publications by Bouillenne et al $(30,31,32)$ and Noel (110, 111), many aspects of the growth and development and physiology of the Impatiens hypocotyl are reported. Noel (III) conducted a study in which he describes the vascular pattern and nature of growth of the hypocotyl of Impatiens. He found a tetrarch xylem structure with alternating zones of phloem tissue foniformly distributed around the periphery of the stele". In this very brief account he also describes the cotyledonary traces as arising from 
the bifurcation of two of the four xylem strands which yields a total of three traces per cotyledon. It is interesting to note that since the studies of Bouillenne and Noel were directed toward the classical subject of the de novo formation of roots by "rizocaline", Noel (110) described the lateral traces as being larger and more "important" than the median traces of the cotyledons with respect to the translocation of the theoretical substance. In this same extensive report, observations of the site and nature of growth of the hypocotyl were made. It was found that in an etiolated hypocotyl elongating from 25 to $75 \mathrm{~mm}$, over $90 \%$ of the growth occurred in the uppermost $10 \mathrm{~mm}$ of the $25 \mathrm{~mm}$ hypocotyl. Noel concludes the following from this data:

The growth of the hypocotyl is realized from the intercalary elongation (of the cells) due to the uptake of water, then in part from the cellular mutiplications of the pseudomeristem tissue at the apex.

Noel assumes that cell divisions do occur at the apex of the hypocotyl which he defines as being immediately below the point of attachment of the otyledons. Since no cytological studies were conducted, the question arises as to whether the concept of a "pseudomeristem" functioning in conjunction with cell elongation is a valid one. Even if cell divisions do occur in this region, do these cell divisions contribute to overall growth?

Other studies on axis elongation provide some insight into the above questions. In studying the growth capacity of the sunflower hypocotyl, de Ropp (50) reported that elongation was limited to the uppermost $10 \mathrm{~mm}$. This data, was collected from cultured hypocotyl segments. Again, because of the lack of cytological data, little can be said as to the mechanism of 
this elongation. BindIos (15) conducted a comprehensive study of stem Gongation in normal and dwarf varieties of Lycopersicum elegans and Zinnia elegans. She makes the significant statement:

It is no longer possible to think that the chief center of cell division is in the relatively short zone of 60 to 100 microns from the stem tip.

This concept is supported by extensive eytological data in which frequent cell divisions are shown to occur in vacuolate cells. Sinnott and Bloch (136) have also described the division of vacuolate plant cells. A similar system could be operative in the Impatiens hypocotyl.

Other interesting facts about the special nature of certain tissue zones of the hypocotyl are reported by Resch (123). He conducted a study of nuclear differentiation in epidermal and subepidermal cells (single layer of cells directly below the epidermis which will hereafter be referred to as the hypodermis) of Vicia faba, Impatiens balsamina, and Cleome spinosa. He found that the epidermal cells in Impatiens remain diploid during the growth of the shoot, whereas the comparatively large hypodermal cells become 8-to 16-ploid. The polyploid condition is brought about by a process of endomitosis in which different chromosomes divided at different times. Resch concludes that the necessary chromosomal growth may be brought about through the reproduction of gene material either in many diploid or in few polyploid cells.

In summary, the fundamental structure and growth pattern of the Impatiens hypocotyl has been described by Noel and forms a basis for further study. The developmental studies of Noel and others on the hypocotyl and stem axis present implications as to the possible meristematic nature of 
npocotyl elongation and growth. The questions of the exact nature of the "Feudomeristem" and the distribution of secondary meristems along the length of the hypocotyl are not answered. These questions are primary objectives of the present study.

Cregical Factors Affecting Anthocyanin Formation and Morphogenesis

The numerous reviews available are indicative of the large volume of work done in the field of plant growth regulators $(13,58,68,138)$. Several comprehensive reviews on the flavanoid pigments $(7,18,19,89)$ are also available. Recent literature indicates an intimate association of flavonoid metabolism with growth and development, but little work has been done to interrelate the two through the external application of chemical factors. Since the initiation of this study such an approach to the study of growth and development has been taken by Klein and Hagen (94).

The action of specific chemical factors on morphogenesis and anthocyanin formation will be treated individually. The following chemical factors are those used in the present study: (1) the sugars, glucose and sucrose, (2) napthalene acetic acid (NAA), (3) triiodobenzoic acid (TIBA), (4) gibberellin, (5) the purine analogies, benzimidazole and azaguanine.

1. Sugars - In general the feeding of simple sugars promotes both growth and anthocyanin formation in many plants (1). Thimann and Edmundson (147) briefly review the work before 1949 and report sucrose most effective for anthocyanin synthesis in Spirodela. Thimann et al (146) later found that glucose was used preferentially for growth while sucrose was used for anthocyanin production. Fructose was found to have an intermediate effect. Eddy and Mapson (55) found that a number of simple sugars enhanced mathocyanin formation in cress seedlings, glucose being the most effective. 
In more recent work Straus (1/4) found sucrase to be more effective for anthocyanin formation than either glucose or fructose in cultured corn endosperm tissue. Contrary to the results of Thimann et al (146), sucrose also supported the best growth of the corn endosperm. Armold and Alston (6) compared the efficiencies of glucose and sucrose in promoting growth and anthocyanin formation in cultured hypocotyl segments of Impatiens balsamina. They found in general that glucose was oonsiderably more fficient than sucrose in supporting anthocyanin formation but was less afficient in supporting the initiation of epidermal hairs and roots. The responses were variad in different segments of the hypocotyl with respect to their position along the axis. At certain points along the axis of the hypocotyl the responses were different than the over-all results. For instance, sucrose was much more effective than glucose in promoting root and hair initiation in segments near the base of the hypocotyl while they were nearly equal in effectiveness in the relatively undifferentiated uppermost few segments. This situation was nearly reversed in respect to anthocyanin formation. This supports the idea (19) that different tissues and experimental objects vary in their utilization of simple sugars. This variability appears to depend on numerous obscure physiological factors.

2. Auxins: Napthalene acetic acid (NAA), Indole acetic acid (IAA) Several recent reviews $(13,58,68,138)$ thoroughly cover the field of indole auxins and related compounds. Galston and Purves (68) summarize the known effects of auxin and remark that only the effect of cell elongation has been intensively studied. They lists the following effects: a) increased cell wall plasticity, b) increased water uptake, c) altered permeability 
patterns, d) decreased protoplasmic viscosity, e) increased rate of oplasmic streaming, f) altered respiratory patterns, and g) altered muleic acid metabolism. All of these effects have been noted in the study of elongation responses. The known and pastulated interconversions of indole derivatives that occur in the plant cell are presented by Fawcett (58). The metabolism of the indole nucleus is a complex process involving many phases of the physiology of the cell. Even though much work has been carried out on the study of auxin action, no reliable conclusions can be drawn as to its mechanism or site of action in the cell (13).

Despite this situation descriptive and biochemical data are available which indicate the action of auxins and their possible interactions with the formation of cellular products such as anthocyanins.

It has long been known that various levels of auxin will stimulate stem growth, inhibit root growth, and cause the initiation of new roots (9). It is interesting that auxin stimulates root growth at $10^{-5}$ to $10^{-4}$ ppm. Whereas it strongly inhibits root growth in the range of 8 to $10 \mathrm{ppm}$. 耳owever, this latter concentration ( 8 to io ppm.) is very effective in thimulating stem growth (9). IAA has been observed to inhibit root formation at high levels in Impatiens balsamina hypocotyls, but favored the Pormation of epidermal hairs (6). Cultured segments of balsam hypacatyls have the capacity to form roots, epidermal hairs, and anthocyanin pigments, all of which are affected by levels of NAA. Similar studies with the sunflower hypocotyl (50) have been made except that pigment formation was not observed. 
High levels of NAA are known to cause tumorous growths in cultured balsam hypocotyl segments and at the same time enhance anthocyanin production $(1,6)$. Studies on the effects of light on auxin activity have shown a close association between flavanoid synthesis and auxin levels. Also, Increased levels of sucrose have been shown to increase auxin activity (121) in etiolated pea epicotyl segments. Numerous workers have tested for the interaction of auxins and gibberellins with photoinduction of flowering $(21,49,98,99,145)$ and photoinhibition of stem elongation (135, 164). Galston et al (67), Furuya et al $(64,65)$, and Hillman et al (83) in extensive studies on the elongation responses of Pisum seedlings and stem sections have shown an intimate connection between indoleacetic acid action and the photoperiod mechanism. It was initially found (67) that low levels of red light in the region of $660 \mathrm{mu}$ caused a l00-fold decrease in sensitivity of Pisum stem sections to indoleacetic acid. In later work $(64,83)$ it was demonstrated that a dialyzable cofactor, acting as an inhibitor of IAA-oxidase, was under the photoreversible control of phytochrome. The latest statement on this work identifies the inhibitor as two different quercitin glucosides which are found only in light treated seedlings (65). In addition two derivatives of kaempierol were found to be natural cofactors. other workers interested in this same problem have isolated an IAA-oxidase inhibitor from pea tips and identified it as a 3-(p-hydroxycinnamoyltriglueosyl) derivative of kmemperol (107, 137). They coneluded that the 3,7 Mydroxy-flavones as a group are auxin inhibitors (107). Also, naringenin and apigenin-7-gIucoside were found to be cofactors for IAA-oxidase. This work effectively links the photomorphogenic system with the action of IAA. 
Various substituted phenols have been known to interact as cofactors or inhibitors in IAA activity $(72,73,74)$. The findings of Mumford et al (107) conld explain the auxin activities of certain phenyl prapanoid ampounds $(158)$. It has been suggested $(65,107,137)$ that the red, farred system may control auxin activity by controlling the balance of IAAaxidase cofactors and inhibitors. These findings have placed considerable Mological and morphogenetical significance upon the flavonoids. Theoretical considerations of Birch and Donovan (16) and later work by Wnderhill et al (157) and Watkin et al (161) have shown the importance of acetate metabolism in the formation of the flavone nucleus. In light of this work, it would seem that any upset of metabolically active acetate would directly effect anthocyanin formation (1). There is considerable evidence that auxins are directly involved in acetate metabalism. The work of Leopold and Guernsey (101) and Siegel and Galston (129) has indicated the formation of a thioester of IAA and coenzyme-A which raises the possibility that auxins may influence the metabolism of aoyl-coenzyme-A compounds. Later, work by Nance and Shigemura (109a) showed that the aerobic evolution of acetaldehyde is promated by various auxins and antiauxins in wheat roots, corn and pea stems. More recent work by Nance (109) and Perlis and Nance (116) using $0^{14}$ - acetate and pyruvate has shown that IAA strorgly affects the uptake and utilization of these compounds by pea stem sections.

Considering the above information it would not be surprising to find that NAA or similar compounds strongly influence anthocyanin formation. The obvious correlations between the well known work of Siegelman and 
Hendricks (131) on the photocontrol of alcohol and aldehyde production in apple skin, the recently show control of auxin activity by the red-far red atomorphogenic system $(64,65,83,107,137)$, and the apparent involvement of auxins with the metabolism of acyl-coenzyme-A compounds (101, 109, 116, 129) indicate the important interrelated metabolie systems through which nthocyanin synthesis may be influenced.

\section{Antiauxins: Triiodobenzoic acid (TIBA) - TIBA is known as an} antiauxin but is not considered as such by all because it does not act as a direct competitor with auxin (13). It has been shown to effectively lower the auxin levels within treated roots (9). TIBA is also known to drasticalIy lower free auxin levels in some seedlings (10, 11) and to induce an abscission layer in kidney bean (Phaseolus vulgaris) internodes upon application to the terminal bud (163). These effects are alleviated by applying auxins. The general class of compounds acting as antiauxins have been shown to be effective in inducing flowering in tomato (173) even in early post-germination stages of growth (51). TIBA has been shown to counteract the effect of supplementary low level irradiation which would rinarily inhibit flowering in the short-day plant; Xanthium (20), whereas applied axin inhibited photoperiodically induced flowering in Xanthium (21). Galston (66) has shown that TIBA causes short-day plants to flower more prolifically even after they have been induced to do so by a favorable photoperiod. Thus far no clear relationship between IIBA and flowering has been shown in long-day plants (9).

In addition to the above anti-auxin properties of IIBA, it has also been shown to suppress apical dominance in rose bushes (8). Bushes treated 
with IIBA ( $1 \%$ solution in lanolin paste) produged nearly three times the number of lateral shoots than untreated controls.

With the exception of the work of Klein and Hagen (94) the author is unaware of any work dealing with TIBA and anthecyanin formation.

Immature petals of Impatiens balsamina cultured in the presence of 5 mg/ 1 of TIBA expanded and lost their chlorophyll as did the controls, but the concomitant onset of anthocyanin synthesis was delayed for two days. After the delay, anthoeyanin formation was rapid and reached 65\% of the controls at the end of 10 days. The significance of this observation is difficult to assay. However, the workers interpreted it as a disturbance between the apparently close relationship of morphological and biochemical events which indicated that both phenomena are under hormonal control. 4. Gibberellin (GA) - The numerous reviews (33, 35, 43, 118, 139 to 142,171 ) dealing with the physiological action, chemistry, and applied aspects of this single class of growth-regulators is indicative of the vast literature dealing with the gibberellins.

The gibberellins are defined (II8) as substances possessing the same earbon skeleton as gibberellin $A_{3}$ (gibberellic acid) or a closely ralated compound. These compounds stimulate cell division, cell elongation, or both when applied to plants (37) and are found as natural products in many plants. There is a series of gibberellins which differ slightly in chemical structure and which are effective as the acid, the salt, or in an acylated or esterified form (139).

Although the gibberellins are known to promote cell division and Llongation, they have been shown by many warkers $(38,91,128)$ to be potent 
inhibitors of rooting. Recently Brian et al (36) have shown that the root inhibiting capacity of gibberellin is independent of the elongation of the test object. This cast considerable doubt on the theory that the gibberellins caused a rapid movement of foods and nutrients to the apex and thereby inhibited root formation (34). It was also shown that the interaction between gibberellin and auxin is non-competitive (36).

Recent work has associated relative activity of gibberellic acid with the presence of flavonoids and phenolic compounds in various plants (154, 155). This work indicates that quercitin glycasides may be recessary for activity.

5. Purine Analogues: Benzimidazole (Bz) and Azaquanine (Aza) Although compounds of this class are generally regarded as antipurine agents, it appears that benzimidazole in particular may act on other systems. Person et al (117) found that the presenee of benzimidazole protected detached wheat leaves floated on water from the rapid degeneration which is usually noted. The usual rise in respiration rate of detached leaves was depressed. Benzimidazole is known to be an effective respiratory inkibitor (172). The leaves treated with benzimidazole did not show as rapid a loss of chlorophyll as in the control, and had lower levels of free amino acids and amides. These effects could not be obtained with numerous purine analogues including az\&quanine. Continuing the studies of the effects of benzimidazole on detached wheat leaves, Samborski et al (127) found an increase in protein content over the controls which was apparently caused by the prevention of protein breakdown. Benzimidazole also prevented an increase of soluble nitrogen and alcohol-soluble earbohydrate which usually 
accompanies leaf detachment. In these studies benzimidazole apparently "conserves protein".

Banzimidazole has been shown to inhibit IAA-induced elongation (69) and cause specific patterns of growth in pea stem seetions. Hillman (82) has reported that root growth is inhibited and frond area in Lemna is 1 tereased by 65-70\%. Hillman also found that benzimidazole is a direct inhibitor of polyphenol oxidase and that at least some of its effects are due to the sequestration of copper. The influence of benzimidazole on mallic cations has been studied by Klingensmith (96) and McCorquodale et al (103). In the latter study it was shown that magnesium ion ( $\mathrm{Mg}^{++}$) relieved root growth inhibition in Vicia faba caused by benzimidazole. The presence of an unidentified black pigment was noted in the treated roots. Growth inhibition was apparently accomplished through the depression of mitotic activity.

Thimann et al $(148,149)$ demonstrated that purine and pyrimidine malogues strongly influence anthocyanin pigment formation in Spirodela. They found that azaquanine was an exceedingiy potent inhibitor of anthocyanin synthesis. The effects of the anti-pyrimidine and purines were attributed in part to the inhibition of copper containing enzymes. Inhibition of anthocyanin synthesis could be alleviated by the addition of copper. Azaquanine on the other hand was shown to inhibit riboflavin ynthesis as well as anthocyanin. The addition of riboflavin reverses the effect of azaquanine on anthocyanin synthesis. Riboflavin also took the place of the light requirement for anthocyanin formation in Spirodela. 
Straus (143), in contrast, reported slight stimulatory effects by - aquanine and inhibitory effects by riboflavin on anthocyanin synthesis in enltired corn endosperm tissue. These differences in effects remain explained, with the exception of the suggestion (143) that the experimental objects used are very different in their physiology. Spirodela was ned by Thimann and coworkers as an intact plant. The corn endosperm tissue used by Straus was undiferontiated, non photosynthetic, and grown in sterile tissue culture.

Action of Iight on Plants

The modern era of the study of the effects of light on plants began with the well known discovery of photoperiodism by Garner and Allard in the early 1920's $(70,71)$. They clearly defined the phenomenon of photoperiodism in plants and initiated a line of research which has born the fruit of much fundamental information on growth and development. The photoresponsive system upon which photoperiodism rests is now known to control many other aspects of growth and metabolism $(23,106)$. Various authors have found photoperiodic responses in the algae (84) and liverworts (160) as well as in the higher plants.

1. The Photoperiodie Mechanism - In general the photoresponses of plants (excluding photosynthesis) can be divided into two types: those Foquiring relatively low energies ( $<.01$ Joule) and those requiring high mergies ( $>1.0$ Jaule) (80). The former type of response is under the control of the photomorphogenetic pigment, phytochrome, and is characterized by saturation extremely low light intensities while the latter type is 
trpified by the direct response to increasing radiant energies over a wide range.

As might be expected, the low energy responses were observed first and have been studied most intensively. As early as 1871, Batalin (12) realized that only very low intensities of light were needed to effect the gomeral development of most plants. Since the pioneering work of Garner and Allard (70, 71) concerned the flowering response, most studies were encerned with surveys of the occurrence of photoperiodism in various plants for more than a decade afterwards (23). A few early workers did consider the effect of the spectral quality of light on photoperiodism previous to the prolication of the first detailed action spectrum for flowering by Parker et al in 1945 (115). The red portion of the spectrum was shown to influence flowering by several investigators. This was shown by Vogt in 1915 (159) and later studied by Trumpf (156) and Lang (100). Also Razumov (122) showed that red light of low intensities could be used to effectively lengthen the photoperiod of both long and short-day plants. He raported that the shorter wave lengths of the visible spectrum had little effect. On the other hand, some researchers claimed that the llowering response could be controlled by light from any part of the Fisible spectrum $(92,95)$. Withrow and collaborators (167, 168) found that low levels of red and white irradiation induced flowering in long-day plants and inhibited flowering in short-day plants. In these experiments the low intensity irradiation was used as a supplement to a natural short day. Certain long-day plants such as the sunflower (Helianthus annuus) Were found to flower in response to blue light as well as red (63). Other long-day plants such as Scabiosa responded only to the long wavelengths 
(63). The literature at this time was replete with such contradictions. Attempts were made to classify the long and short-day plants according to their apparently different responses $(61,62,63)$. Around this time it had been shown by withrow et al (167) and later by Borthwick and Parker (25) that very low intensities of incandescent lamp radiation ( $(0.5$ ft. cd.) were sufficient to cause a photo-periadia response in the China Aster (Gallistephus chinensis) and Biloxi soybean (Soja max (I.) Piper). From this Withrow et al (169) perceived that very small amounts of antaminating red light could cause the apparent response of some plants to blue light. They studied a number of long and short-day plants, faluding those with reportedly anomalous responses, by using combination copper sulfate and gelatine filters which would deliver light of known ppectral purity and equal energy. The results were very significant, because they were able to discount the apparent blue effects and advance a unified hypothesis for the low energy flowering response. Since all plants that they tested responded to red light, they postulated that there must be a pigment with an absorption maximum in the red which was the same in all the plants regardless of their daylength requirements. Other Important observations in this same work were that, total dry matter, height, top-root ratio, and leaf area of the test plants were all Influenced primarily by the red portion of the spectrum. It was also noted in this work that the blue and violet end of the spectrum appeared to have some minor effects.

After the work of Withrow et al (167 to 169) there was an obvious need for detailed action spectra. Action maxima of specific wavelength would yield important clues as to the nature of the photoperiad mechanism. The study of detailed action spectra became possible with the construct- 
ion of the specially designed spectrograph in $19 \psi_{4}$ at the Plant Industry Station of the United States Department of Agriculture, Beltsville, Maryland. This instrument is described in some detail by Parker et al (114, 115). Because of the low energy requirements of the flowering response it was feasible to use an instrument which delivered a high degree of pectral dispersion and purity but yielded low light energies. The Fisible spectrum could be projected at a width of about 2 meters and a helght of $10 \mathrm{~cm}$. $(174)$.

The first action spectra (114, 115) of the fllowering response were found for the short day plants, Bilaxi soybean and the cocklebur, (Xanthium, whartum Wallr). The results for the two plants were essentially Identical showing action maxima in the red at about $660 \mathrm{mu}$ and lesser peaks in the blue at about $440 \mathrm{mu}$. The action found in the blue was low and not consistent. Because of the similarities of these action spectra to that of photo-synthesis, chlorophyll was first considered as the photo-receptor. theoretical considerations (114) of factors involved in the self-screening effect of chloroplasts at points of maximum absorption are used as passible anations of the low efficiency in the blue and of the braad action in the jellow and red (600 to $680 \mathrm{mu}$ ). The Beltsville workers then determined action spectra for the promotion of floweriag of the lang-day plants, barley (Hordeum vulgare) and honbane (Hyocyamus niger I.) (27, 113). The results were qualitatively very similar to the previous studies on the Dort-day plants. At this stage of development the action spectrum of Qtotoperiodism was known to have a prominent maximum at $660 \mathrm{mu}$ and a some- 
what actionable minor action in the blue at about $400 \mathrm{mu}$. The ratio of

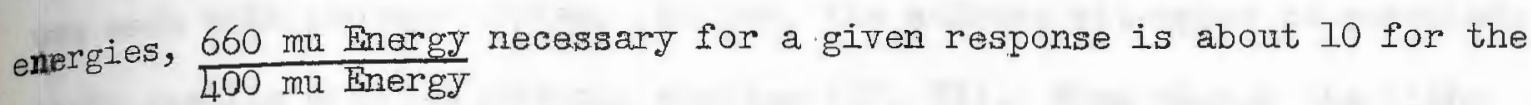
cocklebur, but is appraximately 250 for barley and even greater in henbane (23). This inconsistency cast some doubt upon the validity of the blue action.

The next major step in the quest for the understanding of photoperiodism was not brought about by the study of flowering, but came about from keen observation of the germination of light sensitive seeds (23). Light has long been known to effect the germination of some seeds as is evidenced by the reports of Caspary in 1861 (42) and Resühr in 1939 (124). Reviews on this subject $(47,57,152,153)$ allow one to trace the development of knowledge almost to the present. This review is primarily coneerned with the literature on seed germination of the last decade which has contributed directly to the understanding of the photoperiod mechanism. Certain earlier work, however, is worthy of special comment.

The work of Flint and MaAlister in 1.935 (60) and Flint in 1936 (59) on the germination of light sensitive lettuce seed (Iactuca sativa I.) provided a basis for the concept of photo-reversability. This work is sumarized by Johnston (86). Previously imbibed lettuce seeds were given a dose of red light that would promote $50 \%$ germination and then placed across a prismatic spectrum. The portion of the spectrum from about 600 to $700 \mathrm{mu}$ promoted germination to $100 \%$. The most significant finding was a band from 720 to $770 \mathrm{mu}$ which completely inhibited germination. A relatively waak band of inhibition was also found in the blue between 400 and $500 \mathrm{ma}$. The significance of the inhibitory effect at 
wave lengths longer than about $710 \mathrm{mu}$ was not realized, and no association was made with photoperiodism. Rather, the authors attempted to correlate their results with phototropic studies $(87,88)$. Even though the light treatments were not quantitative the response curve published by Flint and Malister (60) clearly represents the action spectrum of the photoreversable pigment, phytochrome. This work was not improved upon until it was verified by Borthwick et al (29) in 1952 at wave lengths greater than $520 \mathrm{mu}$. The Beltsville group axtended the work of Flint by quantitatively determining the action spectrum of lettuce seed germination. Action maxima for promotion and inhibition were found at $660 \mathrm{mu}$ (red) and $730 \mathrm{mu}$ (far-red) respectively. The action maxima for inhibition and promation of gemination were shown to be reversible effects. That is, imbibed seeds previously potentiated to germinate by exposure to red light were inhibited by exposure to far-red and could be repromoted to germinate by red light. This sequence of Irradiations was repeated for many cyclos and the seeds were always found to respond according to the last irradiation, red promoting and far-red inhibiting germination. This brilliant work firmly established the cencept of a photorevergible pigment system which controls basic life processes. The activity of this system was quickly shown to control flowering in cocklebur (26).

Later, after an exaustive examination of lettuce seed germination (28) at wave lengths greater than $400 \mathrm{mu}$, it was shown that the absorption of radiation in the red or far-red region changes the photo-responsive pigment into the far-red (P735) or the red-absorbing form ( $\mathrm{P} 660$ ), respectively. The action spectra for lettuce seed germination and flowering in coaklebur were found to be the same. Also, it was found that the far-red 
absorbing form of the pigment changes to the red-absorbing form in darkness; darkness has the same effect as far-red irradiation. It is through this conversion of the pigment that the duration of darkness is measured in the photoperiodic control of floral initiation (26, 77). It is interesting to note here that at this point the pigment, which was later named phytochrome (23), had only been detected through physiological responses. The concept of reversibility and the time-measuring, dark reversion of hytochrome was quickly extended to many other phenomena in the morphogenesis of plants. Internode elongation and leaf expansion (54, 78, 80, 93, 166), fern spore germination and sporling growth (39, 97), and control of anthocyanin synthesis $(105,132,133)$ are examples of some of the diverse factors under the control of the rod, far-red pigment system. Phytochrome eluded direct measurement and purification until 1959 (40), when the development of a double beam, bichromatic spectrophotometer (17) by the Beltsville group provided a method for a direct optical assay. This instrument allowed for the in vivo assay of phytochrome and for the necessary in vitro measurement to trace the pigment through the steps of its partial purification carried out by H. W. Siegelman et al (134). Butler et al (4I) have determined the photochemical properties of phytochrome preparations. All evidence indicates that phytochrome is a single proteinaceous pigment which exists in two forms. The interconversion of the two forms can be represented as follows $(23,77)$ :

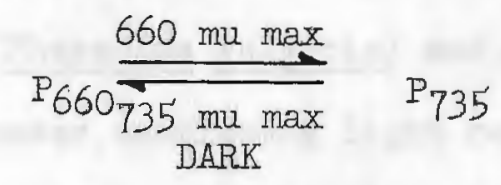

Contrary to earlier ideas $(26,29)$, the photoreaction does not seem to require any other component than the pigment itself (77). Phytochrome is 
photoreversible in vitro after prolonged dialysis and in the presence of strong axidants or reductants which would remove or inactivate cofactors $(23,77)$. The dark reversion of phytochrome $\left(\mathrm{P}_{735} \stackrel{\text { DARK }}{\longrightarrow}\right.$ P660) has not been shown to occur in vitro (77). The dark reaction $i$ s the time measuring derice of photoperiodism and apparently must depend on factors which are present only in vivo. In some manner yet unknown the relatively simple photo-reversible interconversion of phytochrome controls and influences many phases of plant growth and development.

2. High Energy Photoreactions - Considerably less is known about the so-Galled high energy photomorphogenic responses of plants. This phenomena is best illustrated in the literature concerning the photo-control of axis elongation and anthooyanin synthesis to which the remainder of this review will be devoted.

The definitive work concerning the high energy requiring photomorphogenic reactions in plants is of very recent origin. The early literature on the effects of light on anthocyanin formation is reviewed by Arthur in 1936 (7) and Blank in 1947 (18), and recently in an extensive work by Kandeler (89).

Prior to the discovery of the photomorphogenic pigment phytochrome there was no understanding or distinction made between the high and low energy photoresponses of plants. Withrow, Kleir, Price and Elstad (170), studied the pigment formation and photomorphogenie responses in seodlings of Black Valentine bean (Phaseolus vulgaris) and a hybrid field corn (Zea mays, variety U. S. 13) under continuous light regimes of specific wave length bands. Maximum responses were found in the region of 630 to $700 \mathrm{mu}$, while $725 \mathrm{ml}$ exhibited strong responses with the development of only traces 
of Horophyl. Weak photamorphogenic effects were obtained at $765 \mathrm{mu}$ with no tectable chlorophyll development. It is interesting to note that maximum responses in the 630 to $700 \mathrm{mu}$ range occurred at only $2 \mathrm{u}$ w/ $/ \mathrm{cm}^{2}$ while those studied at $700 \mathrm{mu}$ and $725 \mathrm{mu}$ onl $\mathrm{y}$ approached saturation at $450 \mathrm{uw} / \mathrm{cm}^{2}$. Inhibition of hypocotyl elongation and anthocyanin synthesis

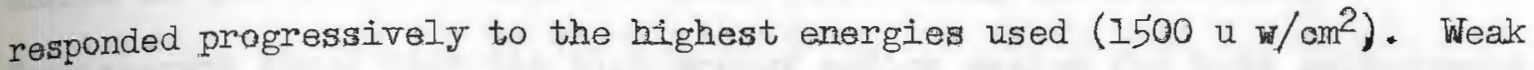
anthocyanin formation and elongation responses were also noted in the blue (436 $\mathrm{mu} \mathrm{Hg}$ line) at $2 \mathrm{u} \mathrm{w} / \mathrm{cm}^{2}$, but with a 1000-fold increase in chlorophyll content over that found at $725 \mathrm{mu}$. In view of later work $(29,132,133)$ the great differences in energy requirement at the different wave lengths which Withrow et al used are the result of the presence of two different photoreceptive systems, or, at least, the result of two types of photoreactions within the same system. Withrow et al also clearly showed that the photomorphogenic responses, even at very high irradiances, are distinct from the photosynthetic reaction. The studies of Siegelman and Hendricks on the action spectrum of anthocyanin synthesis in apple skin (Pyrus malus In*) (132), red cabbage (Brassica oleracea I. var. "Red Acre") and turnip (Brassica sp.) (133) clearly differentiated between the reversible photomorphogenic system and the high energy responses. Dark grown red cabbage șeedlings, which form small amounts of anthocyanin without irradiation, were induced to form more anthocyanin in response to 5 minute irradiances of low energy red light $\left(3.0 \mathrm{X} 10^{-4} \mathrm{w} / \mathrm{cm}^{2}\right)$. Turnip seedlings did not respond to this treatment. Therefore phytochrome in the $P_{735}$ form was necessary for anthocyanin formation in cabbage in the dark, and this effect could be reversed by exposure to far-red light. 
Anthocyanin formation is under phytochrome control in both plants after they are potentiated to form pigment by exposure to high energy red light $\left(=10 \mathrm{~J} / \mathrm{cm}^{2}\right)$ (133). High energy action maxima for apple skin (132), calbage, and turnip (133) were found to occur at $650 \mathrm{mu}$, $690 \mathrm{mu}$ and 725 mu peotively. The cabbage and turnip were also found to have action maxima in the blue near $450 \mathrm{mu}$. Mohr (105) using the Beltsvillo Spectrograph found that the high energy action maxima for both anthocyanin synthesis and inhibition of hypocotyl elongation occurred at about $710 \mathrm{mu}$. These two action spectra are very similar and Mohr suggests that the same photoreceptor is active in both phenomena, although anthocyanin synthesis is also under the reversible cantrol of phytochrome while the inhibition of longation of the hypocotyl is not. Downs et al (54) have demonstrated photoreversibility of elongation of internodes in Pinto beans and several other plants. Downs (52) recently determined the high energy action spectrum for anthocyanin synthesis in milo seedlings (Sorghum vulgare var. Whertland), and found the action maximum to fall in the blue part of the spectrum between 470 to $480 \mathrm{mu}$. Anthocyanin synthesis in milo was also found to be under phytochrome control. That is, the effect of blue light used to induce anthocyanin production can be nullified by brief exposure to ar-red irradiation or reinstated by a subsequent exposure to red. In this work (52), Doms has shown a clear separation between the high and low energy reactions. The absence of any significant high energy action in the red remains unexplained.

There is no direct evidence of physialogical mechanisms of the light reactions, but theoretical ideas have been advanced on the basis of ciroumstantial evidence. These ideas along with morphogenic mechanisms beyond the light reactiong will be taken up in the general discussion. 


\section{Plant Material}

The hypocotyl of Impatiens balsamina $I$. was chosen as the experimental thaterial because different regions of the hypocotyl have been shown to form anthocyanin at different rates (3). Cultured segments of the hypocotyl also differ in their ability to form roots and epidermal hairs. The formation of anthocyanin pigments may be used as a physiological indicator under various conditions that can be correlated with the genesis of roots and hairs in different regions of the hypocatyl. Practical advantages such as the availability of quantities of genetically uniform seed, and the ease of handling and germinating the seedings under sterile conditions suggested that this species was a good choice for a study of growth and differentiation of the hypocotyl.

Vaughn Seed Company's Scarlet Balsam was used in all experiments. This strain corresponds to Davis' $\mathrm{HP}^{\mathrm{r}}$ type (48) having bright red flowers and red stems, or RSWD in Weijer's terminology (162). The stems yield the anthocyanin aglycones, pelargonidin and cyanidin $(4)$.

\section{Hypocotyl Anatomy}

Three seeds were germinatod in darkness in petri dishes containing $10 \mathrm{ml}$ of distilled water and two layers of Eaton - Dikeman \#613 filter paper. The dark-grown seedlings were harvested at either 5 or 10 days after planting. During the period of germination and growth the temperature was controlled at $28^{\circ} \mathrm{C}$. One group of seedlings was germinated and allowed 
to grow in the light at 450 foot-candles at $20^{\circ} \mathrm{C}$ for 15 days. The whole seedlings were killed, fixed, and stored in FAA solution (Table I) (127a).

T A B I E I

FORMUIA FOR FAA KIIIIING AND PRESERVING FLUID

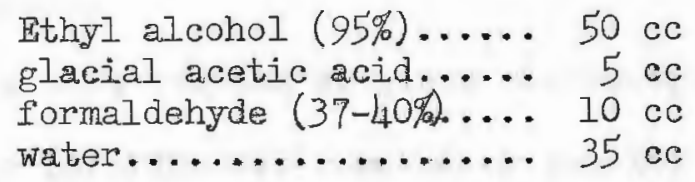

After remaining in FAA for at least 24 hours, the hypocotyls of the 10-dayold seedlings were each cut into 10 pieces of equal length (approximately $5 \mathrm{~mm}$ ), which were labeled $\# 1$ nearest to the cotyledons proceeding to \#10 at the base of the hypocotyl.

Fntire 5-day-old seedlings and the segments of the 10-day-old seedlings were dehydrated by a tertiary butyl alcohol (TBA) series prior to paraffin infiltration (85). Paraffin shavings of low melting point ( 48 to $50^{\circ} \mathrm{C}$ ) were added when the plant material was in pure TBA. The paraffin was allowed to dissolve slowly over a period of several days at about $40^{\circ} \mathrm{C}$. Finally the TBA was evaporated by placing the material in a $52^{\circ} \mathrm{C}$ oven, and approximately 24 hours later, or until no odor of alcohol could be detected, the open vials were placed in a $63^{\circ} \mathrm{C}$ oven and impregnated with rubber based "Tissue Mat" wax (M.P. $56.5^{\circ} \mathrm{C}$ ). The tissue was left in the final change of paraffin for about 24 hours and then cast into blocks in shallow porcelain dishes where the wax was hardened rapidly by submerging the casting dishes in cold water. Blocks containing individual pieces of tissue were cut out of the porcelain dishes and mounted on wooden blocks which could be accomodated by the microtome chuck. 
Sections, 20 microns in thicknegs were cut with an American Optical Company "820" rotary microtome. Serial longitudinal sections were made of the intact 5-day-old seedlings and of all segments of the 10-day-old hypocotyl. Serial cross sections were made of segments \#1, \#5 and \#10 of the 10-day-old hypocotyl.

After sections were mounted on glass microscope slides (25x75) using Haupt's adhesive, the paraffin was removed by passing the slides through two washes of xylene and then to absolute ethanol through a 50\% xylene: 50\% ethanol bath. These sections were stained with either safranin and fast green or Heidenhain's iron-hemotoxylin procedure as outlined by Johansen (85). After staining, the tissue was dehydrated with a graded ethyl alcohol-water series and sealed under \#l glass cover slips with Diaphane. Hand sections of the 15-day-old, light grown seedlings were made using a pith block and straight razor. They were mounted in water and observed imediately for the location of anthocyanin pigments. Sections of the fresh material were also mounted in Iodine-potassium iodide solution to test for starch.

Free-hand india ink drawings were made to illustrate the anatomical features of the 10-day-old hypocotyl. They were photographed on $35 \mathrm{~mm}$ Kodak high contrast copy film (M-135) and printed on Kodabromide A-3 light weight photographic paper.

The distribution of mitotic activity was noted and counts of mitotic figures were made from serial longitudinal sections of 10-day-old dark grown hypocotyl segments at a magnification of $970 x$ under oil emersion. For convenience in counting and for comparisons, segment \#1 was divided into three portions labeled terminal, apex and lower (plate XIV). Mitotic 
figures found in the stele, cortex and epidermis were counted separately. The ections that were counted, were separated by at least $40 \mathrm{u}$ to avoid the solbility of counting the same figures more than once.

Mitotic activity that was obviously associated with lateral root formation was not counted. Only those nuclei having well defined chromosomas were counted as being in an active stage of division. Many nuclei that may have been in early prophase or late telophase were not counted. The length of cortex cells at specific points along the axis of 5 and 19-day-old etiolated hypocotyls were measured using a calibrated ocular micrometer. Those cells which were measured were those intergected by a transverse line drawn through the mid-point of each of 10 equal segments of the hypocotyl. Measurements were taken from radial longitudinal sections in the plane of the hypocotyl arch. Because of its size and varied cell lengths, segment $\# 1$ of the 10-day-old hypocotyl was divided into four equal parts, each of which was measured separately. Separate measurements of cortical cells on the inside and outside of the hypocotyl arch were made. The cell length data are expressed as average values.

\section{Chemical Factors Affecting Anthocyanin Formation and Morphogenesis} Seeds of Impatiens balsamina I. (Vaughn's Scarlet Balsam) were sterilized by placing them in 1\% bromine water for approximately 15 minutes. Then the seeds were rinsed thoroughly with sterile distilled water and transferred to sterile Petri dishes containing $10 \mathrm{ml}$ of sterile water and a double layer of filter paper. Germination of the seeds was conducted in complete darkness at $27-28^{\circ} \mathrm{C}$ with three seeds in each Petri dish. 
After 7 days the roots and cotyledons were excised from the seedlings leaving the bare hypocotyl of about $50 \mathrm{~mm}$ in length. The hypocotyl was then cut into 10 equal segments, which were transferred to a Petri dish containing an agar medium. They were arranged in a radial fashion on the agar, the segment proximal to the eotyledons being designated as \#1 and the more distal as $2,3,4 \ldots$ to \#10. Sterile conditions were maintained throughout.

White's medium (165) was used in all experiments as the basal medium, and it was supplemented in various experiments with the following constituents: a) the sugars glucose and sucrose, b) compounds affecting growth; naphthalene acetic acid (NAA), 2, 3, 5 triiodobenzoic acid (IIBA), gibberellic acid, sodium salt (GA) c) compounds affecting anthocyanin formation; benzimidazole (Bz); 8-azaguanine (Aza), riboflavin (Rb) (Table II).

Petri dishes were sterilized dry at $180^{\circ} \mathrm{C}$ for four hours and the medium was autoclaved at $1210 \mathrm{C}$ for 15 minutes. All congtituents were added to the medium before sterilization with the exception of Rb which was sterilized by filtration.

Each experiment, comprised of 35 cultures, was carried out in darkness or under $450 \mathrm{ft}$. cd. of light from cool white flourescent tubes at $25^{\circ} \mathrm{C}$. In experiments which were conducted in darkness, transfers were made under dim green light. During the experimental period of 10 days the dark cultures received brief periodic exposures which were necessary for the collection of data.

During the experiments visual observations were made on all the cultures at the following intervals: $30,48,60,72,96,144,192$, and 240 
T A B I E I I

CONSTITUENTS OF WHITE'S MEDIUM

Basal Medium

\begin{tabular}{|c|c|}
\hline Components & Concentratior \\
\hline $\mathrm{ZnSO}_{4}$ & $1.55 \mathrm{mg} \cdot / 1$. \\
\hline $\mathrm{H}_{3} \mathrm{BO}_{4}$ & $1.50 \mathrm{mg} \cdot / \mathrm{I}$. \\
\hline KI & $0.75 \mathrm{mg} . / 1$. \\
\hline $\mathrm{MnSO}_{4} \cdot 2 \mathrm{H}_{2} \mathrm{O}$ & $5.70 \mathrm{mg} * / 1$ \\
\hline $\mathrm{KCl}$ & $65.00 \mathrm{mg} . / 1$. \\
\hline $\mathrm{KNO}_{3}$ & $80.00 \mathrm{mg} \cdot / 1$ \\
\hline $\mathrm{Ca}\left(\mathrm{NO}_{3}\right)_{2} \cdot 4_{4} \mathrm{H}_{2} \mathrm{O}$ & $288.00 \mathrm{mg} \cdot / \mathrm{I}$. \\
\hline $\mathrm{NaH}_{2} \mathrm{PO}_{4} \cdot 4_{4} \mathrm{H}_{2} \mathrm{O}$ & $16.50 \mathrm{mg} \cdot / 1$. \\
\hline $\mathrm{MgSO}_{4} \cdot 7 \mathrm{H}_{2} \mathrm{O}$ & $736.00 \mathrm{mg} . / \mathrm{I}$. \\
\hline Glycine & $3.00 \mathrm{mg} \cdot / \mathrm{I}$ \\
\hline Nicotinic acid & $0.50 \mathrm{mg} * / 1$. \\
\hline Pyridoxine & $0.50 \mathrm{mg} / 1$ \\
\hline Thiamine & $0.10 \mathrm{mg} \cdot 1 / \mathrm{.}$ \\
\hline $\mathrm{Fe}_{2}\left(\mathrm{SO}_{4}\right)_{3}$ & $2.50 \mathrm{mg} . / 1$. \\
\hline Sugar & 20 grams/工. \\
\hline Agar & $10 \mathrm{grams} / 1$. \\
\hline
\end{tabular}

Test Compounds

NAA

$5.0 \times 10^{-6} \mathrm{M}$

$5.0 \times 10^{-8 \mathrm{M}}$

TIBA

$5.0 \times 10^{-5}$

$G A$

$2.7 \times 10^{-5}$ 


\section{TA B I I I (CONT'D)}

Test Compounds

\begin{tabular}{cc} 
Components & Concentration \\
\hline $\mathrm{Rb}$ & $3.0 \times 10^{-4}-\mathrm{M}_{\mathrm{M}}$ \\
& $1.0 \times 10^{-4}-$ \\
$\mathrm{Bz}$ & $3.0 \times 10^{-3}-3_{\mathrm{M}}$ \\
$\mathrm{Aza}$ & $3.0 \times 10^{-6} 6_{\mathrm{M}}$
\end{tabular}


hours or $30,42,54,66,90,174,138,186$ and 240 hours in some instances. The resence or absence of anthocyanin pigments, epidermal hairs, and the number of roots were recorded for each of the 10 hypocotyl segments in each culture at the above intervals. These data represent 35 replicates of each of the 10 segments of tissue along the axis of the hypocotyl.

At the end of the 10 day experimental period the relative amounts of thosyanin pigments were estimated by pooling 20 cultures which yield 10 extracts representing segments $\# 1$ through $\# 10$ respectively. Anthocyanins were tracted from the hypocotyl segments by crushing the tissue in $5 \mathrm{ml}$ of $1 \%$ methanolic hydrochloric acid (HCI). Segments were extracted overnight in darkness at $27-28^{\circ} \mathrm{C}$ and the extracts were filtered through glass wool and made up to $10 \mathrm{ml}$ in volumetric flasks with $1 \%$ methanolic HCl. Relative -entrations of anthocyanins were obtained from their absorption spectra between 400 and $600 \mathrm{mu}$ as determined with a Beckman model DU spectrophotometer. \$athocyanin concentration is expressed as the difference between the aborbance at $524 \mathrm{mu}$ and the average of the absorbance values at 450 and 600 mu multiplied by $10^{3}$ to give a whole number (3). In respiration studies, unsterilized seeds were placed into large finger bowls lined with wet filter paper and incubated at $30^{\circ} \mathrm{C}$ for 7 days in darkness. Before readings were taken, pooled hypocotyl segments were ineubated in the Warburg vessel for 30 minutes in $2 \mathrm{ml}$ of White's liquid medium (165) without ferric sulfate and without adding IAA or sugar. innometer readings were taken at 10 minute intervals over a period of two hours. First, the respiration rates of each of the 10 hypocotyl segments were mesured. In order to resolve the respiratory gradient in the region 
of the ryocotyl arch, six consecutive $2 \mathrm{~mm}$ segments (80 replicate segments per Warburg vesgel) were measured. This $12 \mathrm{~mm}$ portion included the complete hyocotyl areh and a short distance toward the base of the hypocotyl. Respiration rates are expressed as ul $\mathrm{O}_{2}$ consumed per ing of fresh weight per hour.

Although the hyposotyls of dark grown seedlings had no visible chlorophyl1, as a precaution all cutting was done in a darkened room and the Warburg apparatus was operated in semi-darkness ( 5 foot candles). At the end of a run the tissue was blotted on filter paper and weighed on an analytical balance. All cell counts were obtained by a method described by Brown and Broadbent ( $38 \mathrm{a}$ ). The segments were macerated in $5 \%$ chromic acid for 24 hours and the resulting cell suspension was drawn through a pipette to break up clumps of cells. Aliquots of the suspension were placed on a haemocytometer slide and the cells were counted. Total number of cells per segment were calculated from the haemocytometer counts.

\section{Responses of the Hypocotyl to Light}

The action spectra for anthocyanin synthesis, elongation of the hypocotyl, and the straightening of the hypocotyl arch were determined between 400 and $500 \mathrm{mu}$. An action spectrum for photoreversibility of anthocyanin gynthesis was determined between 600 and $800 \mathrm{mu}$.

For the action spectra for anthocyanin synthesis Scarlet Balsam seeds were germinated in large plastic refingerator boxes on two layers of white absorbent packing paper. The boxes were placed in complete darkness for five days at $25^{\circ} \mathrm{C}$. Seedlings were prepared for irradiation by removing the basal portion of the hypocotyl with the roots so that all 
hypoeotyls were approximately the same length (about $25 \mathrm{rmm}$ ).

(nypocotyls were irradiated with white fluorescent light, and colored light from a prism spectrograph, or interference filters. Fluorescent light sources were used in preliminary experiments to determine optimum periods of irradiation and darkness; various light intensities measured as foot candles, were obtained by using cheese-cloth filters. The hypocotyls were placed horizontally in Petri dishes containing two layers of Whatman No. 3 filtor paper moistened with water. Different periods of light and darkness, and light intensities were used. Preliminary experiments were designed to test the effect of red and far-red light on anthocyanin synthesis. The red light source was a bank of eighteen 8-foot, cool-white fluorescent lamps with a two layered red cellophane filter which delivered about 0.6 milliwatt per $\mathrm{cm}^{2}$ between 600 and $700 \mathrm{mu}$ at a distance of $100 \mathrm{~cm}$.

Far-red light was obtained from three 300-watt internal reflector incandescent lamps with a filter of two layers of red and two layerg of blue llophane. A $5 \mathrm{~cm}$ layer of water was used to absorb infrared irradiation to reduce heating effects. About 1 milliwatt per $\mathrm{cm}^{2}$ of incident energy was obtained $100 \mathrm{~cm}$ from the source.

Generally, the anthocyanin content of the hypocotyls was measured at the end of a dark period which followed a specific light treatment. After removing the cotyledons the hypocotyls were extracted overnight at $5^{\circ} \mathrm{C}$ in $5 \mathrm{ml}$ of $1 \%$ methanolic HCl. Usually, either 5, 10 or 15 hypocotyls were extracted, depending on the amount of pigment present. The relative concentrations of anthocyanins in the extracts were measured spectrophotometrically as previously described. 
A 10 kilowatt carbon - arc lamp of the type used in the projection of $35 \mathrm{~mm}$ motion pictures was the light source for the spectrograph. The spectrum omitted from the glass prism was focussed on a mirror and reflected onto a table-top. A greater spectral dispersion and focal length were obtained when the spectrograph was used as a double prism instrument, but the incident energies were considerably lower than when the instrument was used with one prigm. It was used as a single prism instrument for the irradiation of the hypocotyls between 400 and $500 \mathrm{mu}$. The projected spectrum between 394 and $507 \mathrm{mu}$ was $24 \mathrm{~cm}$ in width which had a dispersion at $400 \mathrm{mu}$ of $0.30 \mathrm{mu} / \mathrm{mm}, 0.50 \mathrm{mu} / \mathrm{mm}$ at $450 \mathrm{mu}$ and $0.70 \mathrm{mu} / \mathrm{mm}$ at $501 \mathrm{mu}$. The energy distribution was $0.12 \mathrm{milliwatts} / \mathrm{cm}^{2}$ at $400 \mathrm{mu}, 0.30$ milliwatts $/ \mathrm{cm}^{2}$ at $450 \mathrm{mu}$ and $0.52 \mathrm{milliwatts} / \mathrm{cm}^{2}$ at $501 \mathrm{mu}$. Energy measurements were made with a thermopile previously calibrated with a standard light source.

Seedlings to be jrradiated were prepared as previously described. They were placed side-by-side in a row lying across the bottom of square plastic sandwich boxes with two layers of moistened whatman No. 3 filter paper in the bottom. Each plastic box was $11.75 \mathrm{~cm}$ on a side and two such boxes of seedlings gave a row of hypocotyls extending from 400 to about $500 \mathrm{mu}$. The hypocotyls with attached cotyledons were irradiated for 6 hours. A measurement of the exact position of each box in relation to a reference point on the table was recorded so that samples of the hypocotyls taken from the boxes could be related to specific points across the spectrum. After Irradiation the hypocotyls received 10 minutes of red light and were returned to darkness at $25^{\circ} \mathrm{O}$ for 18 hours. At the end of the dark period consecutive samples of 10 hypocatyls each were taken from the plastic boxes. Each sample was extracted in $5 \mathrm{ml}$ of $1 \%$ methanolic HCl. A sample of 10 
hypocotyls covered about a $2 \mathrm{~cm}$ portion of the spectrum. Anthocyanin extracts were measured spectrophotometrically as before and the value obtained for each sample was assigned to that wave length which fell at the midpoint of the sample. A measure of anthocyanin synthesis was obtained at approximately 5 to $10 \mathrm{mu}$ intervals.

Due to the low enargies obtained from the spectrograph only small amounts of anthocyanins were formed. A second action spectrum for anthocyanin gythesis was determined using a carbon-arc light source with interference filters. Iight from the $10 \mathrm{kilowatt}$ arc was passed through a 20 1. carboy and an absorption cell filled with water cooled I $\mathrm{M} \mathrm{CuSO}_{4}$ which removed most of the red and infrared radiation. Following the GusOl filters, the beam was passed through a condensing lens and reflected downward by a mirror through a holder which contained four square interference filters, 2 inches on a side. The carbon-arc lamp, $6 \mathrm{sSO}_{4}$ filters, and condensing lens were inside a small light-tight "walk-in" housing while the four beams of monochromatic light coming from the filters were projected downtard onto the surface of a table outside the enclosure. Hypocotyls were prepared for irradiation as before and placed on the end surface of four solid aluminum eylinders which were wrapped with four layers of cheese cloth and immersed in an ice water bath. Each cylinder with 25 hypocotyls was placed under an interference filter and irradiated for 6 hours. The temperature at the surface of the cylinders was maintained at $25^{\circ} \mathrm{C}$ and the energy delivered by each filter was measured with a calibrated thermopile ( $\mathrm{Tab}$ le III). 
ENERGY DELIVERED AND WAVE LENGTH AT MAXTMUM TRANSMITTANCE OF INTERFEREATCE FILTERS

Wave-length

$500 \mathrm{mu}$

$483 \mathrm{mu}$

$463 \mathrm{mu}$

$441 \mathrm{mu}$

$425 \mathrm{mu}$

$405 \mathrm{mb}$

\section{Milliwatts $/ \mathrm{cm}^{2}$}

$1.30,2.00$

$2.00,2.72$

$1.60,3.30$

1.72

1.50

1.50

A minimum of two replicate experiments were conducted for each wavel angth. After being irradiated the hypocotyls were transferred to Petri dishes containing two layers of moistened Whatman No. 3 filter paper, exposed to 5 minutes of red light, and then placed in the dark for 18 hours. At the end of the dark period, 10 hypocotyls were extracted in $5 \mathrm{ml}$ of $1 \%$ methaxolic HCl. Of the 25 hypocotyls at each wavelength 20 were used which gave two replicate extracts for each wavelength per experiment.

\section{All quantitative values obtained for anthocyanin synthesis were} plotted with relative coneentration of anthocyanin as the ordinate and waveleagth as the abscissa.

In the determination of the action spectrum of photo-reversibility, which is the action spectrum of phytochrone, the spectrograph was used as a two-prism instrument. In this form the instrument has a longer focal length and greater dispersion, but the incident light energies are greatly reduced. The dispersion at $600 \mathrm{mu}$ was $0.46 \mathrm{~m} / \mathrm{mm}, 0.71 \mathrm{mu} / \mathrm{mm}$ at $700 \mathrm{mu}$, and $1.25 \mathrm{ma} / \mathrm{mm}$ at $800 \mathrm{mu}$ hile the energies delivered at these same points of the spectrum were 0.116 milliwatts $/ \mathrm{cm}^{2}, 0.150$ milliwatts $/ \mathrm{cm}^{2}$, and 0.171 milliwatts $/ \mathrm{cm}^{2}$ respectively. 
The hypocotyls placed in the plastie sandwich boxes as previously described were induced to form anthocyanins by exposing them for 4.5 hours to 2000 foot candies of cool-white fluorescent light at $25^{\circ} \mathrm{C}$. Action of the red in the region of $660 \mathrm{mu}$ was determined by exposing one lot of induce hypocotyls to an inhibiting dose of 5 minutes of far-red irradiation. This material was then placed on the spectrograph between 600 and $800 \mathrm{mu}$. Separate lots of hypocotyls were irradiated for 2, 4, 8 and 16 minutes and then maintained in complete darkness for 24 hours at $25^{\circ} \mathrm{C}$. The far-red action was determined in a similar manner except that the hypocotyls induced to form anthocyanins by the high intensity fluorescent light received 5 minutes of red light immediately before being irradiated on the spectrograph. A period of 32 minutes was added to the irradiation schedule. At the end of the 24 hour dark period the hypocotyls were sampled, extracted and the nocyanins were measured as described for the spectrograph experiments .

Intact seedlings were used for the study of the effects of light on hypocotyl elongation and on the straightening of the hypocotyl arch. The seeds were germinated in darkness at $25^{\circ} \mathrm{C}$ in covered polyethylene foodfreezer eontainers with two lajers of moistened packing paper in the bottom. During periods of irradiation the covers were removed from the containers, which were about 3.25 to 3.5 inches square at the base and 4.0 inches deep. Approximately 40 seeds were planted in each container.

The elongation and arch straighteming responses were measured at the same time. Measurements were obtained from 30 seedlings per treatment in all experiments. Flongation responses were measured as the difference between the lengths of the irradiated seedlings and of the dark control. 
The degree of straightening of the hypocotyl arch was measured as the angle which is formed with the hypocotyl axis. The arc through which the cotyledons were moved in the straightening of the arch was divided into six $30^{\circ}$ segments and numbered 1 through 6 . Thus, a hypocotyl which had received no light would have a value near 1.00 , the arch being in the closed position. A completely straightened arch would have a value of 6.00 .

caol-white fluorescent lights and the red and far-red sources were used in preliminary experiments to determine optimum light programs and the action of phytochrome. The carbon arc-interference filter apparatus was used for the action spectra determinations (Table IV).

\section{T A B I E I V}

ENERGY DETIVERED AND WAVEIENGTH AT MAXIMUM TRANSMITTANCE OF INTERFERENGE FIITERS USED IN EIONGATION AND ARCH STRAIGHTENING EXPERIMENTS

\section{Wave Zength}

$517 \mathrm{mu}$

$500 \mathrm{mu}$

$483 \mathrm{mu}$

$463 \mathrm{mu}$

$411 \mathrm{mz}$

$425 \mathrm{mu}$

$405 \mathrm{mu}$
Milliwatts $/ \mathrm{cm}^{2}$
0.86
0.48
1.00
1.00
0.78
0.56
0.49

Seedlings were irradiated periodically over a period of 48 hours. A 24 hour cycle of 2 hours light, 4 hours dark, 2 hours 1 ight and 16 hours of darkness was repeated twice. At the end of each two hour irradiation the seedlings received 5 minutes of red irradiation. All seedlings were measured at the end of the last 16 hour dark period. The data were plotted with the response (amount of inhibition of elongation or degree of arch straightening) as the ordinate and the wavelength as the abscissa. 
Hypocotyl Anatomy

The major tissues found in the etiolated hypocotyl of Impatiens balsamina L. (Plate I) are designated as follows: Fpidermis (Plates II to XI), Fpodermis (Plates III to XI), Cortex (Plates II to I), Fndodermis (Plates II, III, V, VI), Pericycle (Plates II, III, V to VII), PhIoem (Plates II to IX), Fylem (Plates II to IX), and Pith (Plates VIII to IX). The plates referred to above illustrate the organization of the various tissues along the hypocotyl axis. Plate I shows the position of these sections and the gross morphology of the etiolated balsam seedling.

The hypocotyl of Impatiens balsamina I. typifies the concept of the transition region with diverging vascular bundles and a central core of pith, somewhat like an inverted cone, leading to the apical meristem which gives rise to the shoot proper.

The vascular tissue is identical throughout the length of the hypocotyl. A tetrarch pattern of tracheary elements with annular thickenings alternates with strands of phloem tissue. The vascular cylinder contains very little parenchymatous tissue near the base of the hypocotyl, being very similar to the primary root (Plates II, V). About 200 to $250 u$ from the base of the hypocotyl the first indications of a centrally located pith appeared (Plate VI). From this point the xylem strands

1. Roman numerals placed in parenthesis () as a part of the deseriptive dita presented here refer to the plates on pages 48 to 62 . 
gradually separate and diminish in amount as a large central core of pith develops (Plate VII). The phloem forms a cylinder of tissue broken only at the four yylm points. This pattern remains intact until the upper limit of the hypocotyl is approached. The two xylem strands in the vertical plane parallel to the cotyledons divide to form four xylem strands which act as the two lateral strands for each cotyledon (Plate VIII). These strands also appear to provide the vascular attachment to the shoot, as evidenced by the zones of procambium tissue that appear nearer to the apical meristem (Plate IX). The vascular tissue then becomes arranged as three collateral cotyledon traces (Plate IX). These results agree with published descriptions by Noel (110) except that he describes the lateral traces as being larger and more "important" than the median trace. All traces observed by the author appeared to be of the same size with reapect to each other.

The similarity of appearance between the cross sectional anatomy of the root (Plate II) and the basal portions of the hypocotyl (Plate $V$ ) is striking, but there are two notable exceptions. The pericycle of the root appears as a cylinder of cells directly internal to the endodermis, whereas it appears as four small zones at the xylem points in the hypoeotyl. The latter abservation is supported by the rooting pattern of hypocotyl segments. Adventitious roots consistantly appear as opposed pairs (four roots at right angles to each other) and several roots often appear "singlefile" along the length of a segment. As can readily be seen, the four secondary roots (Plates III, IV) of the seedling are formed in this way. The root initiation zones (Plates $\nabla$ to VII) were found to traverse nearly 
the entire length of the hypocotyl. Further evidence was found in longttadinal sections of 10 day old hypocotyls containing early root primordia (Plate XII). These primordia were found as far removed from the base as segment \#7. Serial sections showed that the proliferations were aristng from a zone 2 to 4 cells wide and 1 to 3 cells deep, situated close to a xylem strand.

The second difference is the presence of a layer of large columnar cells just beneath the epidermis termed the hypodermis (Plates X, XI). These cells begin to appear immediately above the primary root and are well atablished at the vary base of the hypocotyl, traversing its entire length (Plates III to IX). Although the hypodermis is anatomically consistent, it shows considerable cytological heterogeneity. Many cells appeared as the typical living cell with well defined nucleus and cytoplasm (PIate X), while others had a dense substance partially adhered to the internal cell wall. No positive identification of a nucleus could be made in the latter cells. Some appeared to be empty. These cells also became very conspicuous when stained with iron-hematoxylin. The two major types of cells were not dispersed randomly but were organized in short longitudinal rows of several similar cells which appeared to be arranged randomly. They were termed as being either in the undifferentiated (Plate X) or in the differentiated state (PIate XI). It is questionable as to whether the latter are actually living ceils. A considerably larger number of cells approximated the "undifferentiated" state. An important correlation to the above condition was noted in examining fresh hand sections of light grown seedlings. Small amounts of anthocyanin pigment 
were found to occur in calls closely associated with the xylem strands. However, the mority of the red pigment was found in the hypodermis, the epidermis and cortex being unpigmented. The pigmented cells were arranged in discontinuous rows interspersed with rows of nonpigmented cells. This situation appeared identical to the pattern observed in the dark grown seedlings. From this it can be said that the cells previously deseribed as being in the differentiated state are actually specialized cells which produce pigment. It is interesting that these cells differentiate in the absence of light, but do not develop anthocyanion pigments. Although the dense terial observed in the hypodermis cells of the dark grown seedlings may be an artifact, it does indicate that these cells are unique and that they must assume a specialized condition in order to produce pigment. This concept is indirectly supported in a publication by Resch (123) in which he studies the incidence of polyploidy in the epidermal and subepidermal cell layers of the growing shoots of several seedlings including Impatiens balsamina. He describes the subepidermal layer (hypodermis) as being comprised of comparatively large cells which are 8 to $16 \mathrm{~N}$ in chromosome. number. The epidermal cells were found to remain diploid. Resch states that the polyploidy was brought about by endomitosis, the different chromosomes dividing at different times. If this were the case in the hypocotyl, then it may very well be correlated with the specialized condition of the hypodermis and the occurrence of pigment. On the other hand, no specialized cells were noted within the stele of the dark grown seedlings, even though pigmented cells appeared in the light grown seedlings. The stelar, pigment forming eells were found closely associated with the xylem strands. Often 
they vere in direct contact with a tracheary element. The significance of this is at present obscure.

The pith and cortex are made up of thin walled parenchyma tissue differing little along the axis except in cell length. These tissues have points of interest in the region of the hypocotyl arch (PIate I) and will be dealt with separately.

A definite endodermis with Casparian strips was noted in the root and it axtended some distance up the hypocotyl. It could no longer be detected above segment $\# 6$, but the presence of a starch sheath which extended to nearly the upper limit of the hypocotyl was noted.

As previously mentioned, the uppermost segment (Plate XIV), because of inferences from published literature and its unique physiological responses, was examined closely to determine the presence or absenee of meristematic activity. In Table $V$ are presented the total number of mitotic figures found in four 20 u sections taken from segment \#I. Whey were selected to give each tissue zone continuous representation along the length of the segment.

Since four 20 u sections yielded nearly 300 definite mitotic figures and the diameter of this portion is about $1000 \mathrm{u}$ ( $1 \mathrm{~mm}$. ), it would seem that a conservative estimate for the total count would be well over I000. There seems to be little question that this meristematic region contributes to the growth of the hypocotyl. The numerical data indicate that the mitotic activity of the terminal portion and the apex of segments is uniform, and a sharp decrease occurs in the lower section of the segment (Plate XIV). In very young seedlings with hypocotyls of only 3 to $4 \mathrm{~mm}$, mitotic activity was found along their entire lengths. From the study of seedlings 
T A B L E V

MITUTIC FIGURES FOUND IN SEGMENT \#I OF IO DAY OTD DARK GROWN HYPOCOTYLS

Terminal Tissue Zone Apex Lower

Section\# Gortex Stele Epi. Cortex Stele Epi. Cortex Stele Epi.

\begin{tabular}{crrrrrrrrr}
\hline 2 & 7 & - & 1 & 15 & 20 & 1 & - & 1 & - \\
5 & 12 & 12 & 3 & 10 & 26 & 3 & - & - & - \\
8 & 17 & 25 & - & 7 & 12 & 4 & - & - & - \\
12 & 28 & 39 & - & 17 & 28 & 2 & - & - & - \\
Indv. Total & 64 & 76 & 4 & 49 & 86 & 10 & - & 1 & - \\
Zone Total & 144 & & & & 145 & & &
\end{tabular}

$* * *$

T A B L E $\quad \forall I$

AVERAGE CELL LENGTHS IN MICRONS ALONG THE AXIS OF THE HYYOCOTYL

Segment

A

1.

B

C

D

2

3

4

5

6

7

8

9

10

\begin{tabular}{|c|c|c|c|}
\hline 10 da & & & old \\
\hline inside & outside & inside & outside \\
\hline 21.2 & 33.3 & & \\
\hline 23.2 & $49-4$ & & \\
\hline 60.5 & 70.8 & & \\
\hline 126.5 & 127.7 & & \\
\hline 187.5 & 270.0 & 20.4 & 34.4 \\
\hline 225.0 & 300.0 & 22.2 & 53.2 \\
\hline 181.0 & 274.5 & 19.3 & 50.1 \\
\hline 275.0 & 220.8 & 31.6 & 49.8 \\
\hline 270.8 & 292.5 & 53.4 & 53.9 \\
\hline 243.0 & 273.0 & 81.2 & 78.5 \\
\hline 224.8 & 252.0 & 76.4 & 70.1 \\
\hline 283.5 & 259.5 & 127.9 & 111.3 \\
\hline 210.0 & 304.5 & 189.8 & 204.2 \\
\hline
\end{tabular}


of intermediate age it could be seen that the active area occupies an increasingly smaller portion of the hypocotyl. The active zone must be considered as a separate meristematic unit since in all material studied the apical meristem was dormant. Certainly the growth of the hypocotyl is determinate, which leads to the conclusion that when the hypocotyl matures, this meristematic zone no longer exists. Thus, new cells are formed through mitosis without the conservation of undifferentiated tissue. Such a meristem must be classified as a transient meristem and is sinilar to intercalary meristems which Prat (119, 120) has described in grasses. The term, pseudomeristem of Noel (110), seems to be most descriptive.

Results from tissue culture experiments have shown that the physiological responsiveness of segment \#1, particularly its ability to elongate, decreases with age. The transient nature of the pseudomeristem causes the age of the seedlings used for physiological work to become a critical factor which can influence the results greatly.

Although the pseudomeristem contributes a great deal to the growth of the pocotyl, the actual increase in length occurs largely through cell elongation. Table VI presents the average length of cortex cells of 5 and 10 day old hypocotyls. The measurements were taken at 10 points al.ong the axis and the cells on the inside and outside of the arch are measured separately. Because of its size and varied cell lengths, segment \#1 of the 10 day old hypocotyl was divided into four oqual parts (A, B, G and D). The data in Table VI indicate that the hypocotyl arch is most probably formed through differential elongation of the cells in that region. Fongation proceeds continuously upward from the base of the hypocotyl until at 10 days nearly all cells, except those of the arch have reached a maximum 
UPPER LIMIT OF HYPOCOTYL

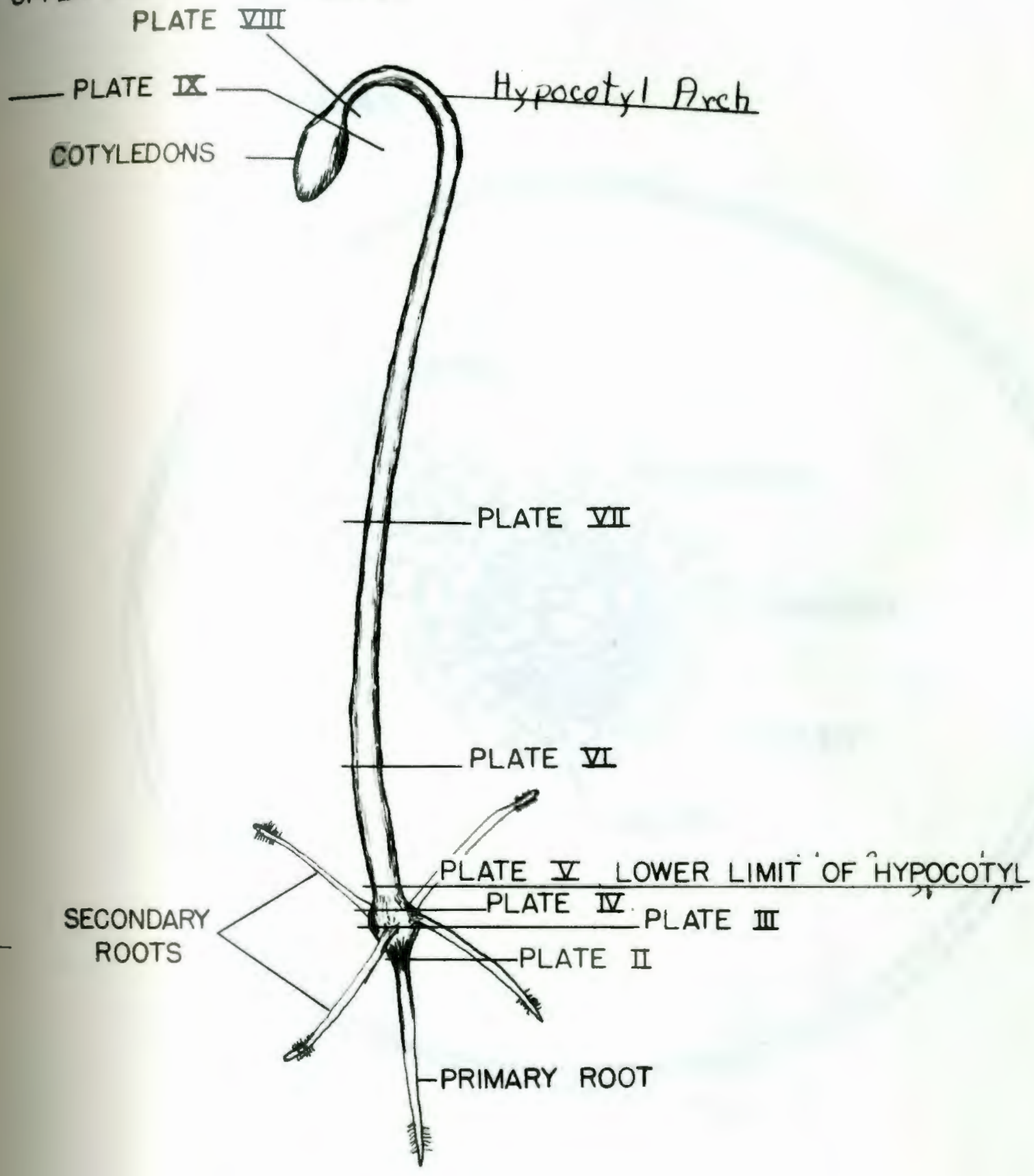

PLATE I

SEEDLING OF

IMPATIENS BALSAMINA 


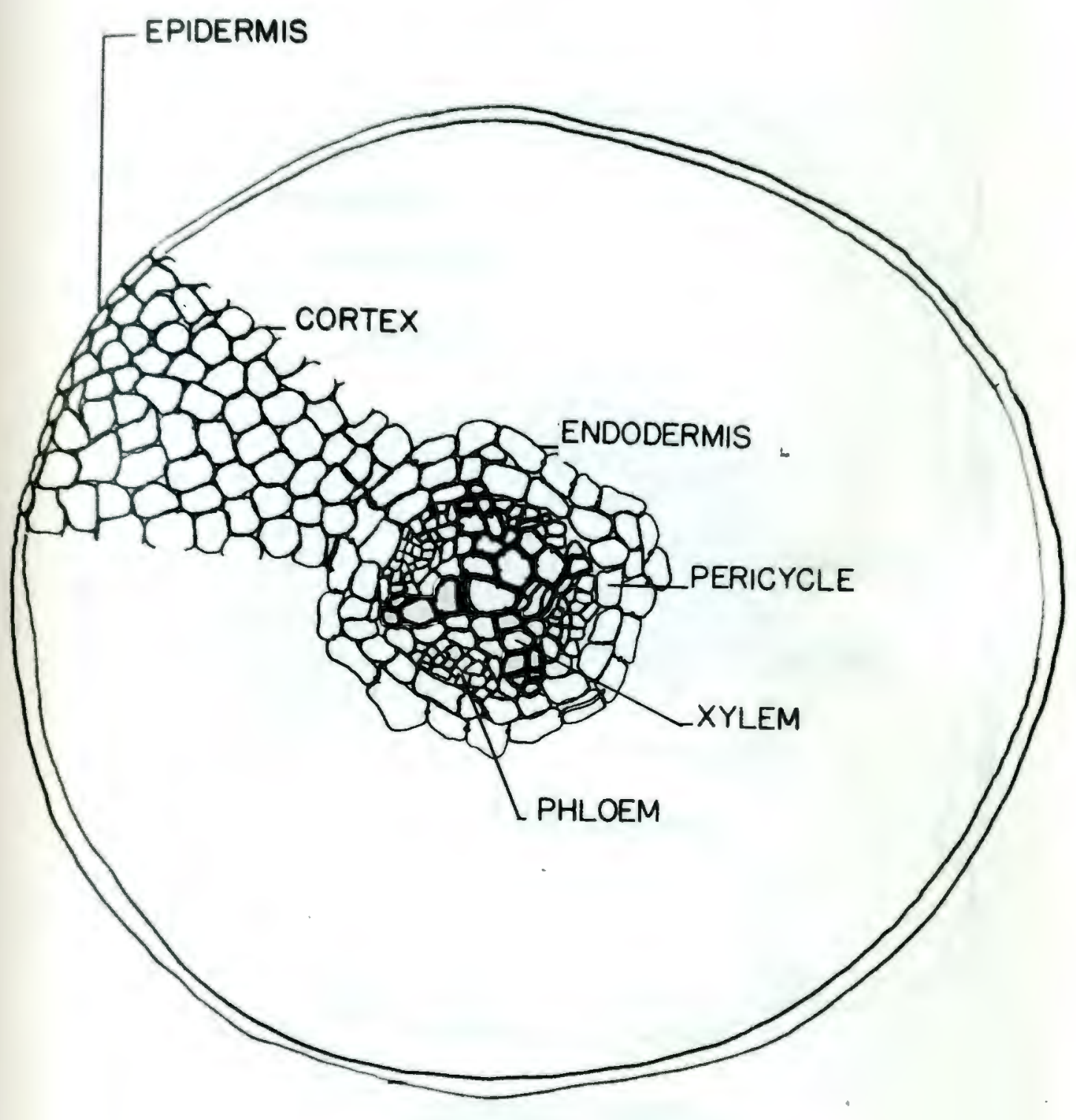

\author{
PLATE II \\ PRIMARY ROOT
}




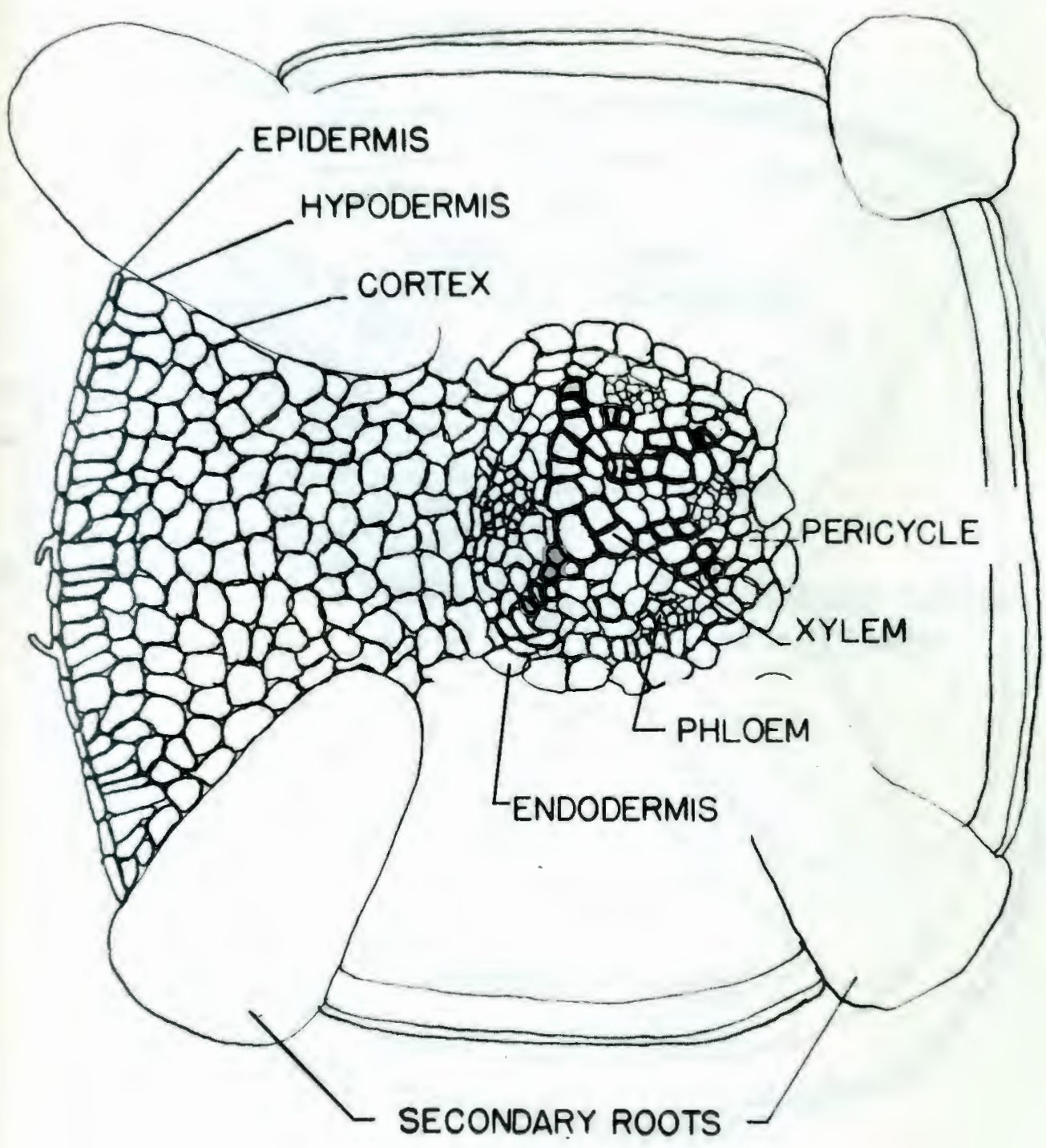

PLATE III

HYPOCOTYL: AREA OF ROOT ORIGIN 


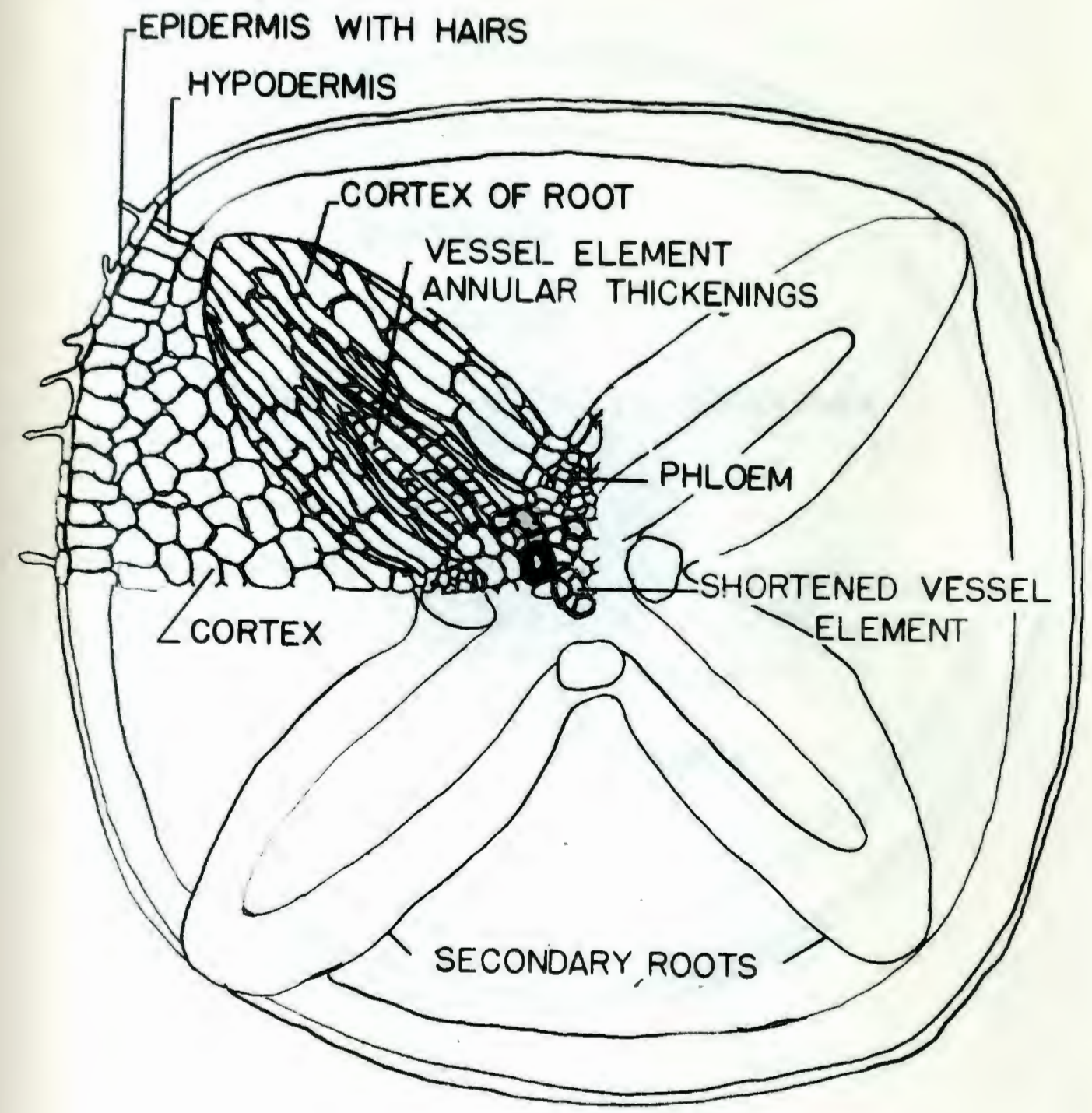

PLATE II

HYPOCOTYL: AREA OF ROOT ORIGIN 


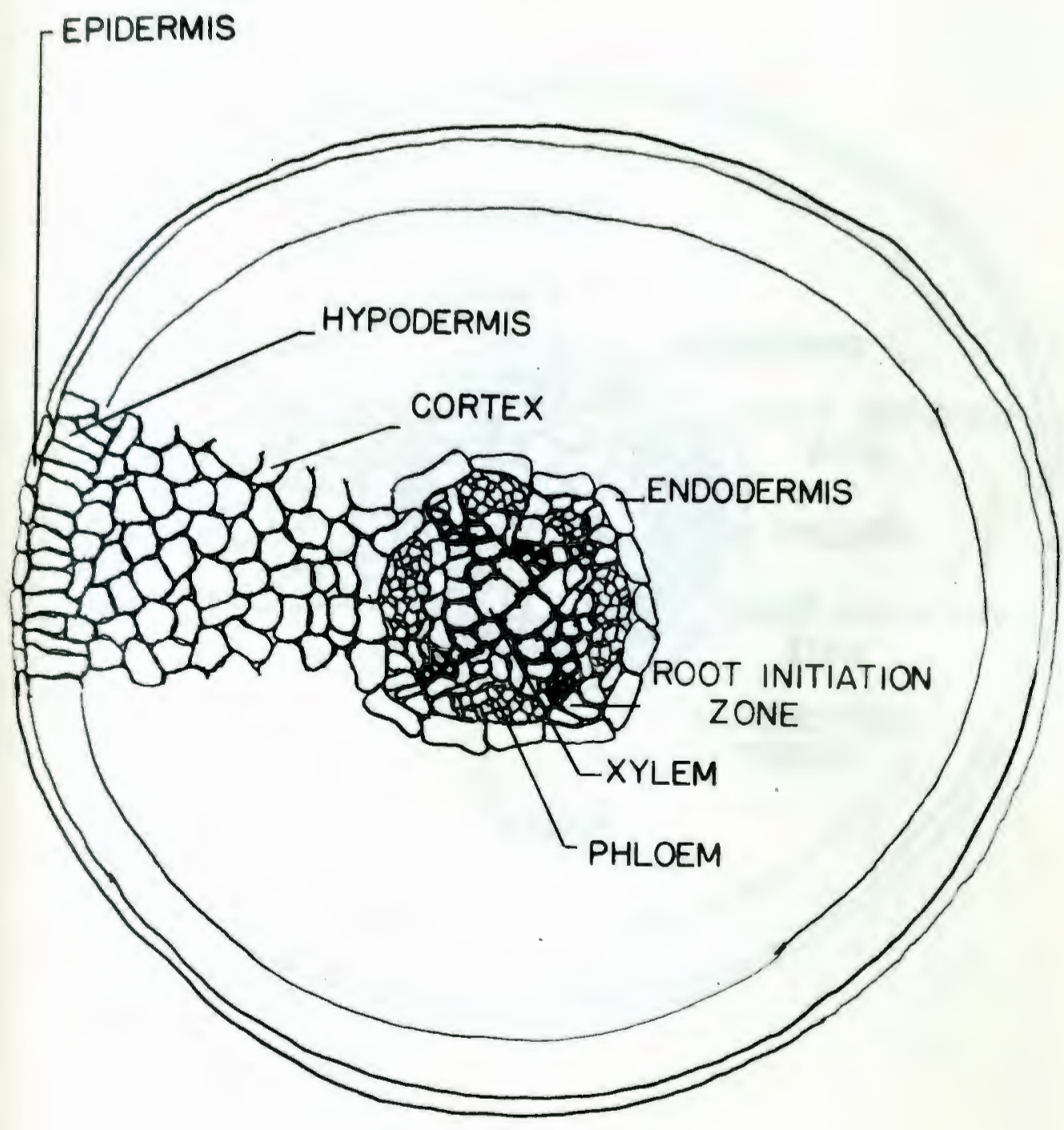

\author{
PLATE I \\ HYPOCOTYL: LOWER LIMIT
}




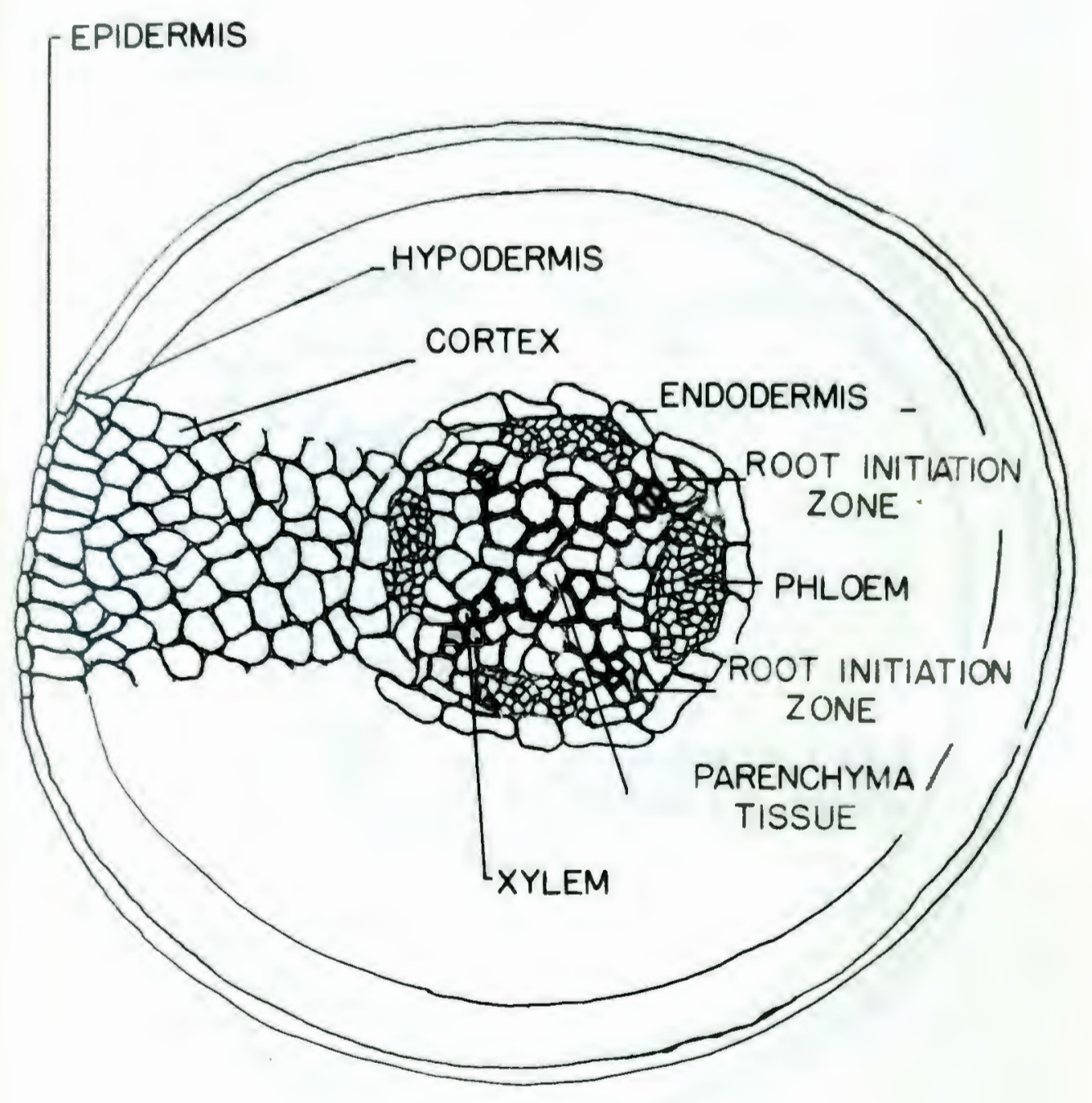

PLATE III

HYPOCOTYL: EARLY TRANSITION 


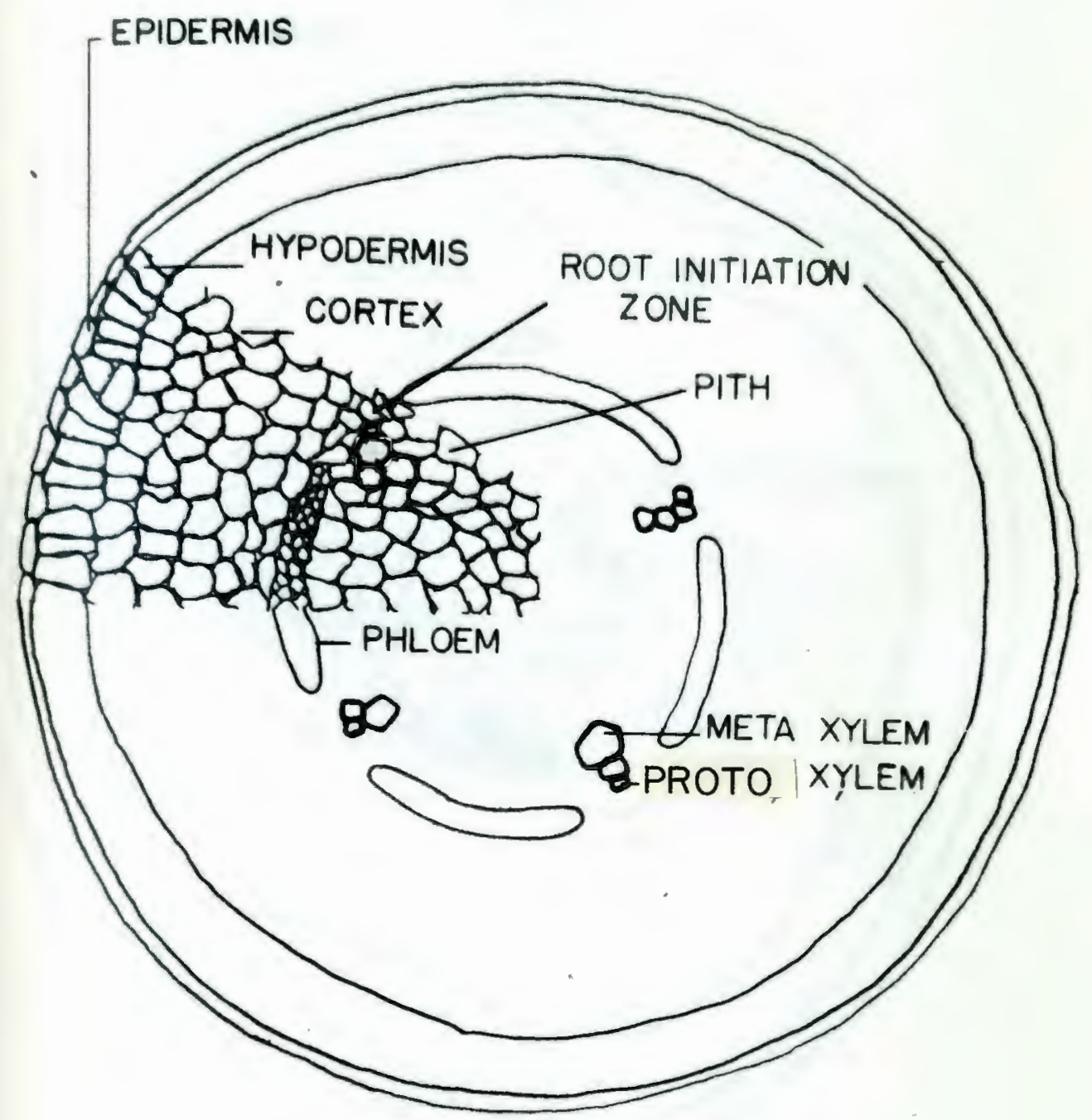

PLATE III

HYPOCOTYL; DEVELOPMENT OF PITH 


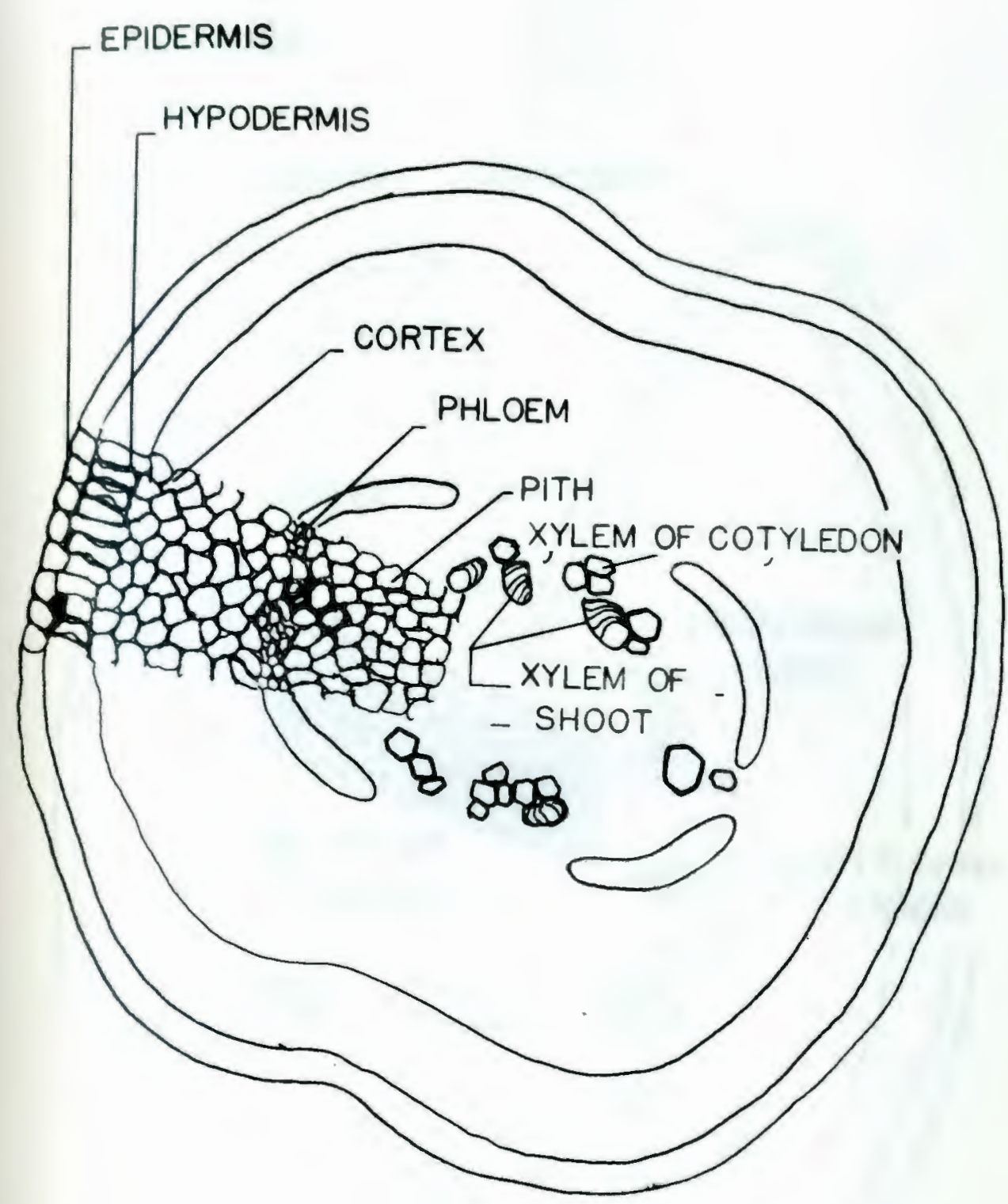

PLATE VIII

HYPOCOTYL: DIVERGENCE OF VASCULAR TISSUE TO FORM "TRIAD" COTYLEDON TRACES 


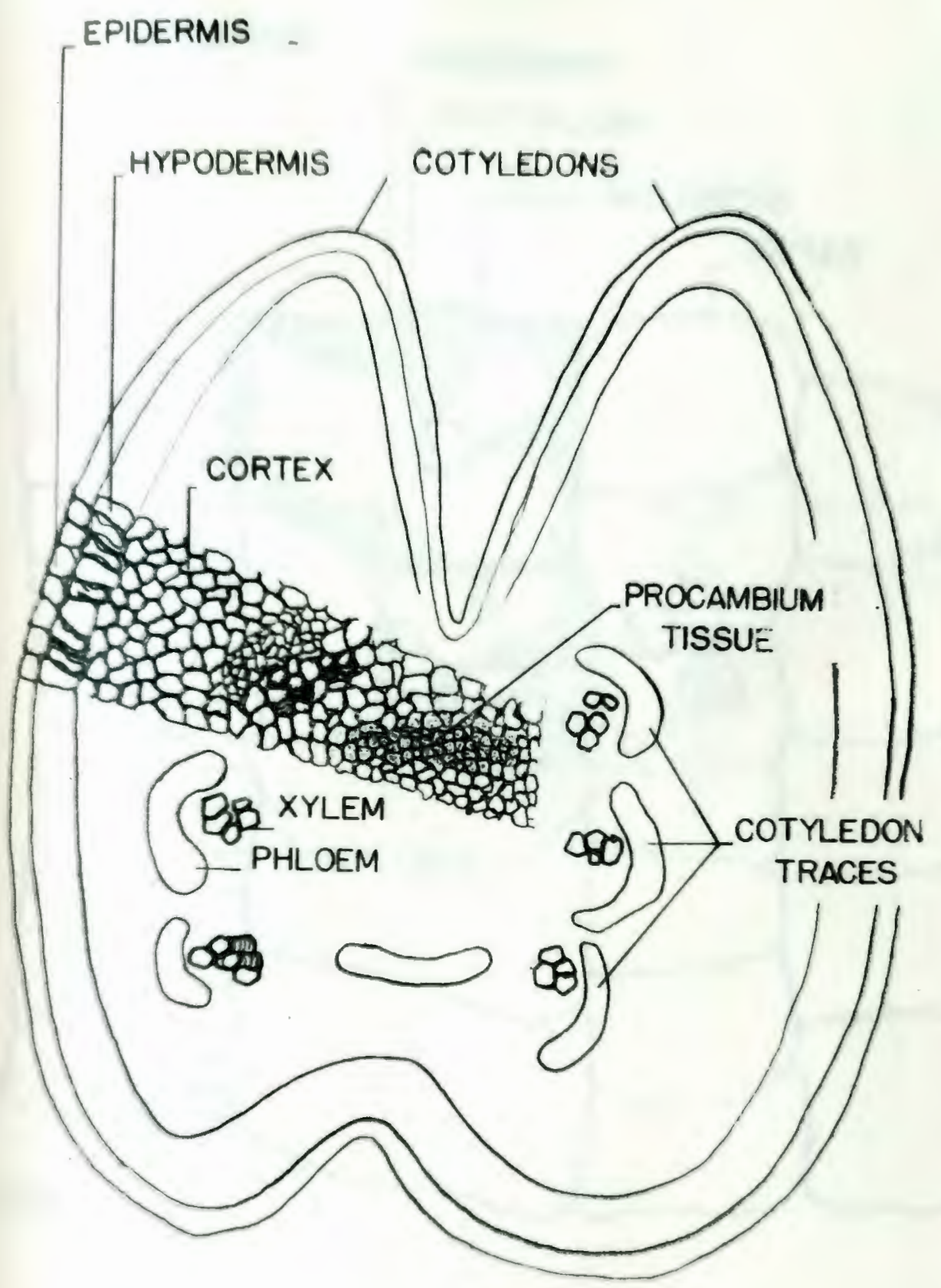

PLATE D

FINAL FORMATION OF COTYLEDON TRACES 


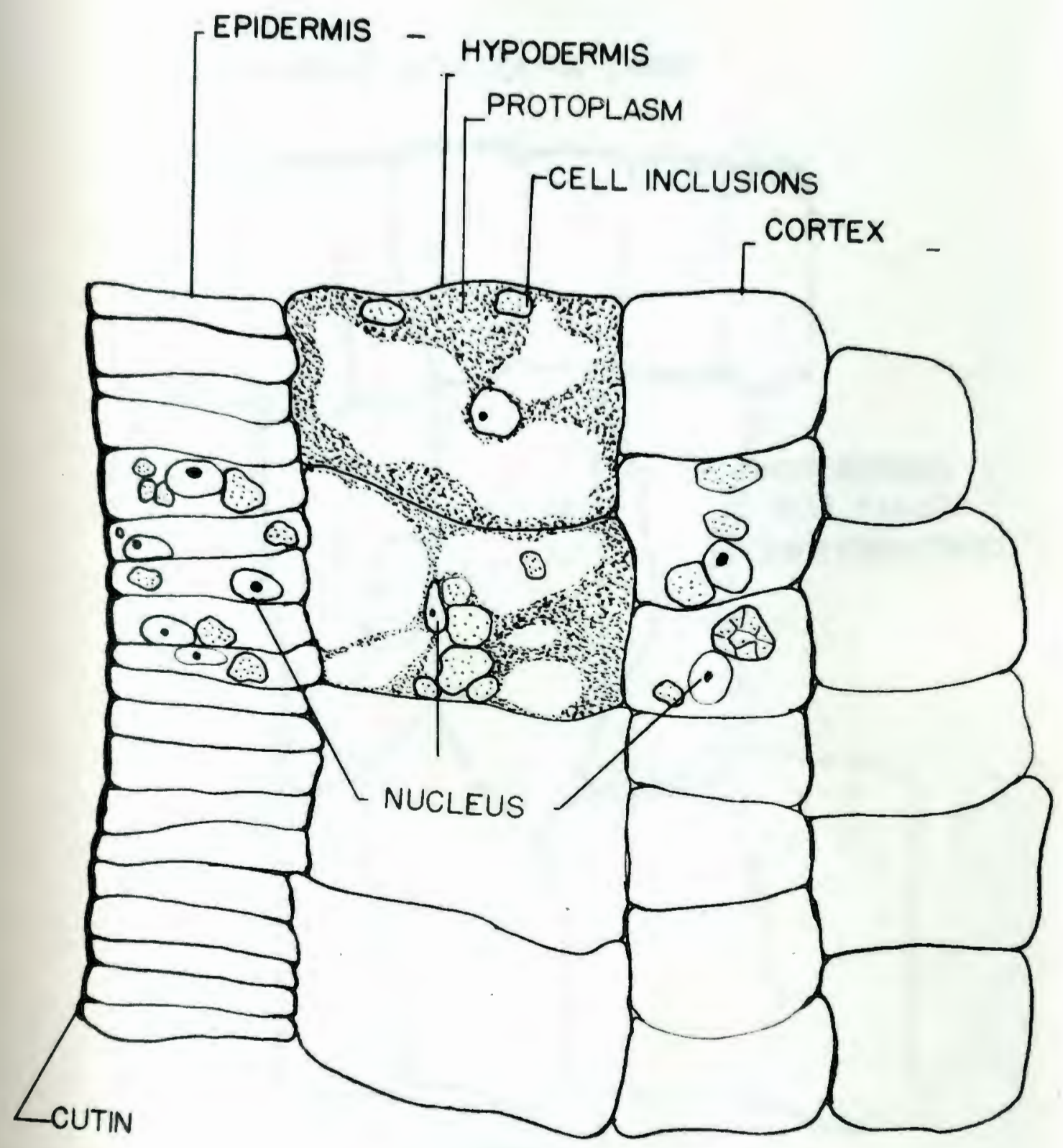

plate $\mathbf{x}$

LONGITUDINAL SECTION OF INNER SIDE OF HYPOCOTYL ARCH SHOWING COMPACT EPIDERMIS AND HYPODERMIS 


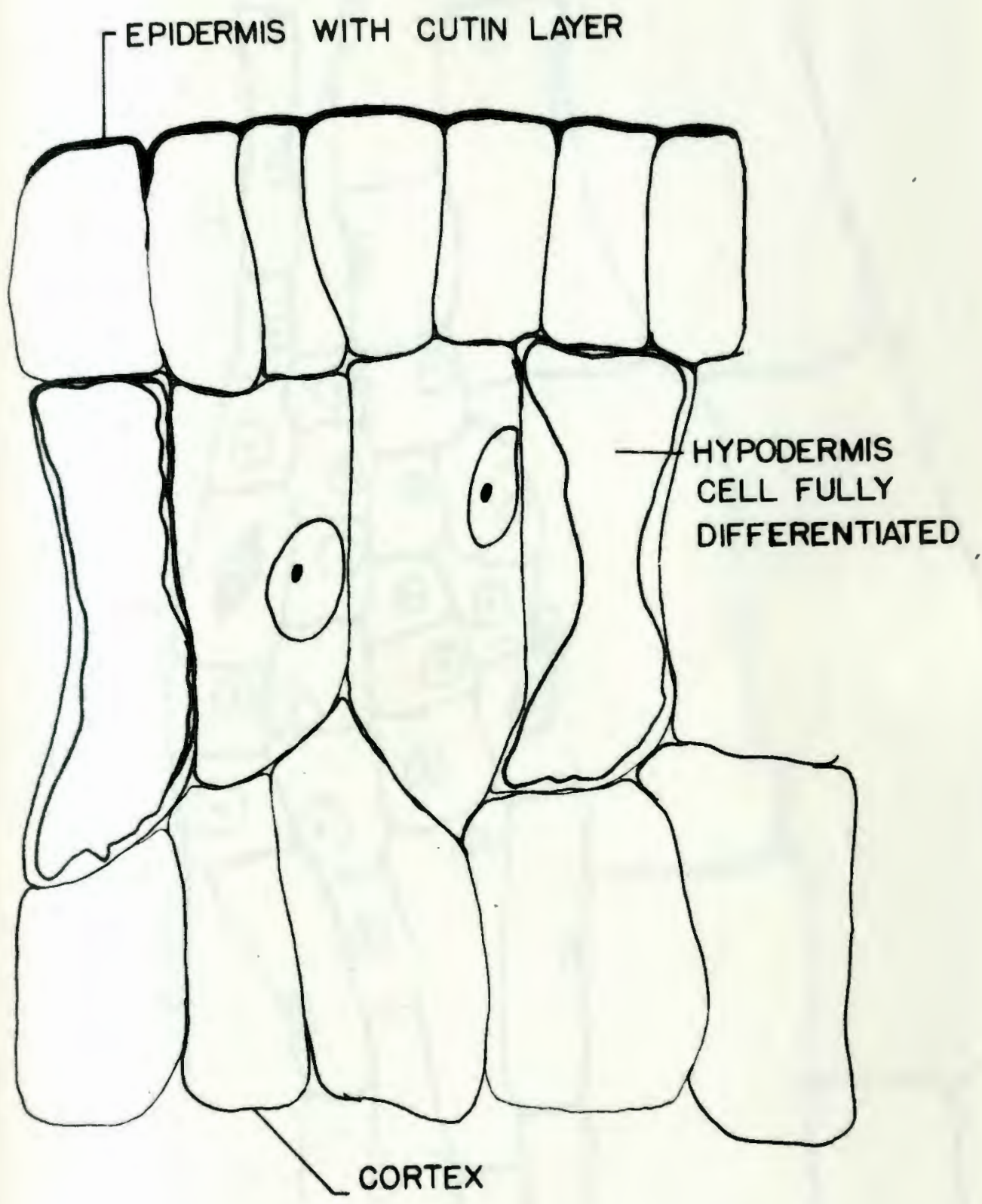

PLATE XI

HYPOCOTYL: CROSS SECTION IN REGION OF HYPOCOTYL ARCH SHOWING MATURE HYPODERMIS CELLS 


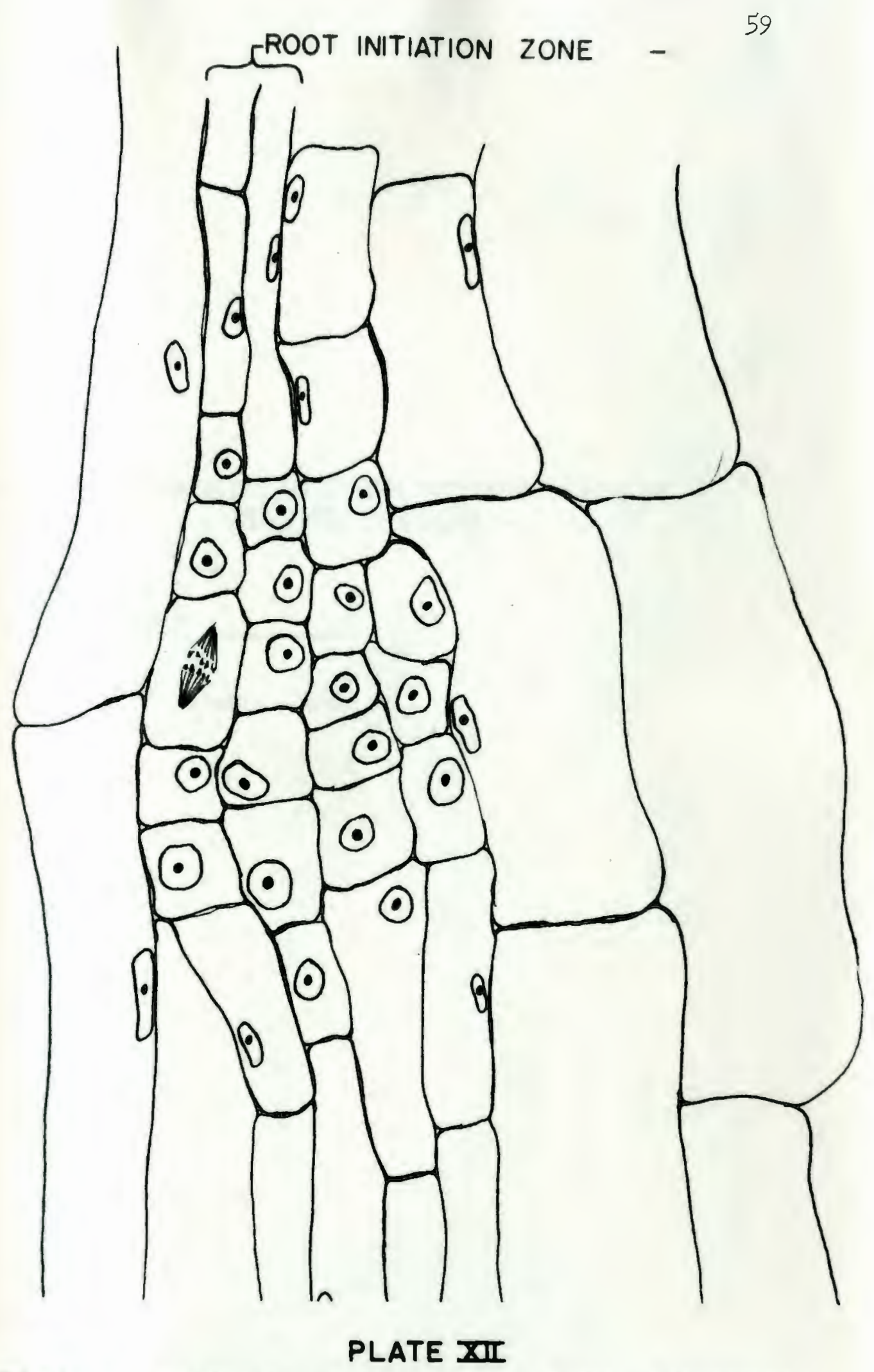

HYPOCOTYL SEGMENT NO.7 LONGITUDINAL SECTION: EARLY ROOT PRIMORDIA 
PIATE XIII: THE ORGANIZATION OF THE GOTYFEDON TRACES OF MMPATIENS BALSAMINA I.

Code: $\mathrm{Xylem}=$ Phloem $=$ 


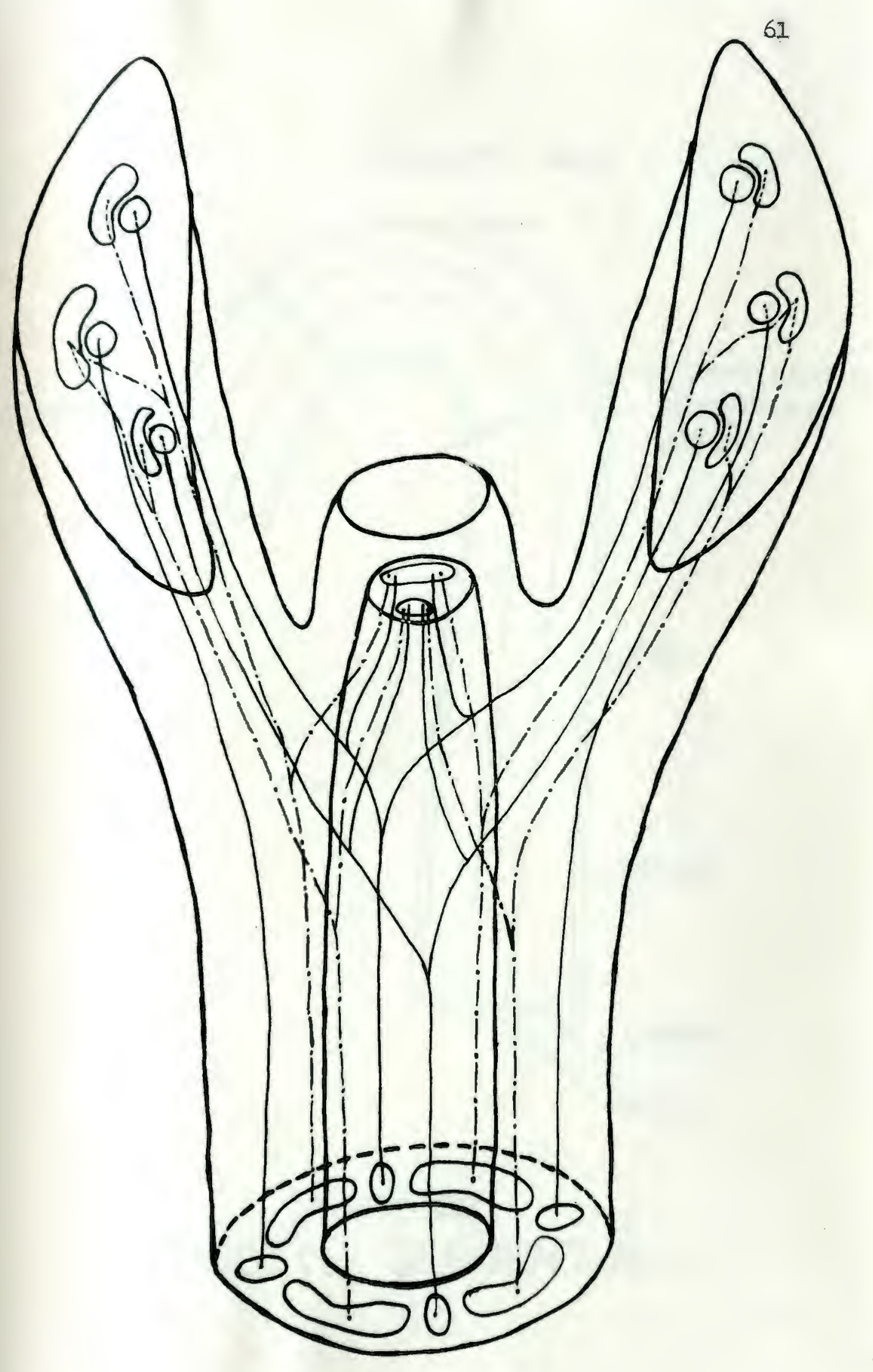




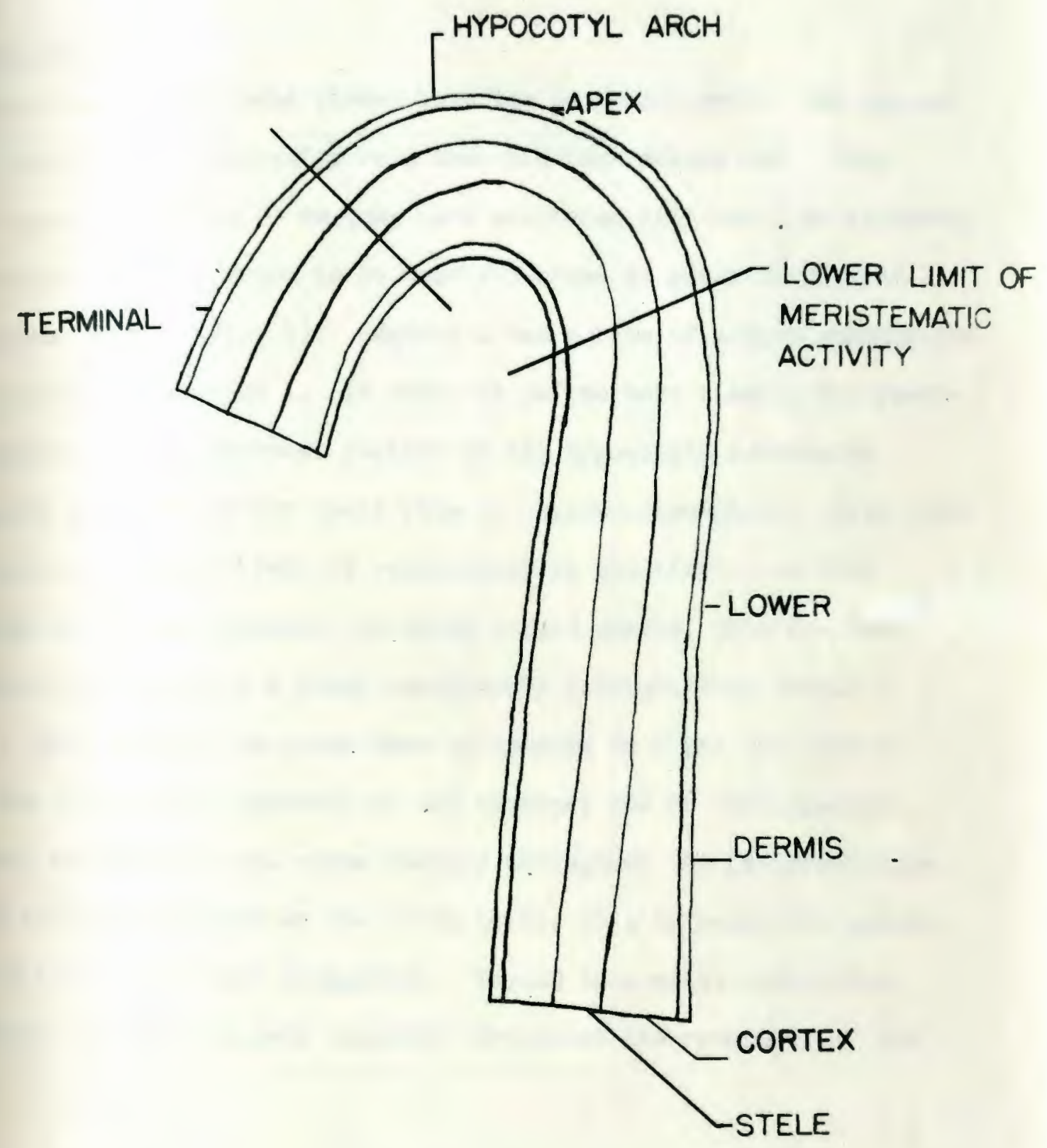

\section{PLATE XIT \\ HYPOCOTYL: SEGMENT NO.I}


length.

\section{Raspiration Studies}

Preliminary experiments showed that the cotyledon end of the hypocatyl had a much higher respiration rate than did the radicle end. When 7-day-old rypocotyls about $50 \mathrm{~mm}$ long were sectioned into ten $5 \mathrm{~mm}$ segments, the respiration rate was found to be nearly 3-times as great in segment 1 as in segments 4 to 10 (Fig. 1). Segment 2 had a rate of oxygen consumption of about one-half of segment 1. In order to define more clearly the resplratory gradient in the uppermost portion of the hypocotyl, successive $2 \mathrm{~mm}$ degments were studied for their rate of oxygen consumption. Data from Tigure 2 indicate that the rate of respiration in the first $4 \mathrm{~mm}$ from the torminal end of the hypocotyl is about 4 -fold greater than the rest of the hypocotyl. There is a steep respiratory gradient even within segment 1. When respiration rates were calculated on a per cell basis (Fig. 2) the minimum rate occurred at the terminal end of the hypocotyl. The per cell respiration rate rises sharply throughout the pseudomeristem region and reaches a maximum at the $10 \mathrm{~mm}$ level; this is below the pseudomaristem in the area of cell elongation. Beyond this point respiration drops sharply and is relatively constant throughout the remainder of the hypocotyl.

Cheminal Iactors Affecting Anthocyanin Formation and Morphogenesis

The data are presented in three sections which correspond to the trpe of test compound under study. The three types are (1) the sugars, (2) those eompounds known to affect morphogenesis, and (3) those compounds kown to affect anthocyanin formation. Some interactions of these compounds 


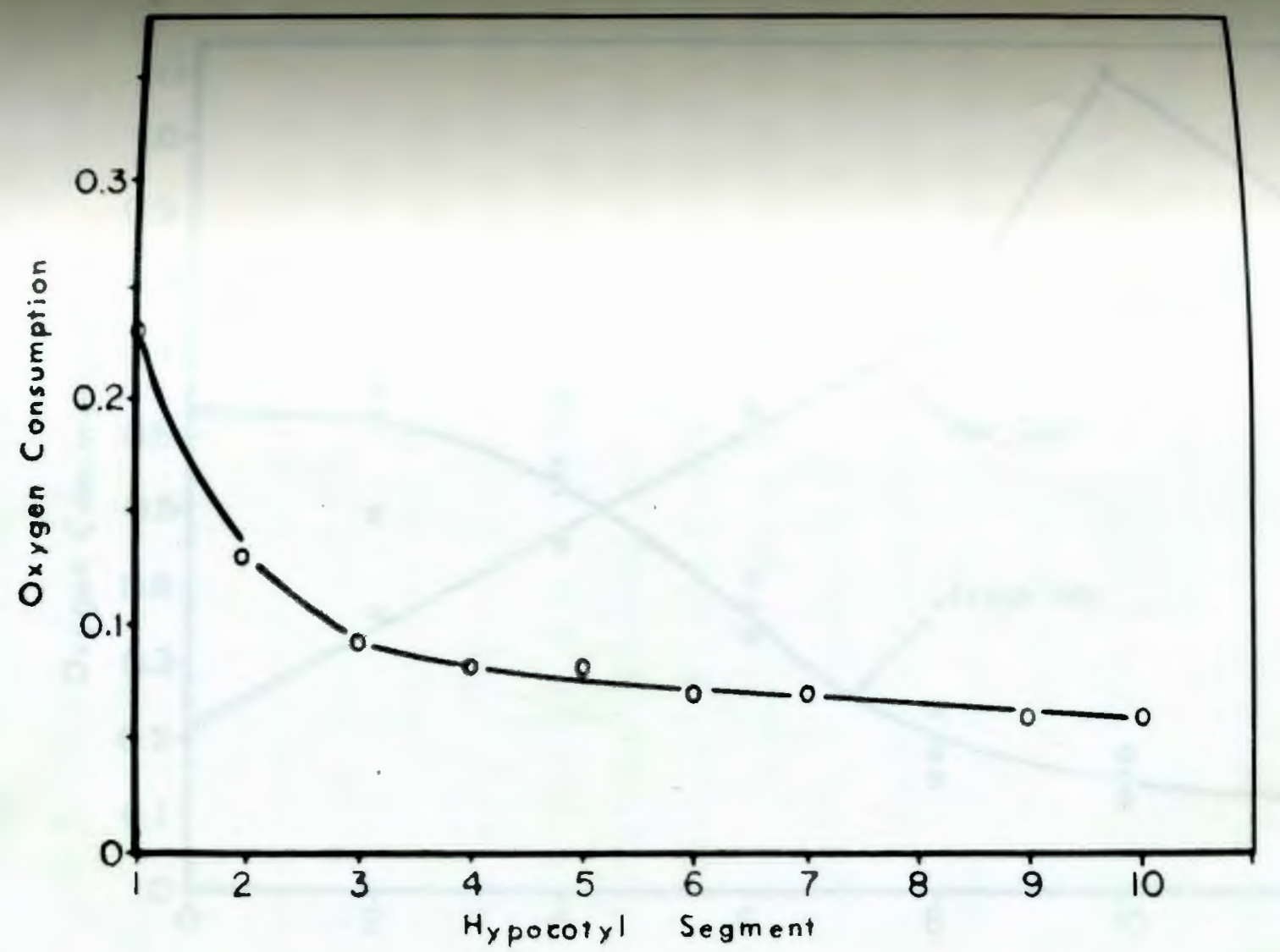

Figure 1. Respiration Rates of $5 \mathrm{~mm}$ Hypocotyl Segments of Impatiens Balsamina L. Oxygen consumption = ul $/ \mathrm{mg}$ fresh $\mathrm{wt} . / \mathrm{hr}$. 


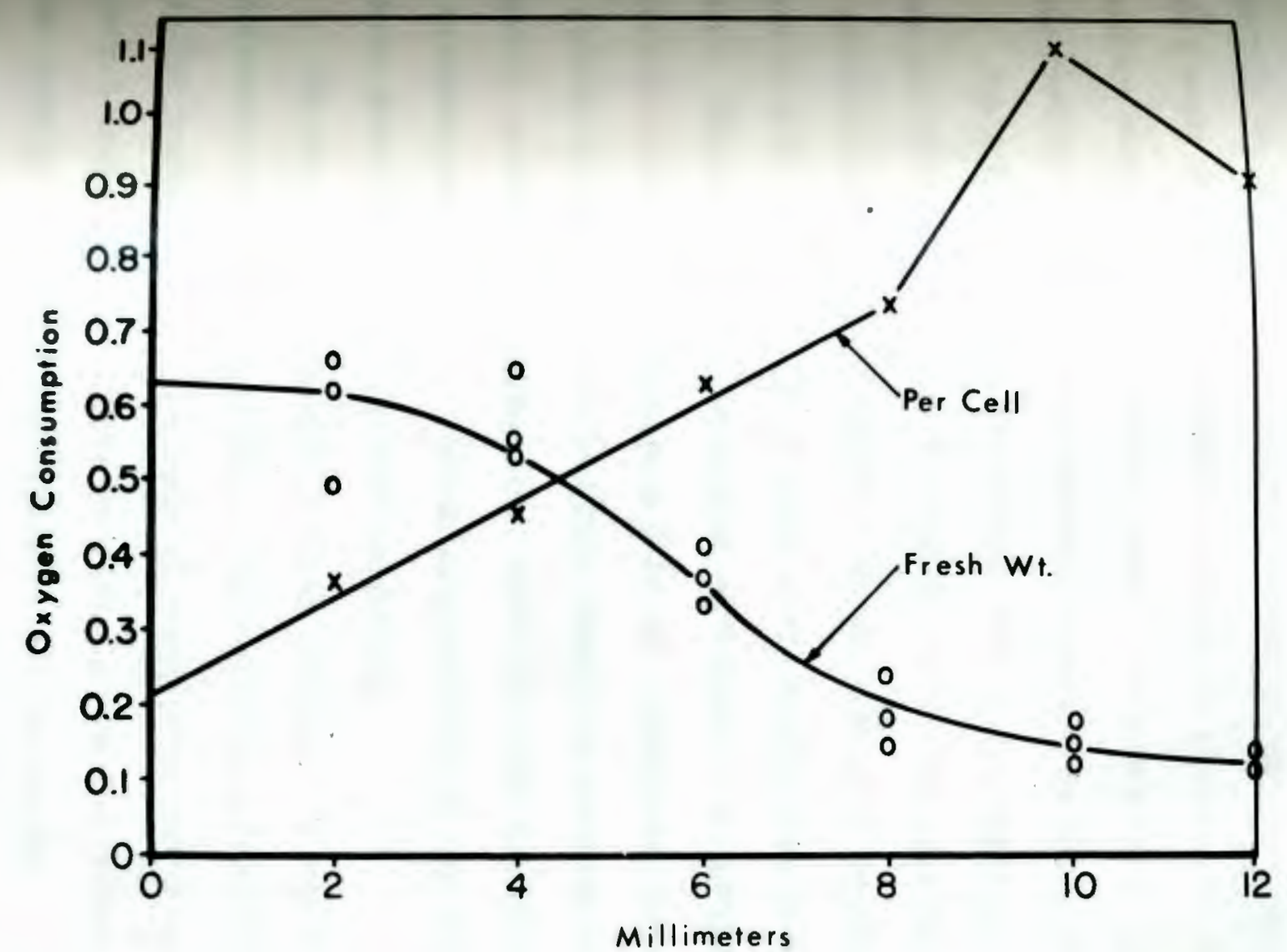

Figure 2. Rate of Oxygen Consumption of $2 \mathrm{~mm}$ Segments from the Terminal End of the Hypocotyl. Per cell = ul oxygen/l05 cells $/ \mathrm{hr}$.

Fresh wt. = ul axygen $/ \mathrm{mg}$ fresh wt. $/ \mathrm{hr}$. 
$\operatorname{ar} 6$
1. Sugars - No (visually detectable) anthocyanins are found in hypocotyl segments grown on White's medium unless the medium is supplemented with a sugar (6). The comparative effects of glucose and sucrose were therefore measured from a control base of no appreciable pigmentation. Thase results have also been reported elsewhere by the author (6).

Pable VII indicates the visual data on the formation of anthocyanin, roots and hairs collected at the end of the 10-day experimental period. No Amreciable differences occurred in the number of segments forming pigments with the exception of those grown in the dark on the $2 \%$ glucose medium. Glucose appeared to be less efficient in supporting anthocyanin formation in the dark in segment: 5 to 10. A similar, lesser efficiency of glucose in promoting root and hair formation occurred in the lower segments, particularly segment 10. Hair formation was generally increased in darkness and the highest values were obtained in the presence of suerose under both light and dark conditions.

The responses of segment 1 which was found to contain primarily meristematic and elongating tissue, were different from the respanses of the other segments. The high rate of regpiration and the elongation of segment I would seem to require more energy yielding substrates than the other egments (6). This was substantiated in the dark experiments, where photosynthate did not alleviate the substrate demands. With glucose as the rubtrate, segment I formed (1) no visible anthocyanias, (2) the least number of roots of any other segment, and (3) fewer segments formed hairs that even those receiving light. In the presence of sucrose, segment I foriwed a few more roots than with glucose and several of them became 
T A B I E $\mathrm{E} I I$

INCIDHNCE OF ANTHUCYANIN PIGMENT AND EPIDERMAI HAIRS, AND NUMBER OF ROOTS UN SEGMENTEED HYPOCOTYLS

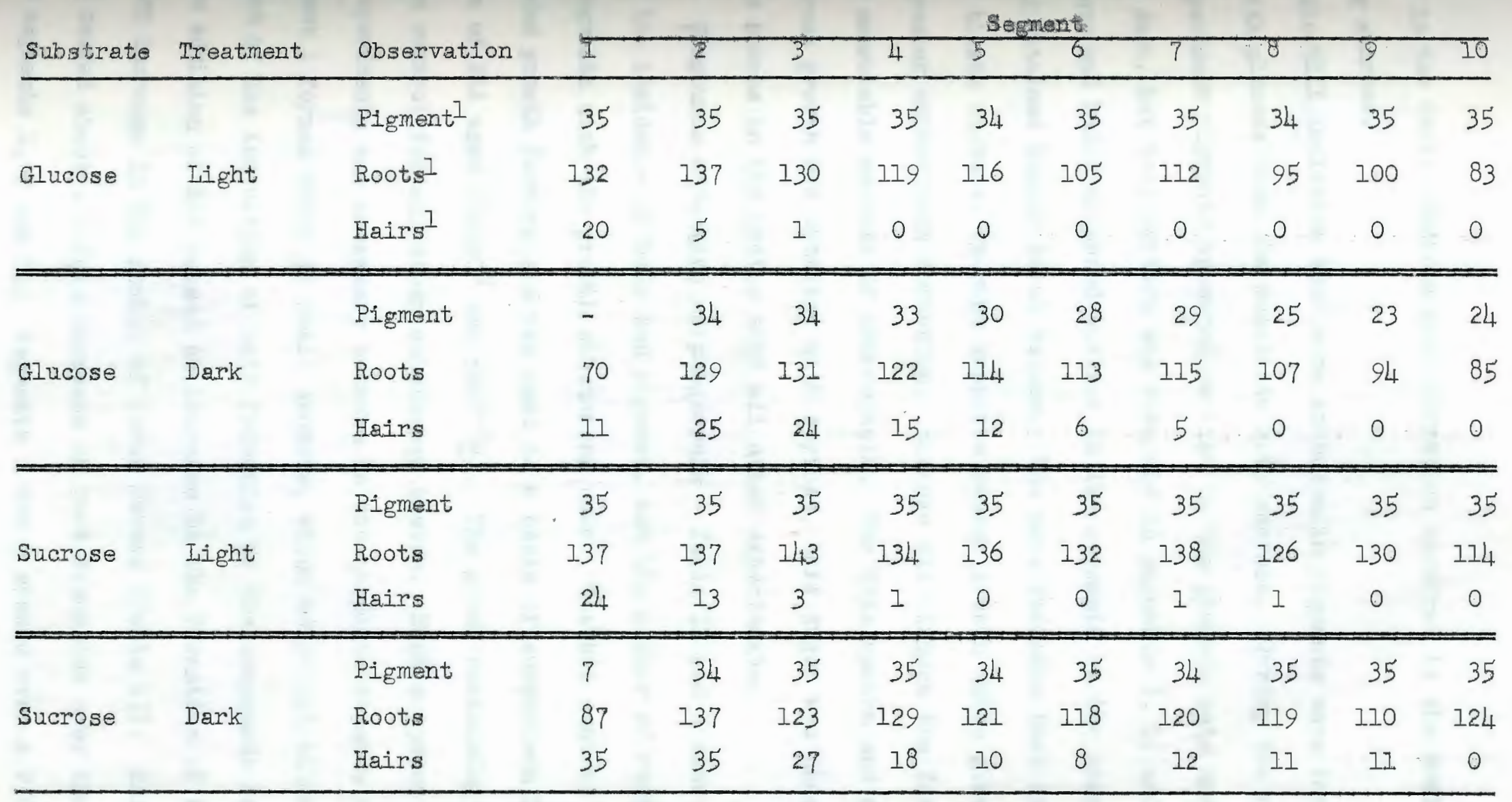

1. Pigment $=$ Number of segment $\$$ with visible anthocyanin per 35 replicates

Roots = Total number of roots on 35 replicate segments

Hairs = Number of segments with epidermal hairs per 35 replicates 
pigmented in the dark. Maximum hair formation occurred in the medium containing sucrose.

Table VIII indicates that more anthocyanin pigments were formed per vegment with glucose than the substrate with sucrose. During the course of the experiment pigments appeared earlier in the glucose sets under both light and dark, but this pattern was reversed in segments 8, 9, and 10 .

Roots and hairs appeared earlier in the segments on the sucrose medium and attained higher total values. The data indicate that in this gystem of tissue culture, sucrose supports better growth while glucose induces greater anthocyanin formation. Sucrose did induce the formation of easily measurable amounts of anthocyanin. For this reason and since more yigorous growth was obtained with sucrose, this sugar was chosen as the earbon source in the medium with all other experiments.

2. Compounds affecting morphogenesis - Table IX and X show the totals of the incidence of hair and pigment, and the number of roots formed for all segments with the growth substances used. The NAA control group had no added growth factors and was used as a basis of comparison for the two levels of NAA used $\left(5 \times 10^{-8}\right.$ and $5 \times 10^{-6}$ M). The group containing $5 \times 10^{-8}$ IAA is the control for all other substances tested. Such a system of control experiments was necessary because in the complete absence of NAA only segment 1 formed hairs in small amounts, which would not allow a masurement of the infibition of hair formation by the compounds used. The addition of NAA carsed an increase in the formation of hairs and a sharp tncrease in the number of roots formed ( $\mathrm{Table} I X$ ). NAA at 5.0 $010^{-6}$ caused about a 2-fold increase in root formation over the control axcept in segments 1,9 and 10. Segments 1 and 9 showed over a 250\% 
T A B I E $\mathrm{E} I I I$

REIATIVE AMOUNTS OF ANTHOCYANIN ${ }^{1}$ FORMED PER HYPOCOTYL SEGMENT IN 10 DAYS

\begin{tabular}{llllllllllllll} 
Substrate & & Treatment & I & 2 & 3 & 4 & 5 & 6 & 7 & 8 & 9 & 10 \\
\hline 2\% Glucose & Iight & 4.141 & 5.46 & 6.29 & 6.29 & 6.74 & 6.51 & 6.89 & 5 & 47 & 5.09 & 4.06 \\
\hline 2\% Glucose & Dark & 0 & 0.61 & 1.00 & 0.97 & 0.96 & 0.82 & 0.83 & 0.88 & 0.87 & 0.63 \\
\hline 2\% Sucrose & Iight & 2.94 & 3.89 & 4.34 & 4.66 & 4.57 & 4.09 & 5.00 & 3.89 & 4.23 & 4.00 \\
\hline 2\% Sucrose & Dark & 0.14 & 0.32 & 0.46 & 0.37 & 0.35 & 0.26 & 0.41 & 0.34 & 0.31 & 0.34 \\
\hline
\end{tabular}

1. Units $=0 . D \cdot \times 10^{3} /$ pigmentèd segment 


\section{T A B I E I X}

EFFECT OF DIFFHRENT LEVELS OF NAA ON THE INCIDENCE OF ANTHOCYANIN AND HAIRS, AND THE FORMATION OF ROOTS ON CULTURED HYPOCOTYI SEGMENTS

\begin{tabular}{|c|c|c|c|c|c|c|c|c|c|c|c|c|}
\hline \multirow{2}{*}{$\begin{array}{l}\text { Test } \\
\text { Compound }\end{array}$} & \multirow{2}{*}{$\begin{array}{c}\text { Molar } \\
\text { Concentration }\end{array}$} & \multirow[b]{2}{*}{ Observation ${ }^{1}$} & \multicolumn{10}{|c|}{ Degitill } \\
\hline & & & 1 & 2 & 3 & 4 & 5 & 6 & 7 & 8 & 9 & 10 \\
\hline \multirow{3}{*}{ NAA-Control } & \multirow{3}{*}{0} & Pigment & 35 & 35 & 35 & 35 & 35 & 35 & 35 & 35 & 35 & 34. \\
\hline & & Roots & 139 & 136 & 123 & 121 & 110 & 111 & 114 & 101 & 102 & 62 \\
\hline & & Hairs & 15 & 0 & 0 & 0 & 0 & 0 & 0 & 0 & 0 & 0 \\
\hline \multirow{3}{*}{ NAA } & \multirow{3}{*}{$5.0 \times 10^{-8}$} & Pigment & 35 & $35^{\prime}$ & 35 & 35 & 35 & 35 & 35 & 35 & 35 & 35 \\
\hline & & Roots & 137 & 138 & 143 & 134 & 136 & 132 & 138 & 126 & 130 & 114 \\
\hline & & Hairg & 24 & 13 & 3 & 1 & 0 & 0 & 1 & 1 & 0 & 0 \\
\hline \multirow{3}{*}{ NAA } & \multirow{3}{*}{$5.0 \times 10^{-6}$} & Pigment & 34 & 35 & 35 & 35 & 35 & 35 & 34 & 33 & 35 & 35 \\
\hline & & Roots & 372 & 208 & 222 & 237 & 224 & 230 & 241 & 212 & 259 & 314 \\
\hline & & Hairs & 29 & 20 & 11 & 5 & 5 & 0 & 0 & 0 & 0 & 0 \\
\hline
\end{tabular}

1. Same as Table VII. 


\section{T A B I E X}

HFFECT OF GA AND TIBA ON THE INGIDENCE OF ANTHOCYANIN AND HATRS, AND THE FORMATION OF ROOTS ON CULTUR FW FYPOCOTYL SEGMENTS

\begin{tabular}{|c|c|c|c|c|c|c|c|c|c|c|c|c|}
\hline \multirow[b]{2}{*}{ Compound } & Molar & 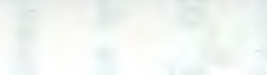 & & - & & \multicolumn{3}{|c|}{ Segment } & & 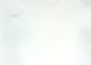 & \multirow[b]{2}{*}{10} \\
\hline & Concentration & Observation ${ }^{1}$ & 1 & 2 & 3 & 4 & 5 & 6 & 7 & 8 & 9 & \\
\hline \multirow[b]{2}{*}{ Control } & & Pigment & 35 & 35 & 35 & 35 & 35 & 35 & 35 & 35 & 35 & 35 \\
\hline & & Roots & 137 & 138 & 143 & 134 & 136 & 132 & 138 & 126 & 130 & 114 \\
\hline \multirow{3}{*}{ GA } & \multirow{3}{*}{$2.7 \times 10^{-5}$} & Pigment & 35 & 35 & 35 & 35 & 35 & 35 & 35 & 35 & 35 & 35 \\
\hline & & Roots & 105 & 138 & 123 & 118 & 120 & 121 & 135 & 137 & 131 & 112 \\
\hline & & Hairs & 14 & 24 & 9 & 11 & 3 & 2 & 3 & 2 & $I$ & 0 \\
\hline \multirow[t]{2}{*}{ TIBA } & \multirow[t]{2}{*}{$5.0 \times 10^{-5}$} & Roots & 36 & 10 & 0 & 7 & 10 & 23 & 20 & 24 & 19 & 57 \\
\hline & & Hairs & 4 & 0 & 0 & 0 & 0 & 0 & 0 & 0 & 0 & 0 \\
\hline
\end{tabular}

I. Same as Table VII. 
therease while segment 10 had a 500\% increase in the number of roots formed. During the course of the experiments, roots and hairs appeared earlier in the NAA treated cultures. The appearance of anthocyanin pigments however, did not follow this pattern. Figures 3 and 4 show that Inerements of NAA in the eulture medium caused a delay in onset of anthocyanin formation. The total amount of anthocyanin produced in most gegments of the hypocotyl increased with the addition of NAA to the medium. (Iable II). Figure 5 shows the total amount of anthocyanin formed for the entire hypocotyl at different levels of NAA. However, the response of each segment of the hypocotyl was not the same. Figure 6 shows that sogments 1 and 2 with $5 \times 10^{-8}$ NAA and segments 1 to 3 with $5 \times 10^{-6}$ MAA formed considerably less anthocyanin than the control. The remaining segments toward the base of the hypocotyl exceeded the control. Increasing levels of NAA also caused a shift in the point of maximum anthocyarin rormation along the axis of the hypocotyl toward the base. Maximum amounts of anthocyanins occurred in segment 1 of the control, segment 4 and 5 with $5 \times 10^{-8}$ MAA, and segment 8 with $5 \times 10^{-6}$ MAA. The rooting rasponse to NAA was somewhat similar in that the greatest increases are found in the lower segments (Figure 7). There was no depression of the upper segments however, and segment 1 formed the most roots of any segment at the highest level of NAA. Curiously, segment 1 showed no response to the $5 \times 10^{-8}$ I level of NAA.

IIBA was found to have no effect on the number of segments forming Digment, but root and hair formation was strongly inhibited (Table X). IIBA also depressed the total anthocyanin formed in all the segments except megment 1 which showed about a 50\% increase (Table XII). Figure 8 shows 
T A B L I X I

EFFECT OF DIFFERENT LEVELS OF NAA ON TOTAL ANTHOCYANIN ${ }^{1}$

FORMED IN HYPOCOTYL SEGMENTS

\begin{tabular}{lcccccccccccc} 
Test & \multicolumn{1}{c}{$\begin{array}{c}\text { Molar } \\
\text { Compound }\end{array}$} & Concentration & 1 & 2 & 3 & 4 & 5 & 6 & 7 & 8 & 9 & 10 \\
\hline NAA-Control & 0 & $4.86^{1}$ & 4.69 & 4.29 & 4.11 & 3.71 & 3.66 & 3.91 & 3.60 & 3.37 & 2.66 \\
\hline NAA & $5.0 \times 10^{-8}$ & 2.94 & 3.89 & 4.34 & 4.66 & 4.57 & 4.09 & 5.00 & 3.88 & 4.23 & 4.00 \\
\hline NAA & $5.0 \times 10^{-6}$ & 4.17 & 3.37 & 3.40 & 4.28 & 5.00 & 4.77 & 5.82 & 6.88 & 6.34 & 6.03
\end{tabular}

1. Same as Table VIII.

T A B I E X I I

HEFECT OF GA AND TIBA ON TOTAL ANTHOCYANIN ${ }^{-1}$ FORMED IN HYPOCOTY SEGMENTS

\begin{tabular}{|c|c|c|c|c|c|c|c|c|c|c|c|}
\hline Test & Molar & & & & & & ment & & & & \\
\hline Compound & Concentration & -1 & 2 & 3 & 林 & 5 & 6 & 7 & 8 & 9 & 10 \\
\hline Control & $\theta$ & $2.94^{1}$ & 3.89 & 4.34 & 4.66 & 4.57 & 4.09 & 5.00 & 3.88 & 4.23 & 4.00 \\
\hline GA & $2.7 \times 10^{-5}$ & 1.86 & 3.34 & 2.77 & 3.06 & 2.94 & 2.95 & 2.92 & 2.94 & 2.89 & 2.32 \\
\hline TIBA & $50 \times 10^{-5}$ & $4 \cdot 32$ & 3.92 & 3.63 & 3.72 & 3.47 & 3.34 & 3.23 & 3.23 & 2.40 & 2.47 \\
\hline
\end{tabular}

1. Same as Table VIII. 


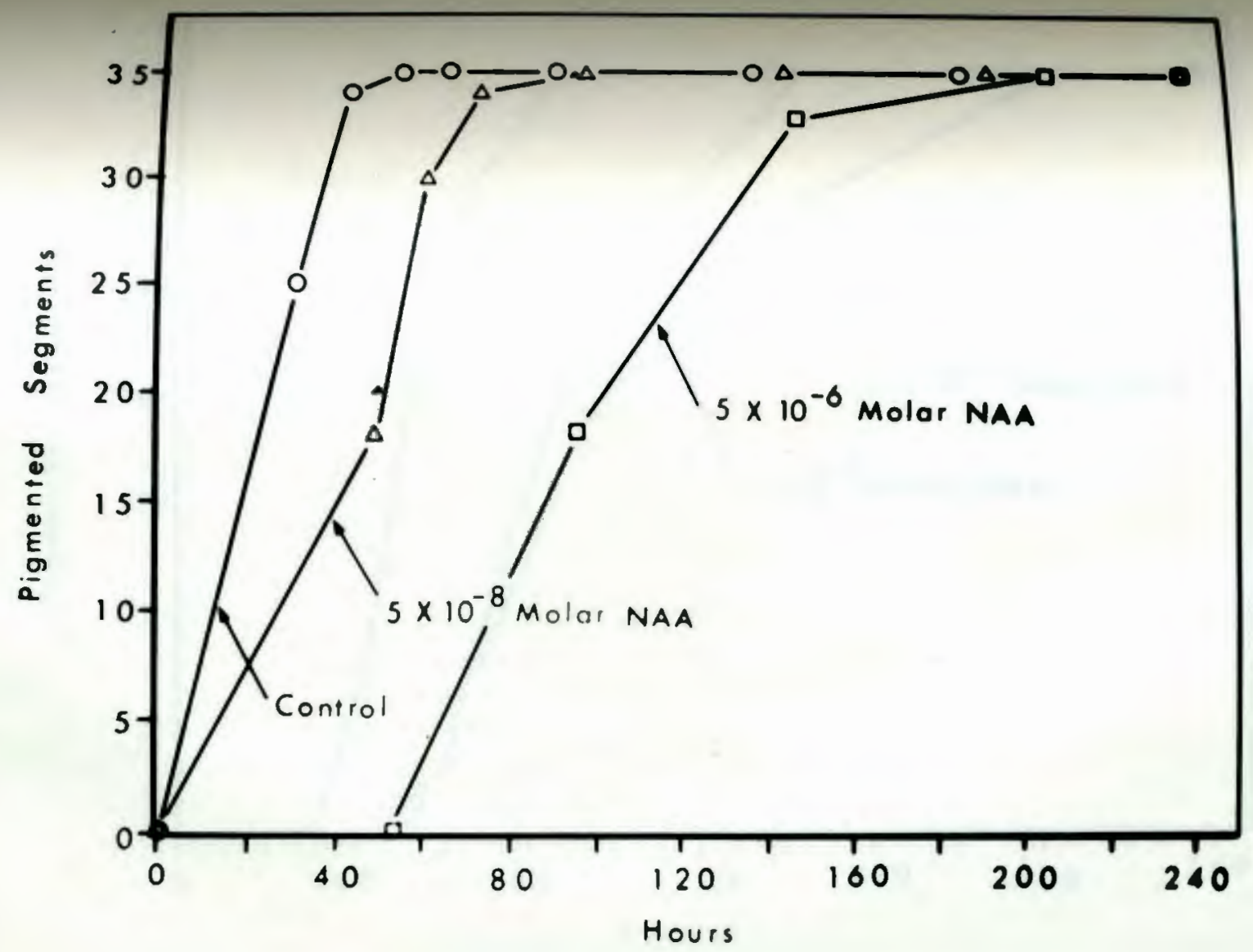

Figure 3. Effect of NAA on the Rate of Appearance of Anthocyanin Pigments in Segment 2 of the Hypocotyl. Pigmented segments = number of visibly pigmented segments/35 replicates. 


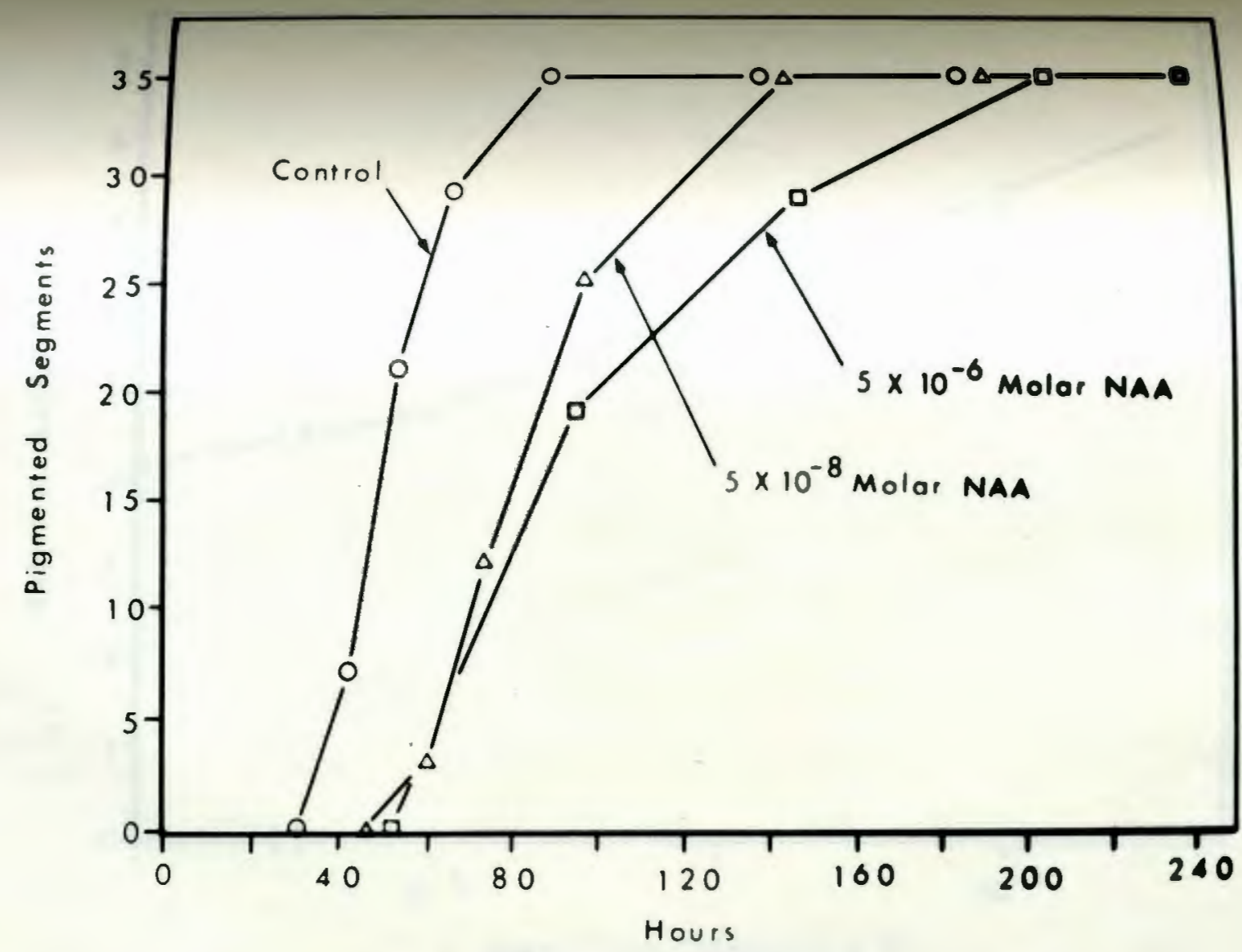

Figure 4. Effect of NAA on the Rate of Appearance of Anthocyanin Pigments in Segment 9 of the Hypocotyl. Pigmented segments $=$ number of visibly pigmented segments/35 replicates. 


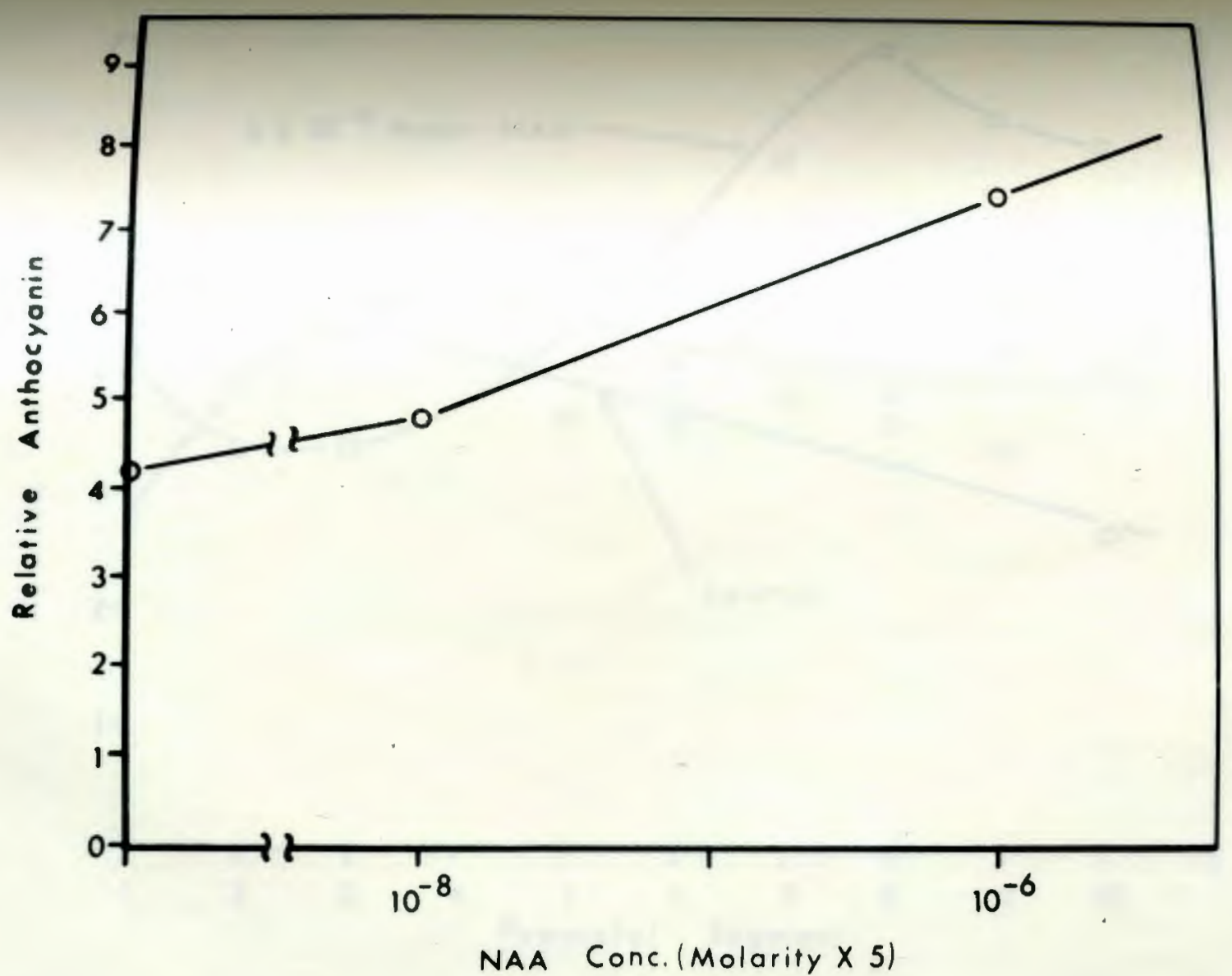

Figure 5. Effect of NAA Concentration of the Total Amount of Anthocyanin Formed per Hypocotyl in 10 days of Culture. Relative anthocyanin $=0 . D$. X $103 /$ hypocotyl. 


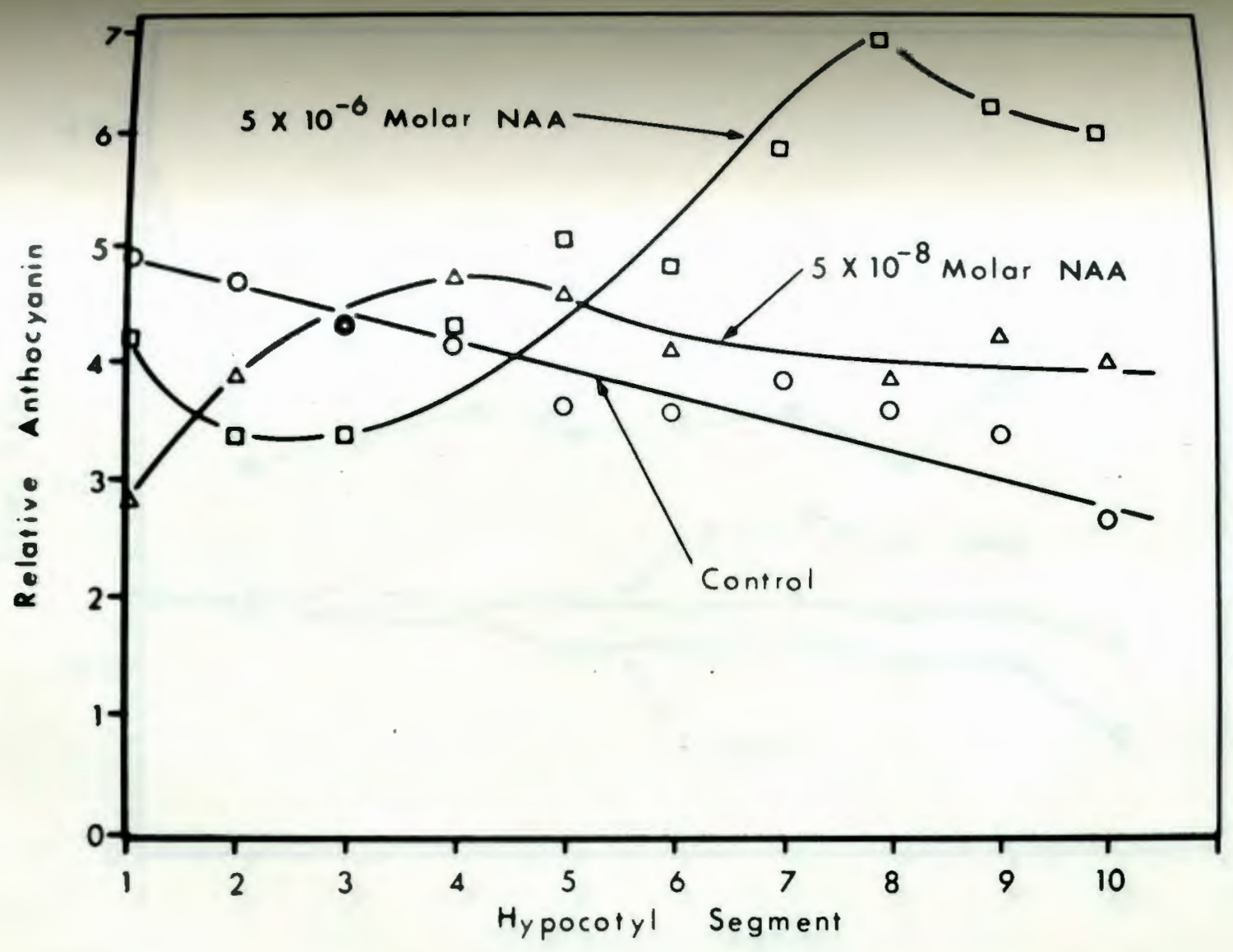

Figure 6. Effect of NAA on the Quantitative Distribution of Anthocyanin Pigments Along the Axis of the Hypocotyl. Relative anthocyanin $=0 . D . \mathrm{X} 10^{3} /$ pigmented segment. 


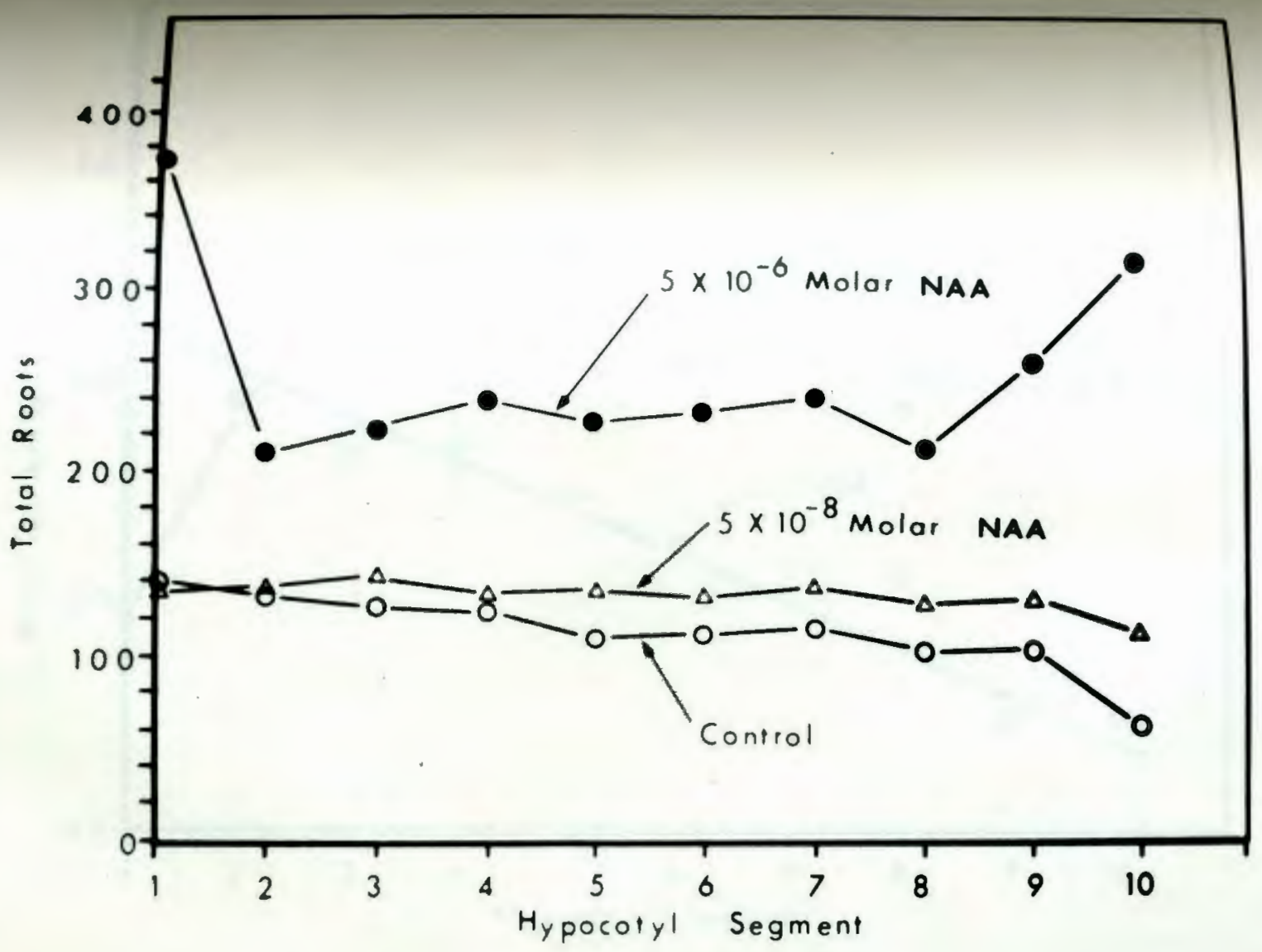

Figure 7. Effect of NAA on the Number of Roots Formed Along the Hypocotyl Axis. Total roots = total number of roots $/ 35$ replicate segments. 


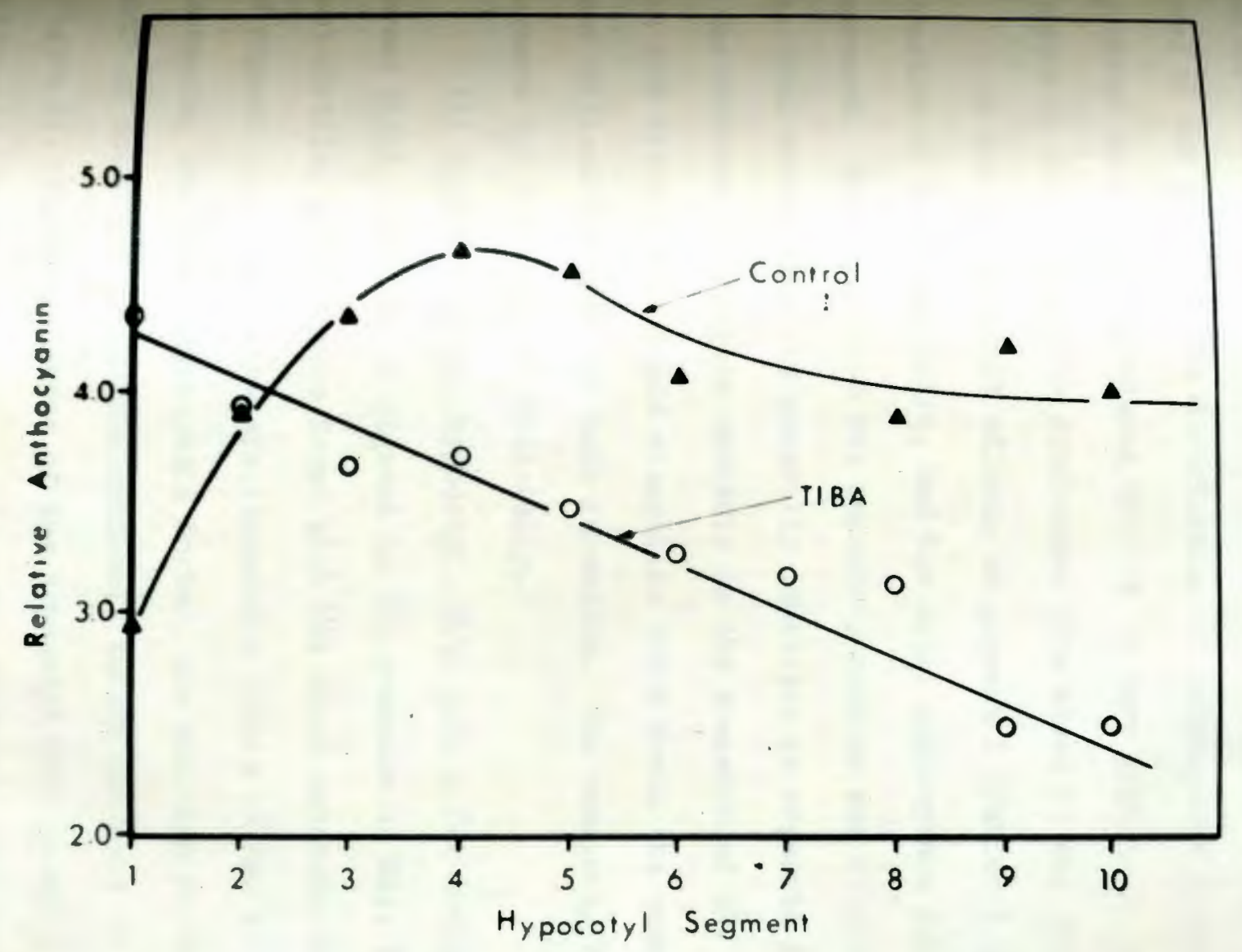

Figure 8. Effect of $5.0 \times 10^{-5 \mathrm{M}}$ TIBA on the Quantitative Distribution of Anthocyanin Pigments Along the Axis of the Hypocotyl. Relative anthocyanin $=0 . D$. X $10^{3} /$ pigmented segment. 
that the pattern of anthocyanin formation along the axis of the hypocotyl was also changed by TIBA. While being generally lower, the TIBA curve shows that segment 1 formed more anthocyanins than the other segments of the Mocotyl, while segments 4 and 5 were maximum in the control. The curve of the quantitative distribution of anthocyanin pigments along the hypocotyl axis in the presence of PIBA is very similar to the NAA control (F1gure 6) where no growth substances were added to the medium. GA had its greatest effects on segment $I$ (Tables $X$ and $X I I$ ). The formation of roots and hairs, and the total anthocyanin formed were depressed. Hair formation was enhanced, rooting was slightly affected and the total anthocyanin was generally inhibited in segments 2 to 9 . Segment 1 was observed to elongate markedly in the presence of GA, as it did in the dark without GA. Rapid elongation could drain the energy that would have been ntllized for root and hair formation. The remaining hypocotyl segments did not elongate noticeably.

All segments of the hypocotyl, with only a few isolated exceptions, formed visible amounts of pigment in the presence of HAA, TIBA or GA. The most ariking effects were found with NAA which enhanced the formation of pigment roots and hairs simultaneously (Table IX and XI). Besides increasing the total anthocyanin formed, the addition of NAA caused a shift of the point of maximum synthesis toward the base of the hypocotyl (Iigure 6), Different parts of the hypocotyl were found to respond quite differently to the same treatments. For instance, anthocyanin synthesis was Lhibited in segment 2 by NAA, while in segment 10 anthocyanin synthesis was greatly enhanced by the addition of MAA. 
3. Purine analogues (benzimidagole and azquanine) and riboflavinThe Visual 10-day data for the effects of Ara and $\mathrm{Bz}$ on the formation of pignent, hairs and roots of cultured hypocotyl segments are sumarized in Table UII. Both purine analogues effectively inhibited hair production in all segments. The responses of segment 1 were found to be different from the rest of the segments. Aza severely inhibited raot formation in all egments at both levels used. $\mathrm{Bz}$, on the other hand, had little efect on segment 1 , while reducing the number of roots formed on segments 2 to 10 to negligible values. The relative ineffectiveness of $\mathrm{Bz}$ as ompared with Aza on segment I, while both compounds inhtbit rooting in the rest of the hypocotyl indicates the uniqueness of segment 1 . The data for the total anthocyanin produced at the end of the 10day experimental period are presented in Table XIV. Both compounds perally inhibited anthocyanin formation. As reported by whimann and Radner (149), Aza was a much more potent inhibitor of anthocyanin ynthesis than $\mathrm{Bz}$. In segments 2 to $10,3.0 \times 10^{-5}$ molar was about as equally effective as $3.0 \times 10^{-3}$ molar Bz. Again, segment $I$ is of particular interest. Aza had relatively little effect on anthocyanin snthesis in segment 1, whereas Bz inhibited pigment formation in segment $I$ as well as the other segments. The anthocyanin formed in segment $I$ with $3.0 \times 10^{-6}$ molar is equal to the control, while the remaining segments formed only about 20 to $30 \%$ of the total anthocyanin found in the eentrol.

$\mathrm{Rb}$ at $3.0 \times 10-4$ molar was found to inhibit anthocyanin formation by hypocotyl segments in the dark as shown in Table XV. Straus (143) has ahown that $\mathrm{Rb}$ inhibits anthocyanin synthesis in cultured corn endosperm Mssue. Rb also appeared to inhibit root and hair formation slightly in vegment $I$. 
T A B I $\mathrm{X} I I I$

FFFECT OF AZA AND BZ ON THE INCIDENCE OF PIGMENT AND HAIRS, AND ROOT FORMATION IN CULTURED HYPOCOTYL, SEGMENTS

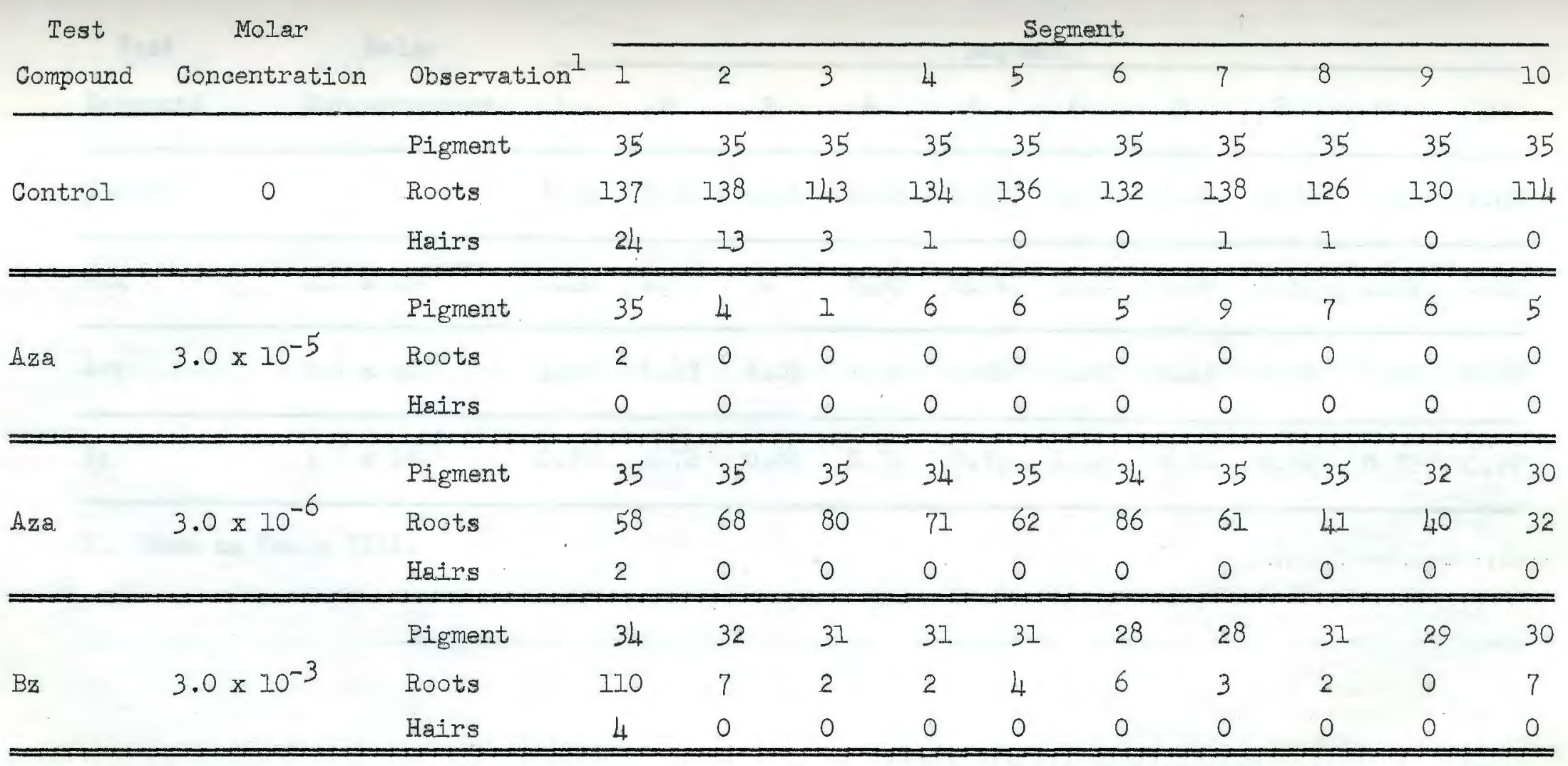

1. Same as Table VII. 


\section{T A B I E X I V}

EFFECT OF AZA AND BZ ON TOTAL ANTHOCYANIN ${ }^{1}$ FORMED IN CULTURED HYPOCOTYL SEGMENTS

\begin{tabular}{|c|c|c|c|c|c|c|c|c|c|c|c|}
\hline Test & Molar & & & & & Segm & & & 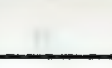 & & \\
\hline Compound & Concentration & 1 & 2. & 3 & 4 & 5 & 6 & 7 & 8 & 9 & 10 \\
\hline Control & 0 & $2.94^{1}$ & 3.89 & $4 \cdot 34$ & 4.66 & 4.57 & 4.09 & 5.00 & 3.88 & 4.23 & 4.00 \\
\hline Aza & $3.0 \times 10^{-5}$ & 1.40 & 0.87 & 0 & 0.92 & 0.92 & 1.10 & 0.28 & 0.57 & 0.42 & 0.60 \\
\hline Aza & $3.0 \times 10^{-6}$ & 3.03 & 1.17 & 1.03 & 1.29 & 1.00 & 1.65 & 1.43 & 1.03 & 1.06 & 0.73 \\
\hline $\mathrm{Bz}$ & $3.0 \times 10^{-3}$ & 0.71 & 0.72 & 0.68 & 0.71 & 0.74 & 1.00 & 0.96 & 0.92 & 0.72 & 0.97 \\
\hline
\end{tabular}

1. Same as Table VIII. 
T A B L E X V

HFFECT OF $3 \times 10^{-4}$ MOLAR RB ON HYPOCOTYL SEGMENTS CULTURED IN THE DARK

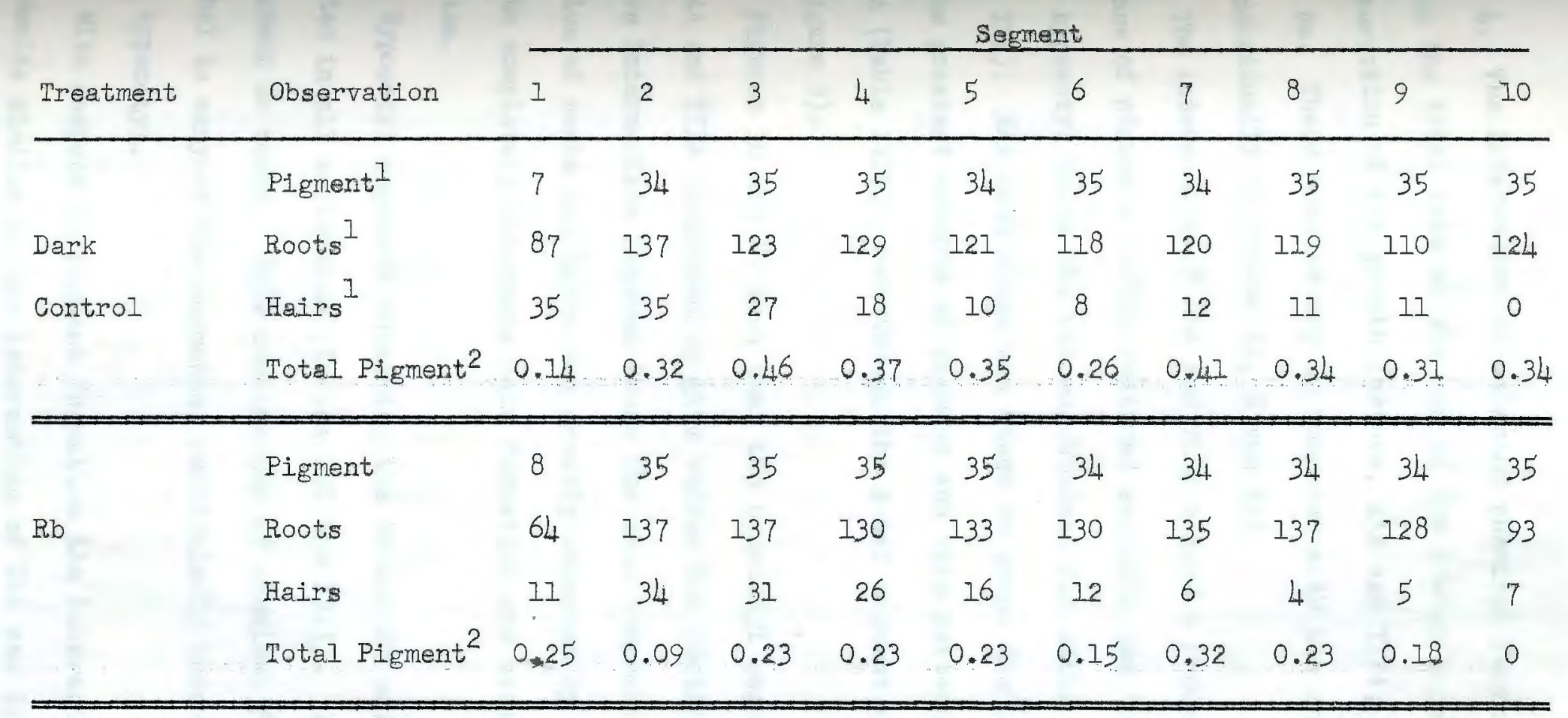

1. Same as Table VII.

2. Same as Table VIII. 
4. The interaction of selected chemical factors - Table XVI presents the total data at the end of the 10-day experimental period for the theraction of the growth factors, NAA and TIBA; and the compounds, $\mathrm{Br}$ and $\mathrm{Rb}$. These results may be compared with the data for the compounds used individually in Tables IX, $X$ and XII.

The interaction of NAA and PIBA caused a reduction of both the incidence of pigments in the cultured segments and total pigment formed in the kypocotyl below the values obtained for either NAA or TIBA alone (Table XVI). NAA used alone was found to cause the lower segments to form the greatest amounts of pigment and this pattern was not disturbed by TIBA (Table XVII), even though the total pigment was reduced by about $50 \%$ (rigure 9).

IIgures 10 and 11 show that the hypocotyl segments receiving both NAA and TIBA responded to give values for rooting and hair formation that are intermediate between those for each compound used alone. The formation of roots and hairs was greatly enhanced by NAA, while TIBA was found to completely eliminate hair formation and severely limit root formation.

Hypocotyl segments receiving the $\mathrm{Bz}$ and $\mathrm{Rb}$ medium were severely lnhibited in all activities (Tables XVI and XVII). OnIy segment 1 formed any pigment or roots. This combination of chemical factors appeared to be Gethal to many of the segments, particularly those in the lower half of the lupocotyl.

With respect to pigment formation the interaction of $\mathrm{Bz}$ and NAA gave results similar to the interaction of NAA and PIBA (Table XVI). The ambination of $\mathrm{Bz}$ and NAA reduced both the incidence of and the total 
T A B I E $\mathrm{X} \vee \mathrm{I}$

INTERACTIONS OF SELECTED CHBMICAT FACTORS ON THE INCIDENCE OF ANTHOCYANIN AND HAIRS, AND ROOT FORMATION IN CULTURED HYPOCOTYI SEGMENTS

Test

Molar

Segment

Compounds Concent

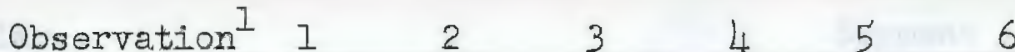

$6 \quad 7$

8

\begin{tabular}{|c|c|c|c|c|c|c|c|c|c|c|c|c|}
\hline NAA & $5.0 \times 10^{-6}$ & Pigment & 28 & 29 & 35 & 33 & 29 & 27 & 29 & 28 & 32 & 33 \\
\hline TIBA & $5.0 \times 10^{-5}$ & Roots & 60 & 103 & 103 & 87 & 66 & 68 & 65 & 49 & 43 & 58 \\
\hline
\end{tabular}

\begin{tabular}{|c|c|c|c|c|c|c|c|c|c|c|c|c|}
\hline \multirow[t]{2}{*}{$\mathrm{Rb}$} & $1.0 \times 10^{-4}$ & Roots & 4 & 0 & 0 & 0 & 0 & 0 & 0 & 0 & 0 & 0 \\
\hline & & Hairs & 0 & 0 & 0 & 0 & 0 & 0 & 0 & 0 & 0 & 0 \\
\hline
\end{tabular}

\begin{tabular}{|c|c|c|c|c|c|c|c|c|c|c|c|c|}
\hline $\mathrm{Bz}$ & $3.0 \times 10^{-3}$ & Pigment & 4 & 5 & 3 & 4 & 1 & 10 & 21 & 18 & 23 & 26 \\
\hline NAA & $5.0 \times 10^{-6}$ & Roots & 36 & 10 & 0 & 7 & 10 & 23 & 20 & 24 & 19 & 57 \\
\hline
\end{tabular}

1. Same as Table VII. 
T A B I E X $\mathrm{X} I I$

INTHRACTIONS OF SELECTED CHEMICAI FACTORS ON TOTAL ANTHOCIANIN ${ }^{1}$ FORMED IN CULTURED HYPOCOTYL SEGMENIS

Test

Molar

Segment

Gompounds

Concentration

$13 \quad 3 \quad 56$

6

8

$9 \quad 10$

NAA

$\begin{array}{lllllllllll}5.0 \times 10^{-6} & 1.5^{1} & 2.00 & 1.94 & 2.03 & 2.55 & 3.26 & 3.24 & 3.18 & 3.16 & 2.73\end{array}$

TIBA

$5.0 \times 10^{-5}$

$\mathrm{Bz}$

$3.0+30-3$

$\mathrm{Rb}$

$3.0 \times 10^{-3} \quad 0.23$

$1.0 \times 10^{-4}$

$\begin{array}{llllllllllllll}\mathrm{Bz} & 3 . & \times 10^{-3} & 0 & 0.4 & .67 & .25 & 0 & 0.4 & 0.1 & 0.28 & 0.26 & 0.31 \\ \mathrm{NAA} & 5.0 \times 10^{-6} & & & & & & & & & & & & \end{array}$

1. Same as Table VIII. 


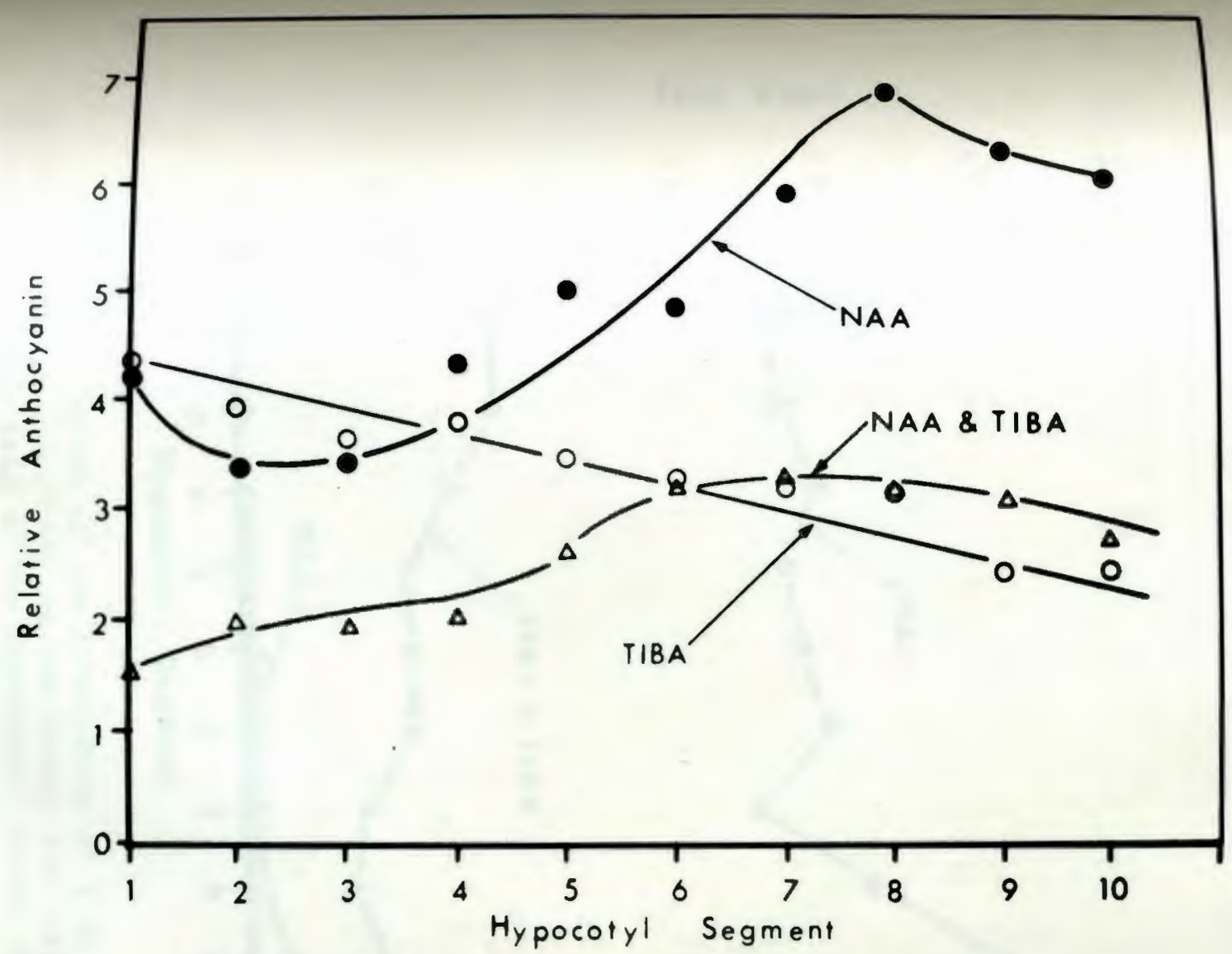

Figure 9. Fffect of the Interaction of TIBA (5.0 X $10^{-5} \mathrm{M}$ ) and NAA ( $5.0 \times 10^{-6} \mathrm{M}$ ) on the Quantitative Distribution of Anthocyanin

Pigments along the Axis of the Hypocotyl. Relative anthocyanin $=0 . D$. $\mathrm{X} 10^{3}$ pigmented segment. 


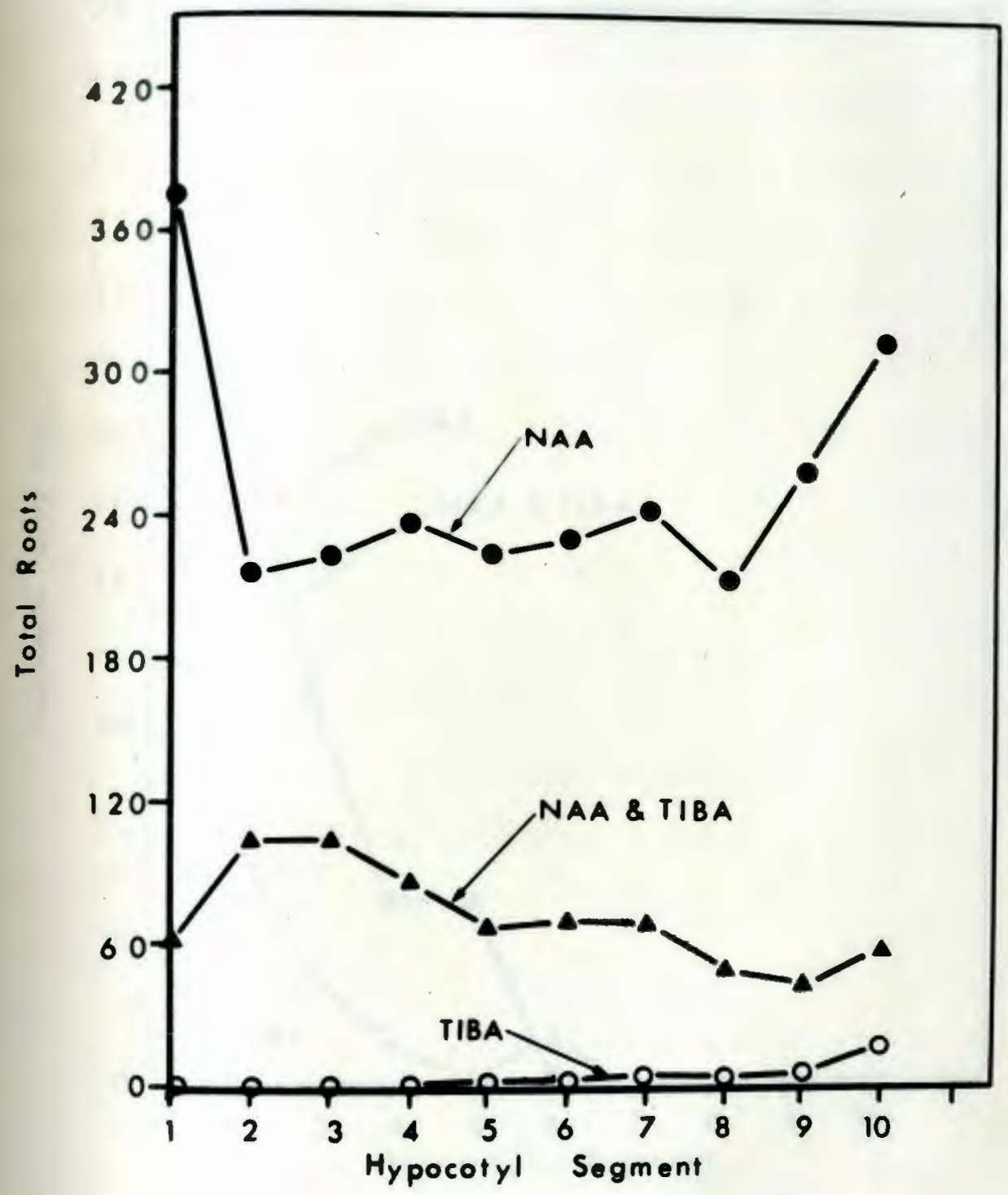

Figure 10. Eiffect of the Interaction of TIBA (5.0X $10-5 \mathrm{M})$ and NAA $(5.0 \mathrm{X} 10-6 \mathrm{M})$ on the Number and Distribution of Roots Along the Axis of the Hypocotyl. Total roots = total number of roots/35 replicate segments. 


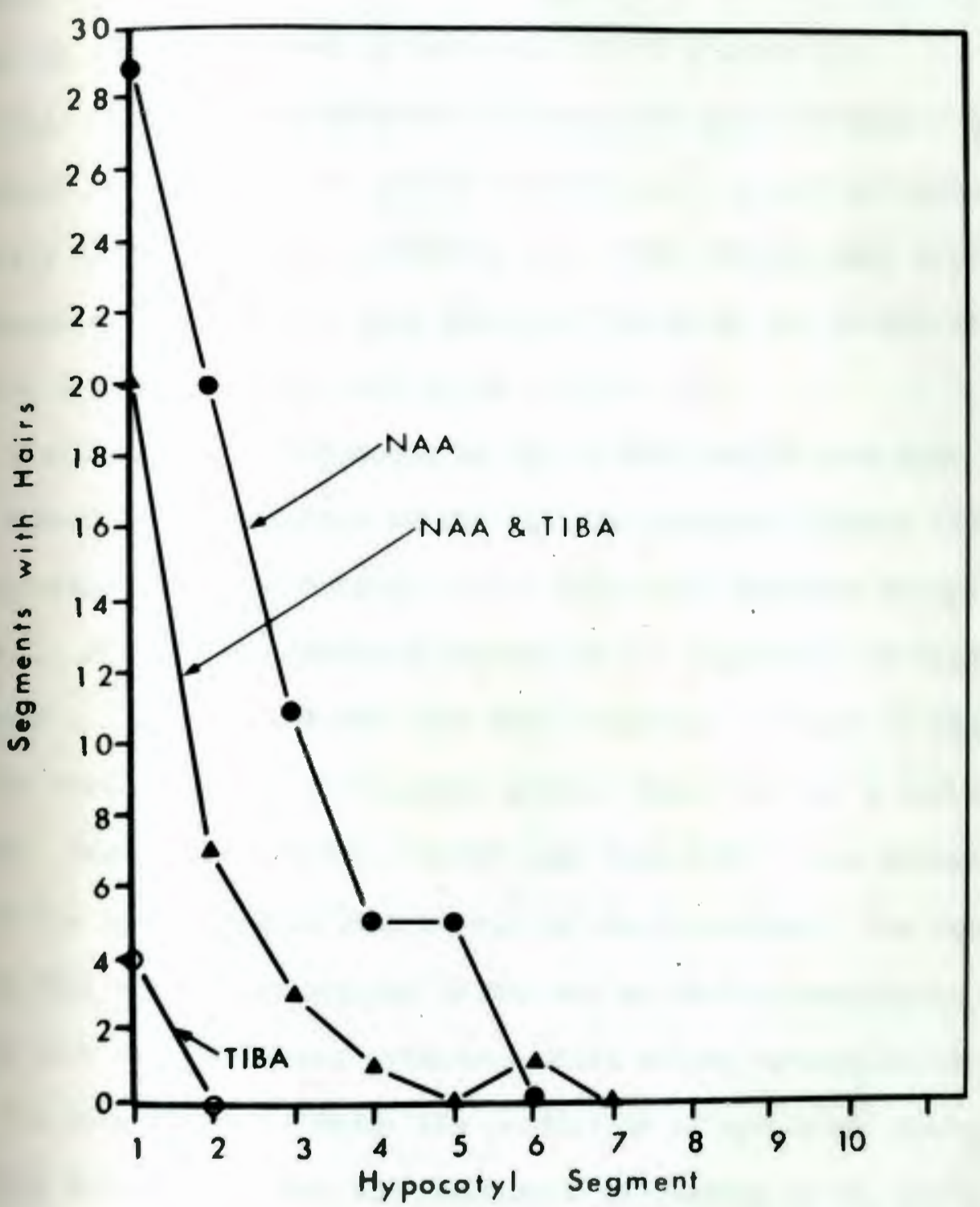

Figure 11. Effect of the Interaction of TIBA (5.0 X $\left.10^{-5 \mathrm{M}}\right)$ and NAA (5.0 X 10-6M) on the Formation of EpidermaI Hairs Along the Axis of the Hypocotyl. Segments with hairs = number of segments $/ 35$ replicates . 
hocyanin formed per segment well below the values for each compound used alone (igures 12 and 13). The suppression of the incidence of Igment was very pronounced in segments 1 to 5 (Figure 12).

Hair formation was effected in nearly an opposite manner to thoeyanin formation by the Bz-NAA interaction. Bz per se almost Tpletely eliminated hair production while NAA favored hair production. Hore segments were found to have epidermal hairs on the Bz-NAA medium than with either substance used alone (Figure 14).

Similar opposing responses on the Bz-NAA medium were also noted in the number of roots formed on the various segments (Figure 15). Bz alone severely inhibited rooting in all hypocotyl segments except Eegment 1. NAA per se, enhanced rooting in all segments, partiarlarly in segment 1 . When $\mathrm{Bz}$ and NAA were used together, rooting in segments 2 to 10 was about equal to or slightly greater than that in a medium with $\mathrm{Bz}$ lone. Segment 1, however, formed less than $40 \%$ of the number of Ioots on the $\mathrm{Bz}-\mathrm{NAA}$ medium than it did on the Bz-medium. The results Indicate that a compound such as $\mathrm{Bz}$ may act as an NAA antagonist for a response such as anthocyanin synthesis while acting synorgistically with NAs in the same tissue to cause the production of epidermal hairs. Tathermore NAA counteracted the inhibition of rooting by Bz in the more Mighly Afferentiated tissue of segments 6 to 10, while NAA acted mergistically with $\mathrm{Bz}$ to cause a minimum number of roots formed in agment 1 which contains the pseudomeristem.

\section{Responses of the Hypocotyl to Light}

I. Action spectra for anthocyanin synthesis - Preliminary experiments with fluorescent light characterize the response of anthocyanin 


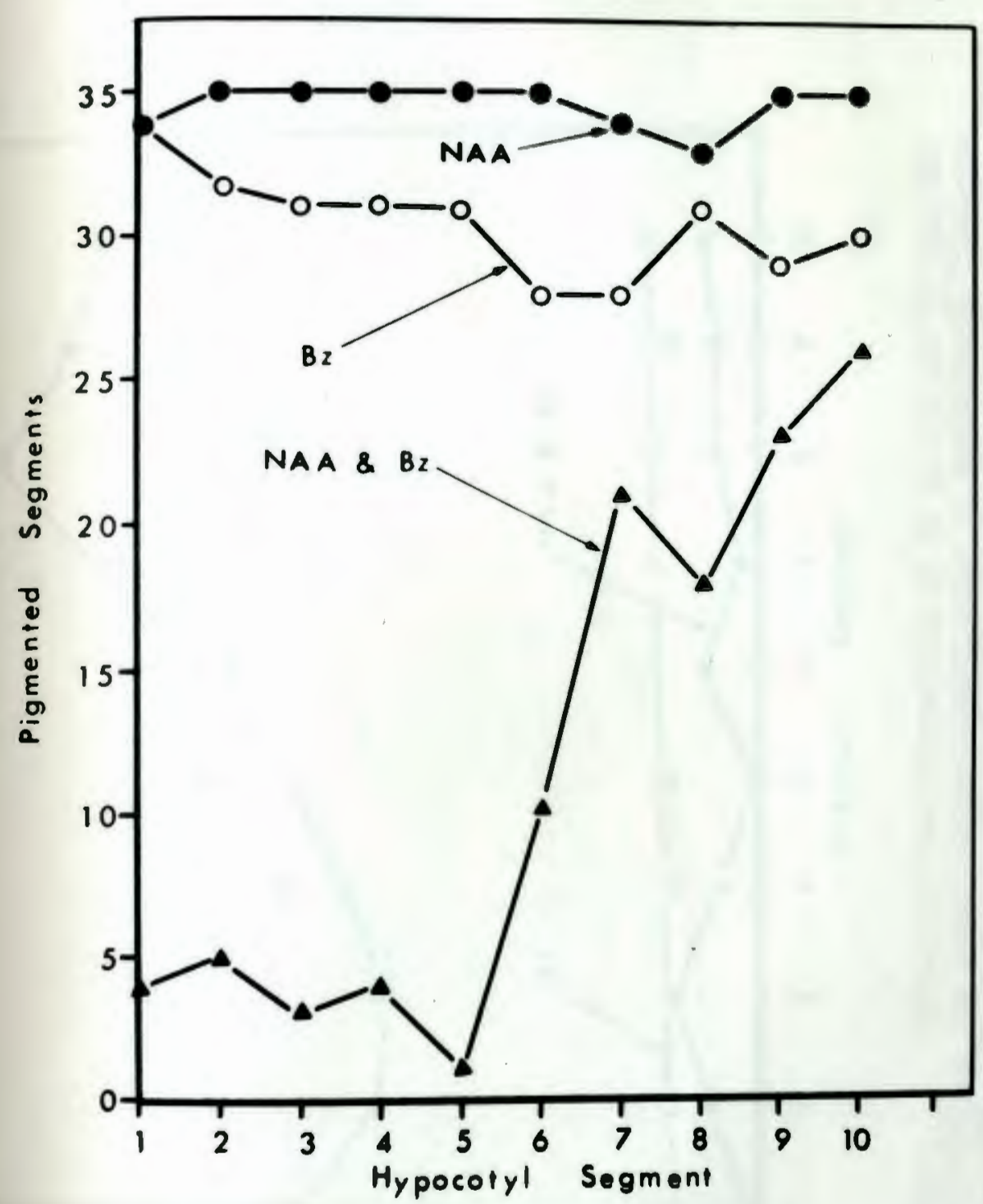

Figure 12. Effect of the Interaction of $\mathrm{Bz}$ (3.0 X 10-3M) and NAA ( $5.0 \mathrm{X} 10-6 \mathrm{M}$ ) on the Formation of Anthoyanin Pigments Along the Axis of the Hypocotyl.

pigmented segments = number of visibly pigmented segments/ 35 replicates. 


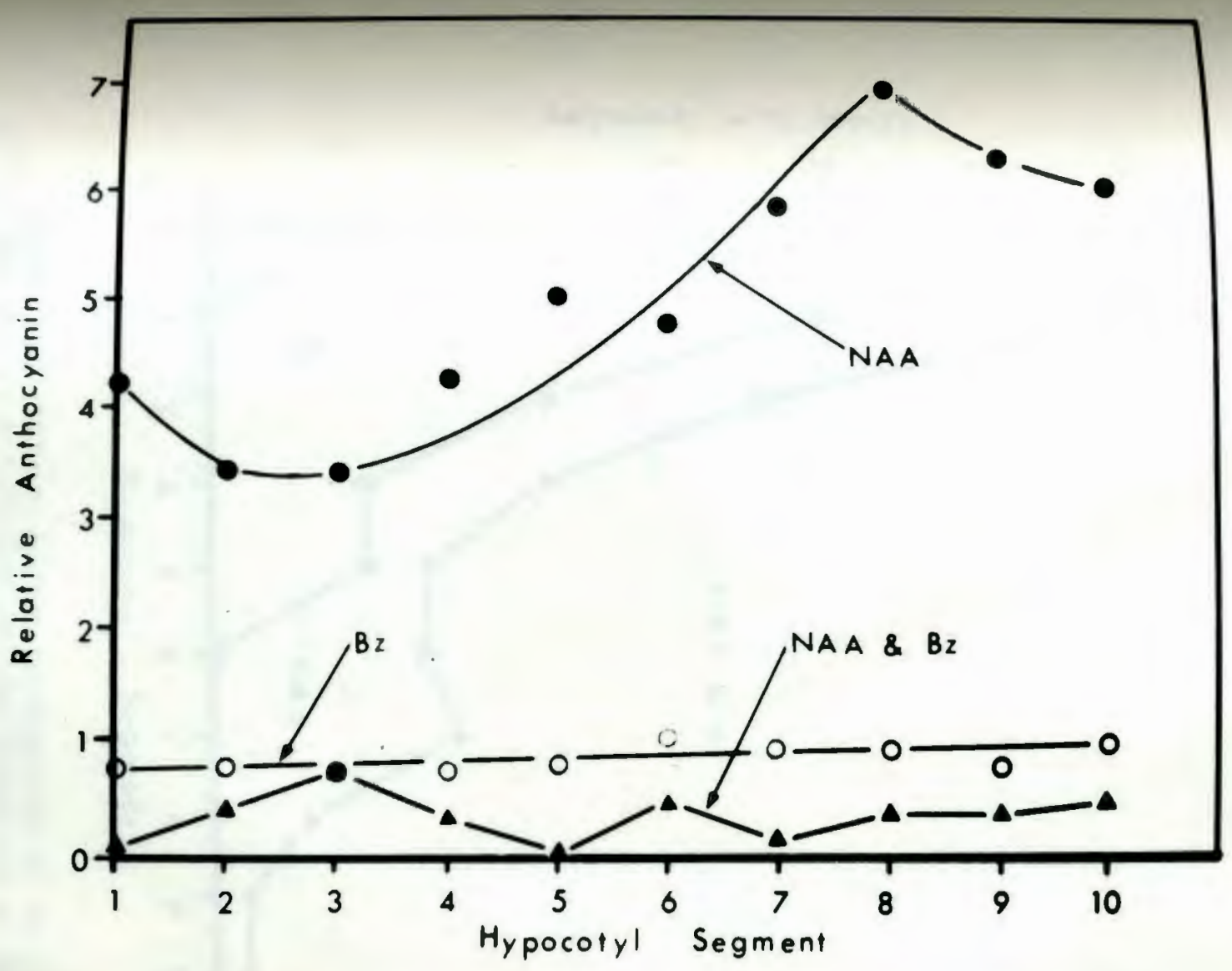

Figure 13. Effect of the Interaction of $\mathrm{Bz}\left(3.0 \times 10^{-3} \mathrm{M}\right)$ and NAA (5.0 X $\left.10^{-6 M}\right)$ on the Quantitative Distribution of Anthocyanin Pigments Along the Axis of the Hypocotyl. Relative anthocyanin =0.D. X 103/ pigmented segment. 


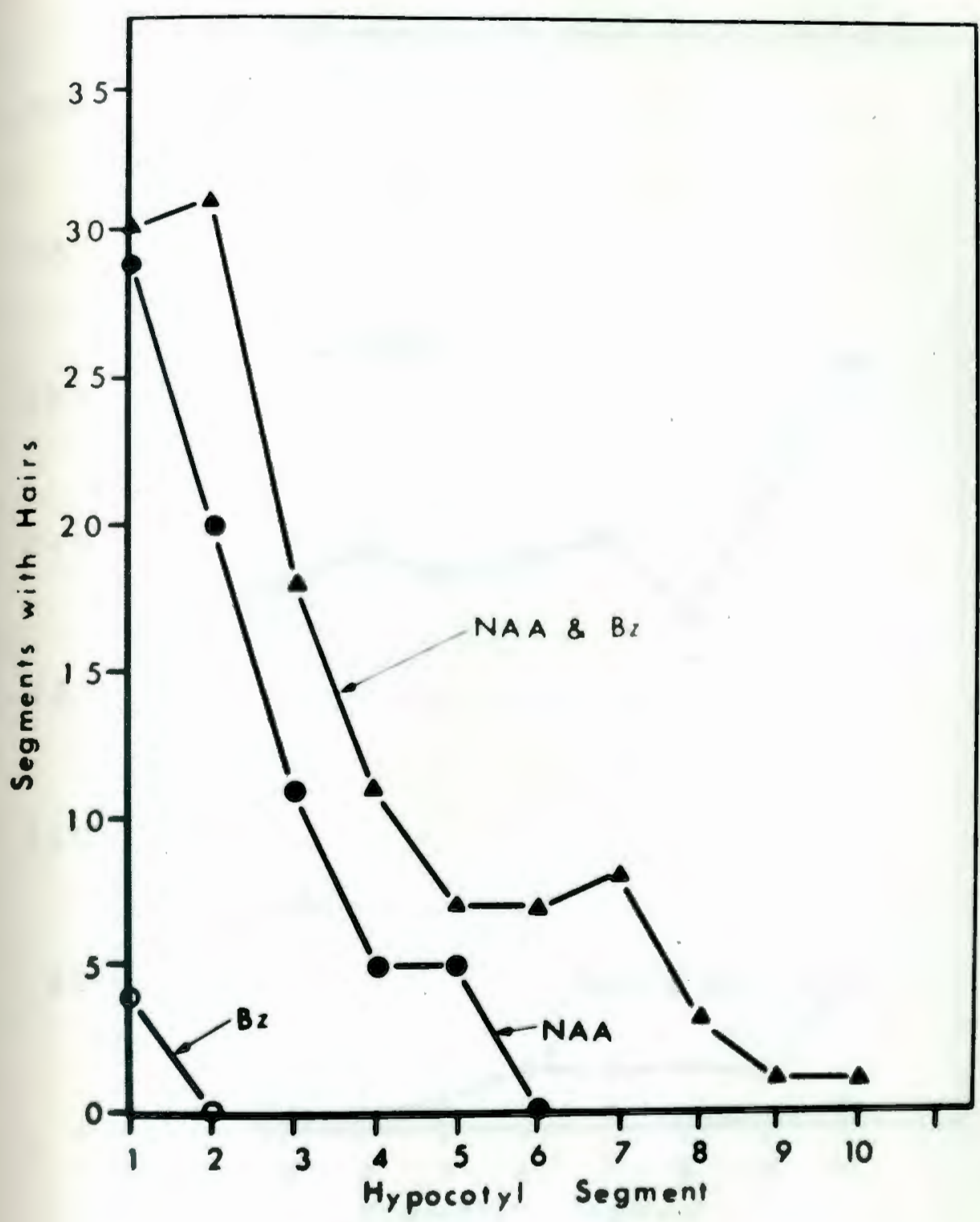

Tigure 14. Effect of the Interaction of $\mathrm{Bz}$ (3.0 X $\left.10^{-3} \mathrm{M}\right)$ and NAA (5.0 X 10-6M) on the Formation of Epidermal Hairs Along the Axis of the Hypocotyl. Segments with hairs $=$ number of segments $/ 35$ replicates. 


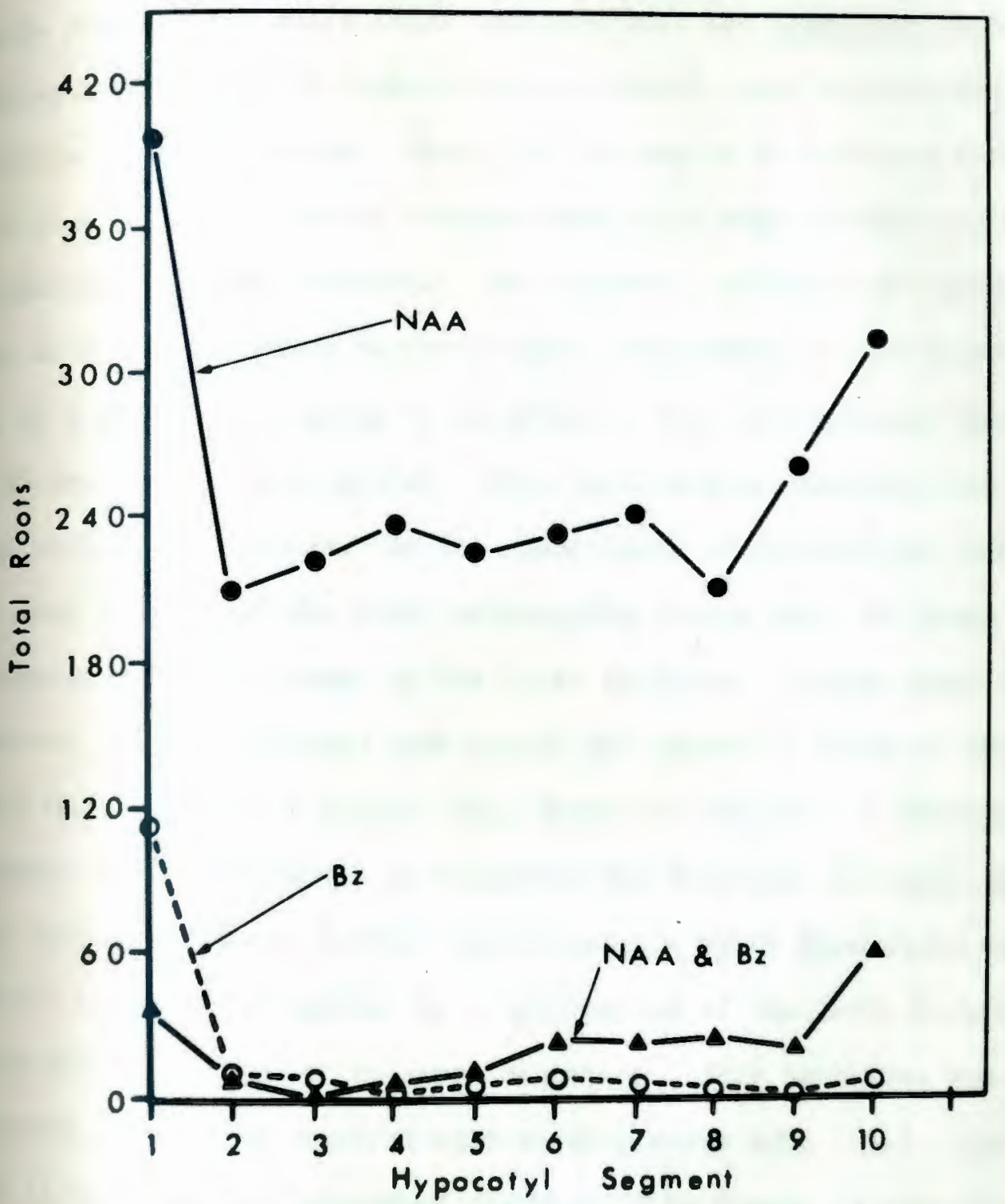

Figure 15. Effect of the Interaction of $\mathrm{Bz}\left(3.0 \times 10^{-3}\right.$ $\mathrm{M})$ and NAA ( $5.0 \mathrm{X} 10^{-6} \mathrm{M}$ ) on the Formation of Roots Along the Axis of the Hypocotyl. Total roots = total number of roots/ 35 replicate segments. 
Fisthesis in the hypocotyl and deternined the irradiation program to be used with the spectrograph and interference filter light sources. The Iogults presented in Table XVIII indicate that the Impatiens hypocotyl wquires long periods of irradiation in order to form appreciable quantities of anthocyanins. Thus, the process of anthocyanin formation required a certain period of time and was not always directly related to the quantity of light delivered. For instance, 48 hours of continuous Iight at 400 foot candles caused no more anthocyanin to be formed than only 16 hours of light given in alternating four hour periods throughout the 48 hour experimental period. This relationship, however, was not found at 200 foot candles. At the lower level of irradiation (200 ft. ed.) less than 25\% of the total anthocyanin formed under 48 hours of ntinuous light was formed in the first 24 hours. Pigment was formed, therefore, at a much higher rate during the second 24 hours of irradiation at 200 foot candles. A similar "lag phase" in the rate of anthocyanin Nnthesis was also observed by Siegelman and Hendricks in apple skin (132). These results suggested further experiments in which hypocotyls were "preinduced" to form anthocyanins by a long period of low level irradiation (about $200 \mathrm{ft} . \mathrm{cd}$. ) prior to experimentation. This technique was successful for action spectrum studies with apple skin (132). Results given in Table XIX and expressed graphically in Figure 16 show the relative amounts of anthocyanins formed after 4 and 8 hours of high Intensity irradiation ( 1500 foot candles) with and without a 16 hour preinduction period at 250 foot candles. It was found that a 2 to 3 -fold Inerease in anthocyanin synthesis occurred when the hypocotyls received 16 hour preinduction period. 
T A B I E X V I I I

RETATIVE AMOUNTS ${ }^{I}$ OF ANTHOCYANIN FORMED UNDER DIFFERENT FLUORESCENT IIGHT REGIMES

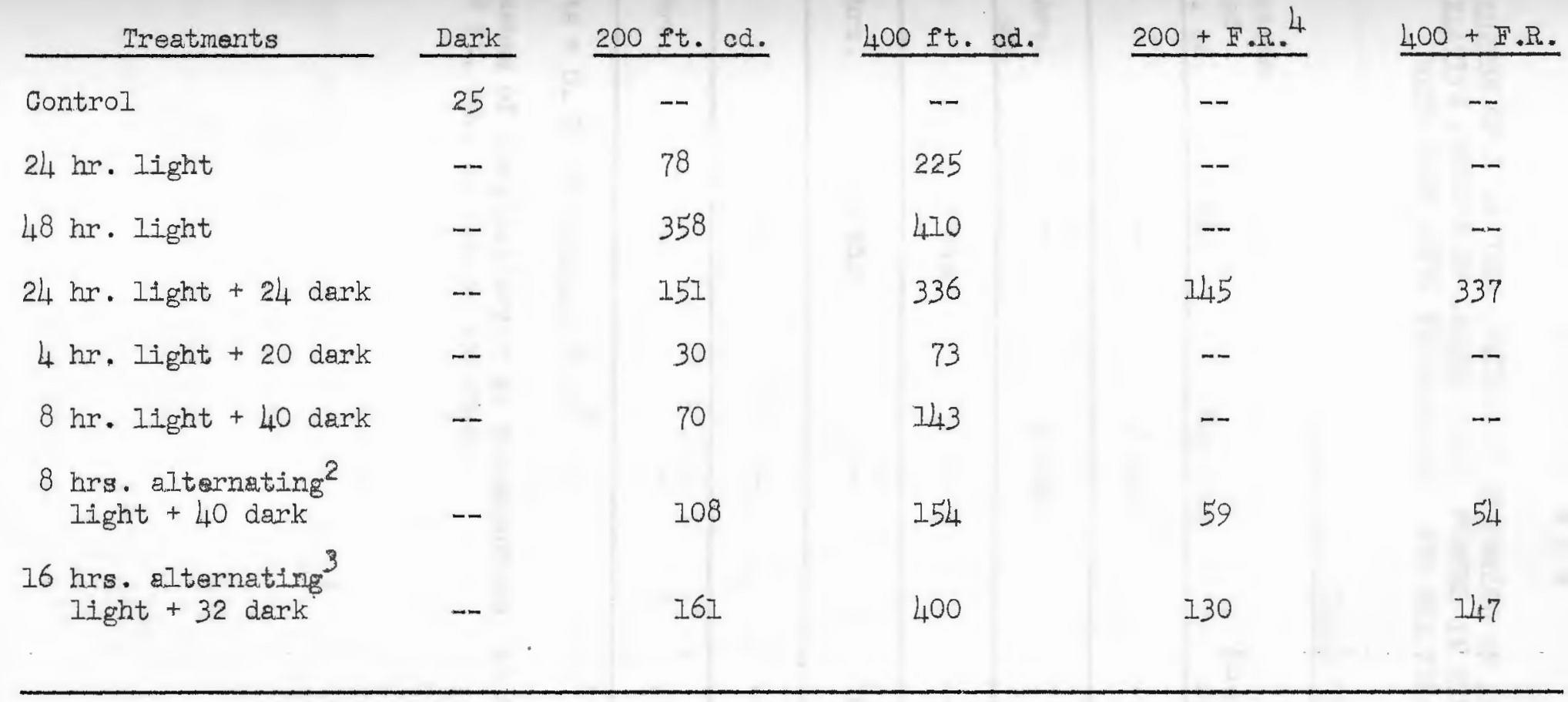

1. Units $=0 . D$. of extract $\times 10^{3}$

2. $4(1 \mathrm{hr}$. Iight $+1 \mathrm{hr}$. dark $)+16 \mathrm{hrs}$. dark for two $24 \mathrm{hr}$. periods.

3. $4 \mathrm{hr}$. light $-4 \mathrm{hr}$. dark $-4 \mathrm{hr}$. Ifght $+12 \mathrm{hr}$. dark for two $24 \mathrm{hr}$. periods.

4. Far-red given for 5 min. at end of light period(s). 
TA B I E XI X

QNILUNCE OF A 16 HOUR PREINDUGTION PERIOD OF IRRADIATION ON THE REIATIVE AMOUNTS OF ANTHOCYANINI FORMED IN HYPOGOTYLS TREATED WITH HIGH LEVEL FLITORESCENT, RED AND FAR-RED IIIGHT

\begin{tabular}{|c|c|c|c|c|c|}
\hline & & \multicolumn{4}{|c|}{ Iight Ireatments ${ }^{2}$} \\
\hline $\begin{array}{l}\text { Induction } \\
\text { period } \\
250 \mathrm{ft.} \text { cd. }\end{array}$ & Red & Far-red & $\begin{array}{c}\text { Hour: } \\
0\end{array}$ & $\begin{array}{r}\text { uoreso } \\
t \quad 1500 \\
4 \\
\end{array}$ & $\begin{array}{l}\text { ent } \\
8 \mathrm{~cd} . \\
\end{array}$ \\
\hline -- & -- & $5 \mathrm{~min}$ & - & 21 & 61 \\
\hline $16 \mathrm{hrs}$. & - & $5 \mathrm{~min}$ & 77 & 75 & 139 \\
\hline-- & $5 \mathrm{~min}$ & -- & -- & 43 & 87 \\
\hline $16 \mathrm{hrs}$. & $5 \min$ & -- & 76 & 158 & 254 \\
\hline- & -- & $-\ldots$ & - & 64 & 89 \\
\hline $16 \mathrm{hrs}$. & -- & - & 78 & 145 & 205 \\
\hline
\end{tabular}

1. Units $=0 . D$. of extract $x 10^{3}$

2. Iequence of irradiations $=a$ ) preinduction, b) fluorescent at 1500 ft. cd., c) red or far-red. 


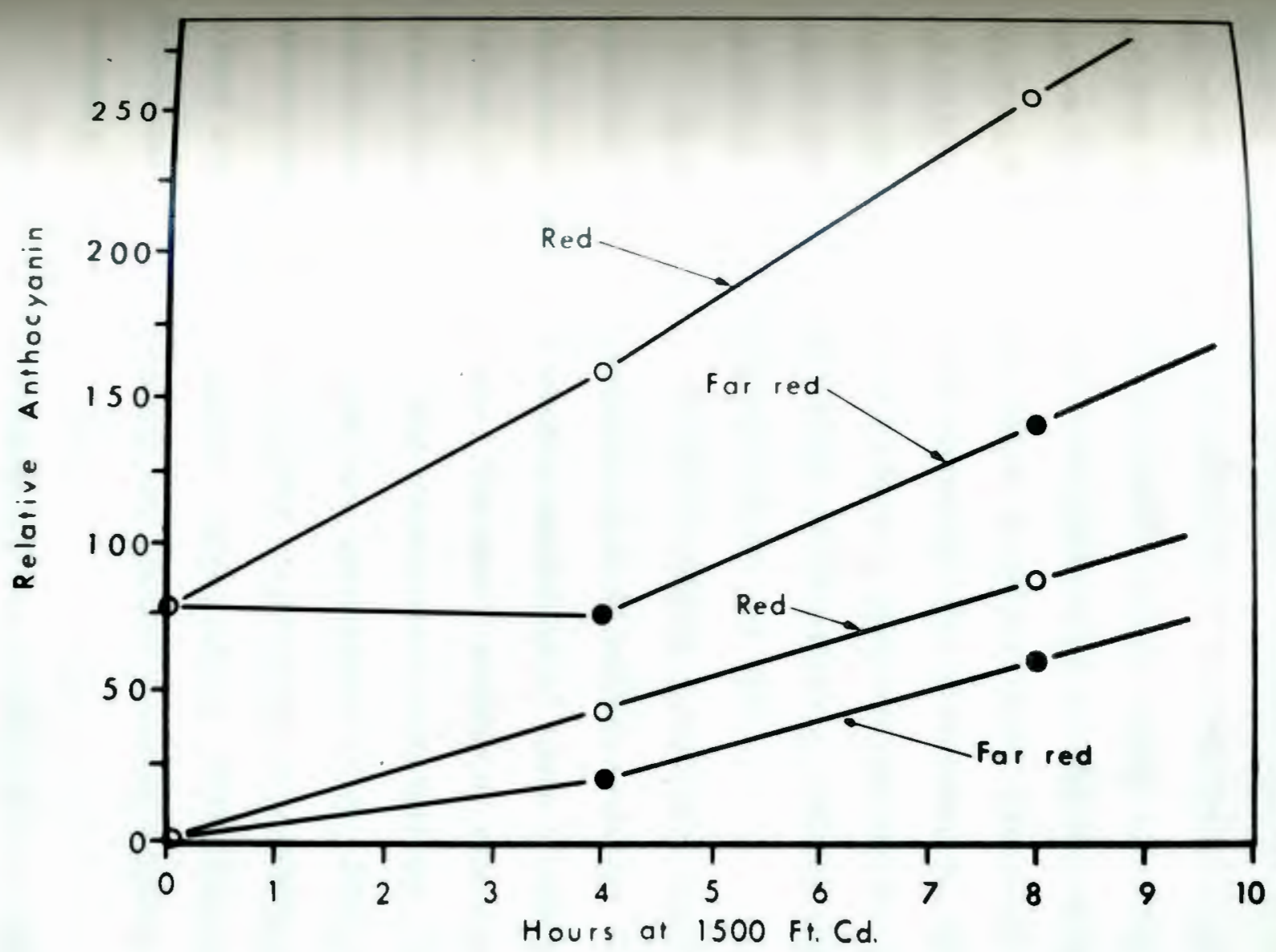

Figure 16. The Influence of a 16 Hour Preinduction Period of Irradiation at $250 \mathrm{ft}$. cd. on the Relative Amounts of Anthocyanin Formed in Hypocotyls Treated with High Level Fluorescent, Red and Far-Red Iight. Upper curves received 16 hour preinduction period. Red or far red designation $=5 \mathrm{~min}$. at end of period at $1500 \mathrm{ft}$. cd. 
The results presented in Tables XVIII and XIX and Figure 16 Indicate that anthocyanin synthesis is under phytochrome control in the Impatiens hypocotyl. Far-red light inhibited pigment formation when applied at the end of the light period in most cases. Table XVIII also Indicates that far-red was ineffective following a 24 hour light period, whereas it strongly inhibited anthocyanin formation when applied following a 1 or 4 hour period of irradiation. Figure 16 shows that farred trhibition was nearly complete after four hours of high intensity luorescent llght with or without a preinduction periad. Part of this eantrol was lost after 8 hours of irradiation, but the amount of Lhibition was quantitatively about the same.

On the basis of the above results (Table XIX) hypocotyls were Irradiated with the spectrograph or interference filter light sources after recelving a preinduction period of 16 hours of white fluorescent light at 250 foot candles. Only small amounts of anthocyanins were formed after exposure to the monochromatic irradiation. The 16 hour preinduction control formed some anthocyanin (Table XIX), but it was more variable than dark controls used in previous experiments which were Whout a preinduction period. Since it was difficult to measure small Afferences between controls and treated hypocotyls, this approach was abandoned.

Purther experimentation indicated that a 6 hour irradiation followed by an 18 hour dark periad yielded measurable amounts of anthooranins. The very consistent values obtained from dark controls made porsible the measurement of small amounts of anthocyanins formed under Low Ingt intensities. In further experiments on the effect of light 
intensity and the determination of the high energy action spectrum for anthocyanin synthesis a 6 hour period of irradiation followed by an 18 hour dark period was adopted.

A study of the relationship between total light energy applied and the whount of anthocyanin formed was undertaken. This information was necessary so that different colored light at different intensities may be mpared as to their effect upon anthocyanin synthesis. The average values for anthocyanin synthesis are given in Table XX. These values plotted as a function of the log of light intensity, pertain to the 6 hour period of irradiation. Anthocyanin content was measured and all values reported are minus the dark control. Anthocyanin formed was a linear function of light intensity up to 25 foot candles (H1gure 17). The dashed curve in Flgure 17 represents a hypothetical linear response of thocyanin formation to light intensity. A distinct plateau in the response appeared between 25 and 100 foot candles, and linearity was again attained between 200 and 800 foot candles with a gradual decrease above 800 foot candles. Figures 18 and 19 illustrate the two segments of the response curve up to 100 foot candles and from 200 to 2000 foot andles respectively on an arithmetic scale of light intensity. The data ndicate that there are two levels of "light saturation" in anthoganin gynthesis in the hypocotyl of Impatiens.

Table XXI shows the relative amounts of anthocyanin formed at various wave lengths of light between 396 and $500 \mathrm{mu}$. The first experiment was andeted using the spectrograph which yielded very low levels of athocyanins in the hypocotyls. The values from the spectrograph determination in Table XXI are adjusted to equal energy across the 
THE EFFECT OF DIFFERENT LEVELS OF FLUORESCENT LIGHT ${ }^{1}$ ON THE REUATIVE AMOUNTS OF ANTHOCYANIN2 FORMED IN IMPATIENS HYPOCOTYLS

\begin{tabular}{|c|c|c|c|c|c|}
\hline $\begin{array}{l}\text { Light intensity } \\
\text { ft. ad. }\end{array}$ & & $\begin{array}{c}\text { Repl } \\
\text { term } \\
2 \\
\end{array}$ & $\begin{array}{c}\text { cat } \\
\text { nat } \\
3\end{array}$ & $\begin{array}{r}4 \\
4 \\
\end{array}$ & Average \\
\hline 5 & 3 & 5 & 3 & 0 & 2.75 \\
\hline 10 & 5 & 5 & 8 & - & 6.00 \\
\hline 25 & 8 & 19 & - & - & 13.50 \\
\hline 50 & 19 & 12 & 16 & 10 & 14.25 \\
\hline 100 & 21 & 16 & - & - & 18.50 \\
\hline 200 & 32 & 43 & - & - & 37.50 \\
\hline 400 & 60 & 64 & - & - & 62.00 \\
\hline 800 & 103 & 120 & - & - & 111.50 \\
\hline 1600 & 147. & 149 & - & - & 148.00 \\
\hline 2000 & 154 & 149 & - & - & 151.50 \\
\hline
\end{tabular}

1. Anocyanin measured after $6 \mathrm{hrs}$. light $+18 \mathrm{hrs}$. dark

2. Units $=0$. D. of extract $\times 10^{3}$. 


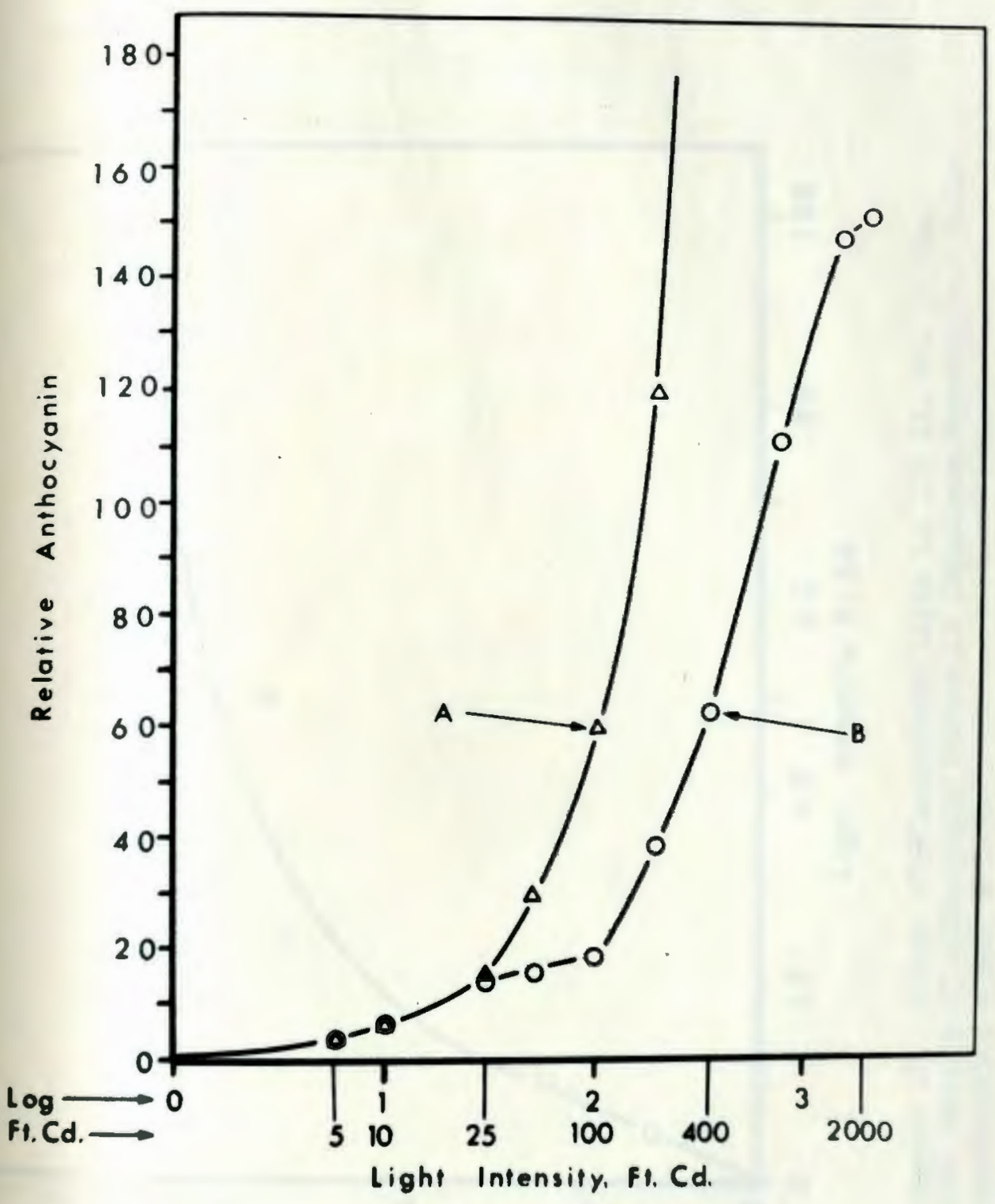

Figure 17. Fffect of Different Levels of Fluorescent Light on the Relative Amounts of Anthocyanin Formed in Impatiens Hypocotyls. Relative anthocyanin $=0 . D . X 10^{3}$. Curve $A(\Delta)=$ hypothetical linear response, $B(0)=$ observed response. 


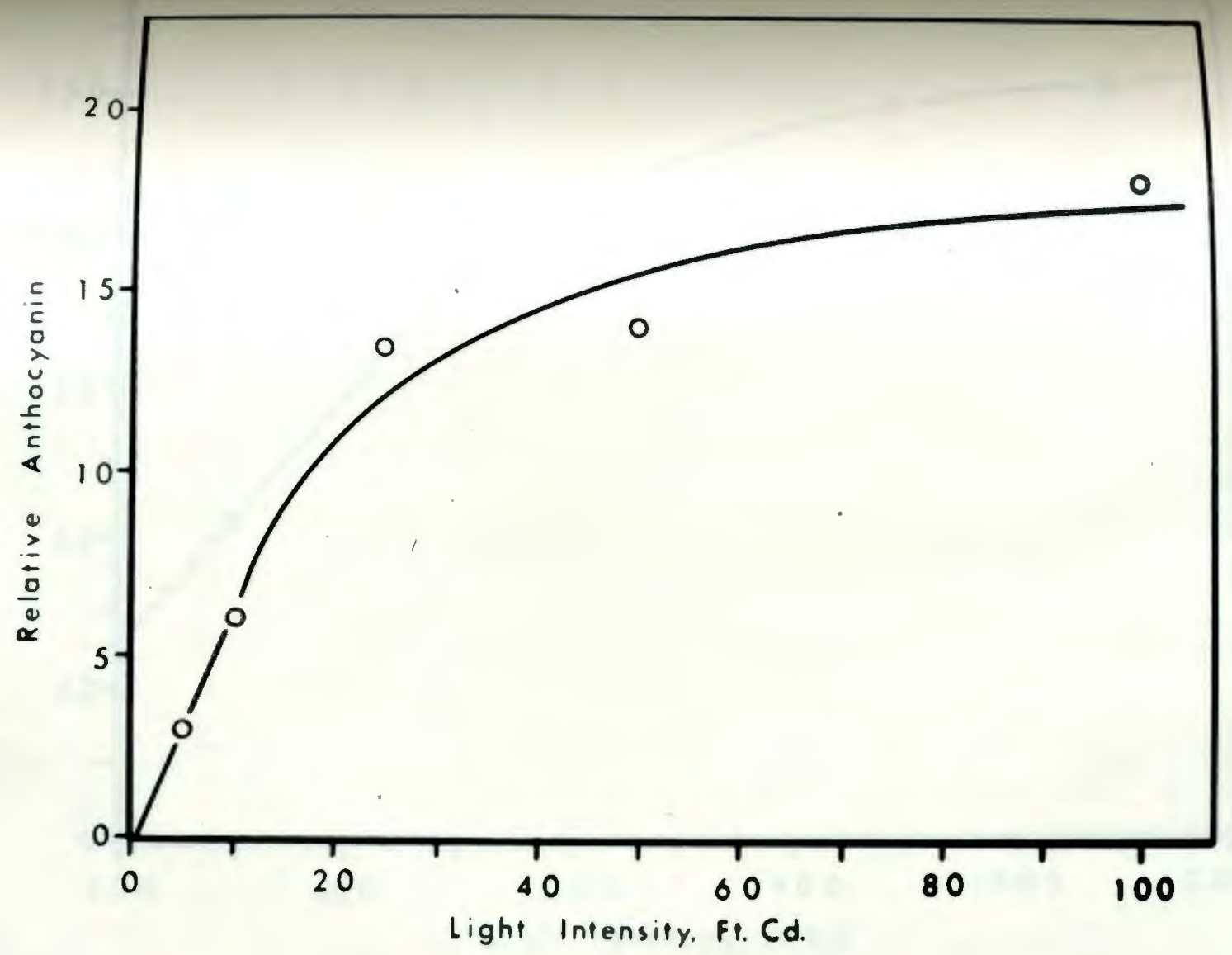

Figure 18. Effect of Fluorescent Light to $100 \mathrm{ft} . \mathrm{cd}$. on the Relative Amounts of Anthocyanin Formed in Impatiens Hypocotyls. Relative anthocyanin $=0 . D . X 10^{3}$. 


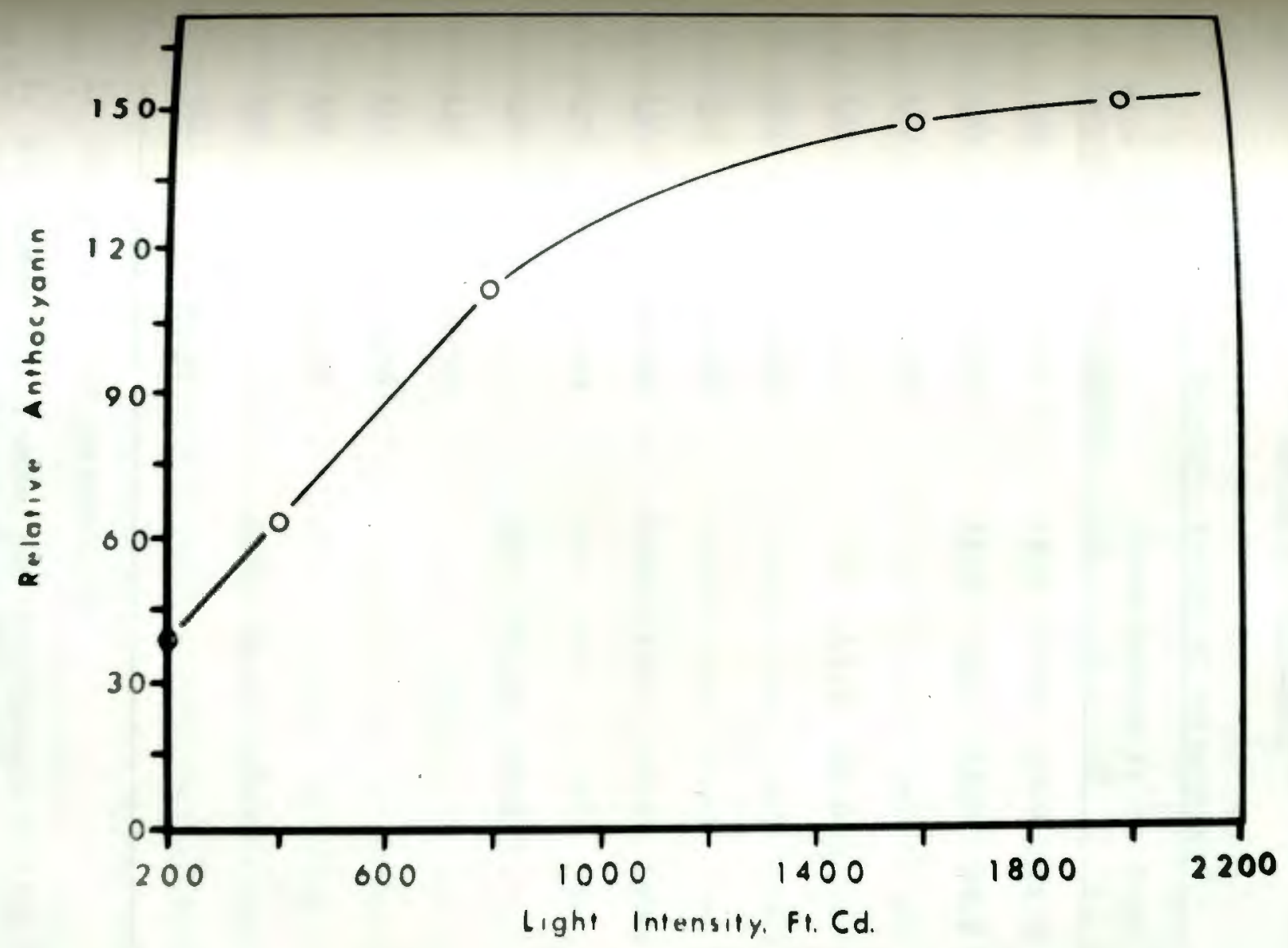

Figure 19. Effect of Fluorescent Light Above $200 \mathrm{ft} . \mathrm{cd}$. on the Relative Amounts of Anthocyanine Formed in Impatiens Hypocotyls. Relative anthocyanin $=0.0 \times 10^{3}$. 
THE ACTION SPECTRTM FOR ANTHOCYANIN SYNTHESIS IN THE HYPOCOTYL OF IMPATIENS BALSAMINA I.

\begin{tabular}{|c|c|c|c|c|c|c|c|}
\hline \multirow[b]{2}{*}{ 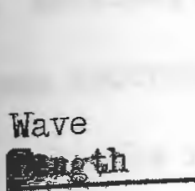 } & \multicolumn{6}{|c|}{ Relative Amount of Anthocyanin ${ }^{1}$} & \multirow[b]{2}{*}{ Aterage } \\
\hline & Spectrograph & $\begin{array}{l}\text { Int } \\
I\end{array}$ & $\begin{array}{c}\text { ference } \\
2 \\
\end{array}$ & $\begin{array}{c}\text { Filte } \\
3\end{array}$ & $\begin{array}{c}\text { Reps. } \\
4\end{array}$ & 5 & \\
\hline 500 & 4.00 & 18.0 & 20.0 & 17.0 & 24.0 & 16.0 & 17.0 \\
\hline 483 & 16.30 & 33.0 & 24.0 & 45.0 & 30.0 & - & 33.0 \\
\hline 472 & 10.08 & - & - & - & - & - & \\
\hline 463 & - & - & 47.0 & 45.0 & - & - & 46.0 \\
\hline$\$ 61$ & 10.45 & - & - & - & - & - & \\
\hline 451 & 18.00 & - & - & - & - & - & \\
\hline 441 & 20.90 & 45.0 & 45.0 & 34.0 & 49.0 & - & 43.25 \\
\hline 431 & 19.60 & - & - & - & - & - & \\
\hline 425 & - & 65.0 & 65.0 & 70.0 & - & - & 66.67 \\
\hline 423 & 27.00 & - & - & - & - & - & \\
\hline 471 & 28.16 & - & - & - & - & - & \\
\hline 406 & 20.16 & - & - & - & - & - & \\
\hline 405 & - & 55.0 & 44.0 & 48.0 & - & - & 49.0 \\
\hline 396 & 21.32 & - & - & - & - & - & \\
\hline
\end{tabular}

1. Units $=0$. D. of extract $\times 10^{3}$

2. Replicates 1 to 4 under the interference filters $=1.30 \mathrm{mw} / \mathrm{cm}^{2}$; replicate $5=2.00 \mathrm{~mm} / \mathrm{cm}^{2}$ at $500 \mathrm{~mm}$

Ropligates 1 and $2=2.72 \mathrm{mx} / \mathrm{cm}^{2}$; replicate 3 and $4=2.00$ mow $/ \mathrm{cm}^{2}$ at $483 \mathrm{~mm}$

Replicates $I$ and $2=3.30 \mathrm{mw} / \mathrm{cm}^{2}$; replicate $3=1.60 \mathrm{mw} / \mathrm{cm}^{2}$ at $463 \mathrm{~mm}$. 
Thetrum, assuming that reciprocity holds. This was done on the basis of grvious findings that the rate of anthocyanin synthesis bears a linear ationship to light energy at relatively low levals (Figure 17, Table Ix). Wryelengths below $450 \mathrm{mu}$ were shown to be most effective with a aximum occurring in the region of 411 to $423 \mathrm{mu}$. It was believed that more reliable results could be obtained with the carbon-arc, interference filter light source. Thus, by using interference filters, a several fold increase in anthocyanin production was obtained over that from the atrograph irradiations. This increase is due to the considerably Hgher radiant energies obtained from the interference filters. The 500, 483 and $463 \mathrm{mu}$ irradiations were made at two energy levels in each case (Fable XXI). No increase in anthocyanin production could be detected in asponse to increasing amounts of energy. For this reason the results are imply recorded as the raw data minus the dark control and are not djusted to an equal energy basis. The assumption must be made that these wadians fall in that portion of the enorgy-response curve (Figure 17) where reiproaity does not hold. Results from the interference filter Wations verified and clarified the results obtained with the Whograph showing that the greatest amounts of anthocyanin were formed at welengths shorter than $463 \mathrm{mu}$ with a prominent maximum at $425 \mathrm{mu}$. this peak is considered valid because of (I) the agreement with the matrograph results and (2) the energy delivered at 425 mu was Hoximately equal to, or less than, the energies delivered at other relengths. Thus any adjustment to place the values on an equal energy asis would tend to increase the magnitude of the $425 \mathrm{mu}$ maximum. Both 
notion spectra for anthocyanin synthesis in the Impatiens hypocotyl as Mermined with the spectrograph and with the interference filters are wented graphically in Figure 20.

The low energy action spectrum for photoreversible control of Dhocyanin formation was investigated using the spectrograph as a twoprism Instrument. Greater wave length dispersion was achieved allowing more precise measurements in the red end of the visible spectroum. Mrfficient data were not obtained to construct an action spectrum. However, the results in Table XXII clearly show photoreversibility of Gocyanin synthesis. Action maxima for red and for far-red light were found to lie in the regions of 630 to $680 \mathrm{mu}$ and 700 to $780 \mathrm{mu}$ respective1y. Since the action spectrum for phytochrome has been shown to have wction maxima at $660 \mathrm{mu}$ for the red and $730 \mathrm{mu}$ for the far-red for the Thoreversible control of numerous light-dependent plant responses Maluding anthocyanin synthesis (23, 2/4, 131 to 133), the above data fadicate that anthocyanin synthesis in Impatiens is under the photoreverwible control of phytochrome.

2. Action spectra for elongation of the hypocotyl and straightening of the rypocotyl arch - Table XXIII and Figure 21 present the rate of growth in length of Impatiens balsamina seedlings grown in complete arkness from the time of planting until harvested. All experiments on elongation and straightening of the hypocotyl arch were conducted on pallings that were between 100 and 160 hours old. During this period the maximum rate of elongation occurred.

Results of preliminary experiments indicated that a program of 2 tours light, 4 hours of darkness, 2 hours of light, and 16 hours of 


\section{TA B L E X X I I}

ACTION MAXIMA FOR THE PHOTOREVERSIBILITY OF ANTHOGYANIN SYNTHESIS IN THE HYPOCOTYL OF IMPATIENS BAISAMINA I.

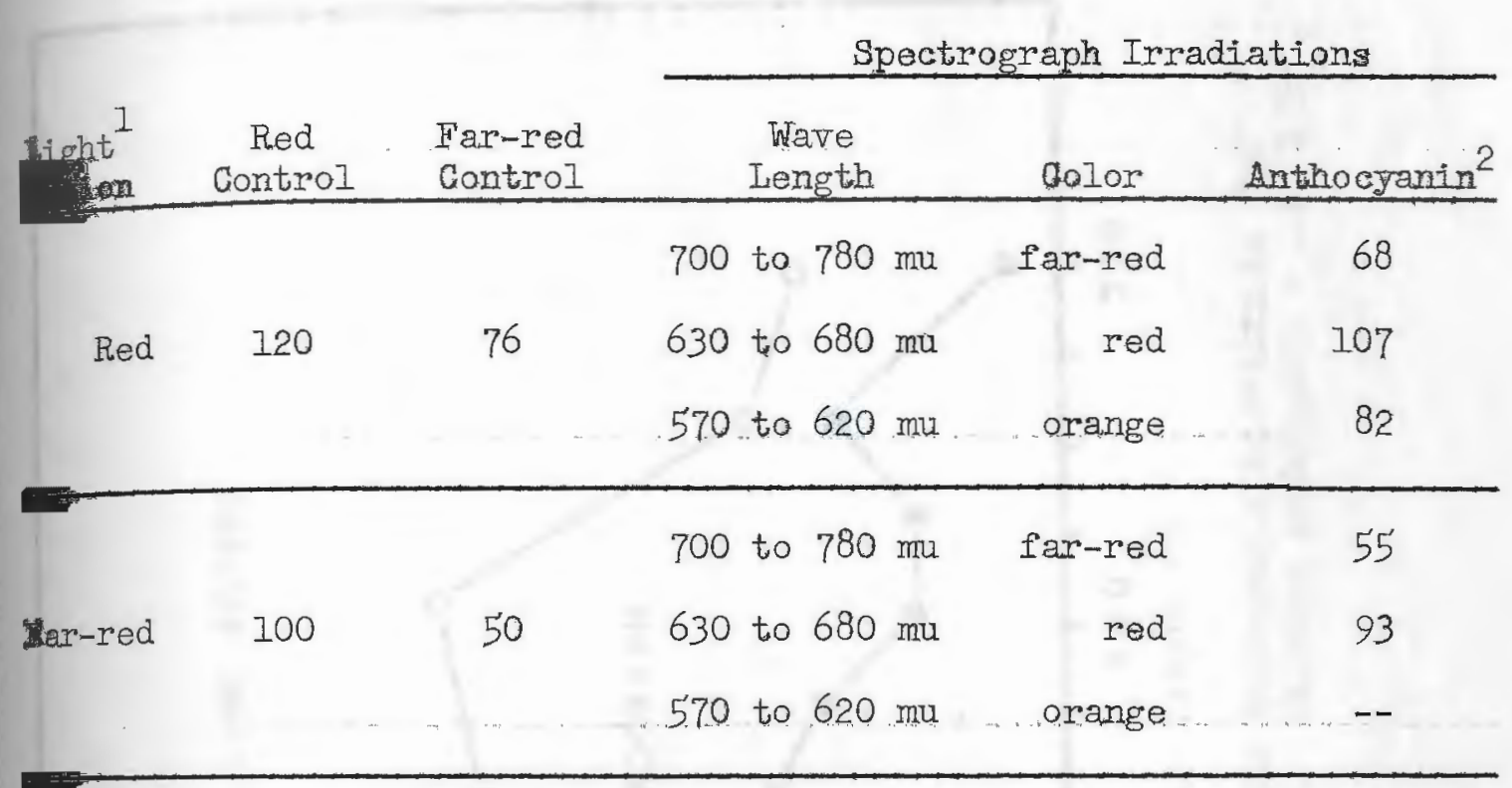

1. Red action: Controls received $5 \mathrm{~min}$. of red or far-red after $4 \mathrm{hrs}$. of $2000 \mathrm{ft}$. cd. fluorescent light. Spectrograph Irradiations $=4$ hrs. fluorescent + 5 min. far-red + spectrograph - Far-red action: Controls are same as above. Spectrograph Irradiations $=4$ hrs. Iuorescent + 5 min. red + spectrograph.

2. Units $=0 . \mathrm{D} \cdot \mathrm{X} 10^{3}$

\section{TA B L E X XIII}

RATE OF ETONGATION OF IMPATIENS SEFDIINGS GROWN IN DARKNESS AT $25^{\circ} \mathrm{C}$

\begin{tabular}{|c|c|c|c|c|c|}
\hline \multirow{2}{*}{ Hours } & \multicolumn{3}{|c|}{ Replichte Averages } & m. & \multirow[b]{2}{*}{ Overazl Average } \\
\hline & 1 & 2 & 3 & 4 & \\
\hline 40 & 0 & 0 & 0 & 0 & 0 \\
\hline 72 & 2.0 & 2.0 & 2.0 & 1.6 & 1.90 \\
\hline 96 & 10.0 & 11.2 & 9.4 & 10.4 & 10.25 \\
\hline 148 & 55.4 & 47.8 & 53.2 & 53.8 & $52.55^{\prime}$ \\
\hline 196 & 83.6 & 76.6 & 87.2 & 86.2 & 83.40 \\
\hline
\end{tabular}

wach value represents the average of 5 seedlings. 


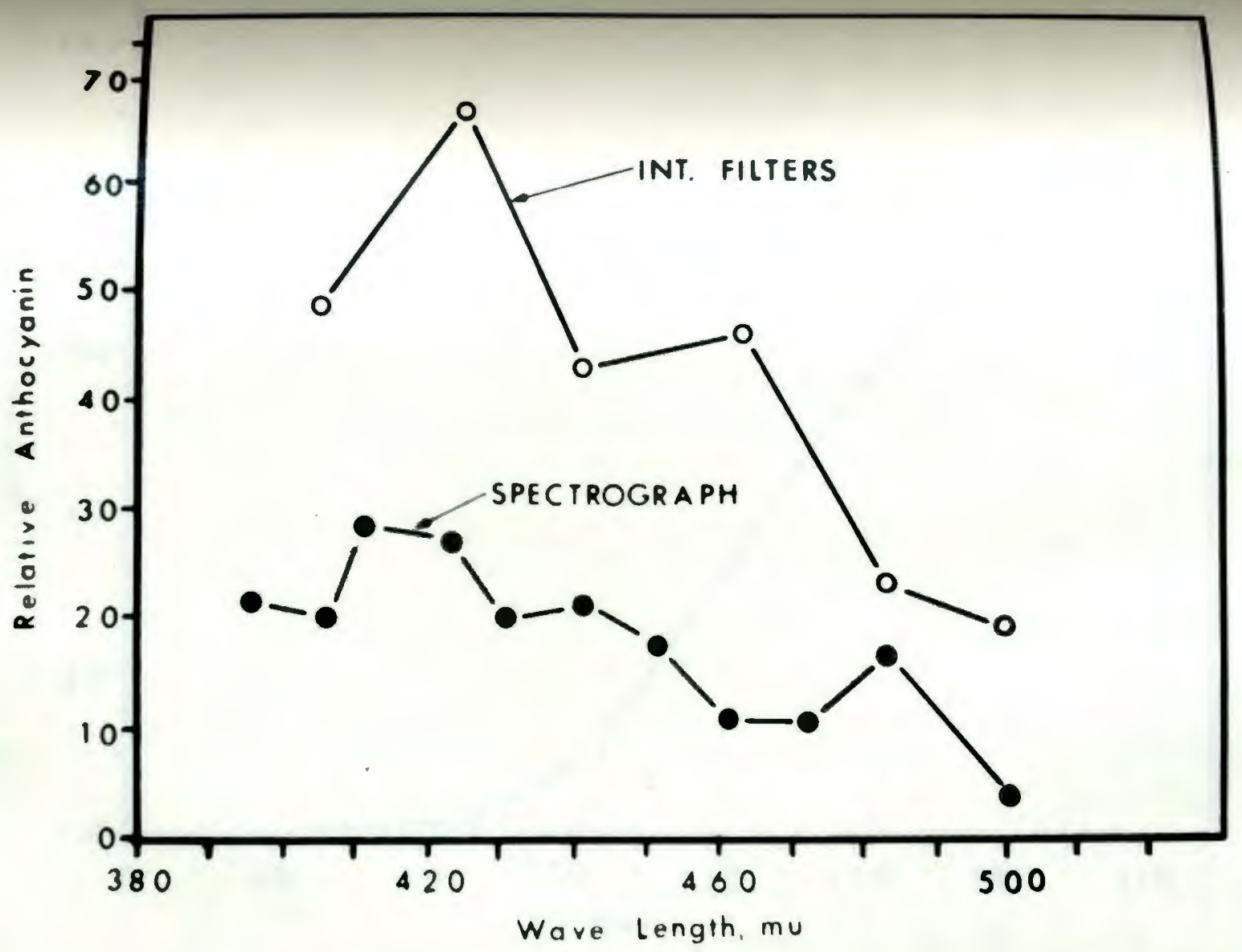

Figure 20. Action Spectrum for Anthocyanin Synthesis in the Hypocotyl of Impatiens Balsamina L. Relative anthocyanin = 0.D.X $10^{3}$. 


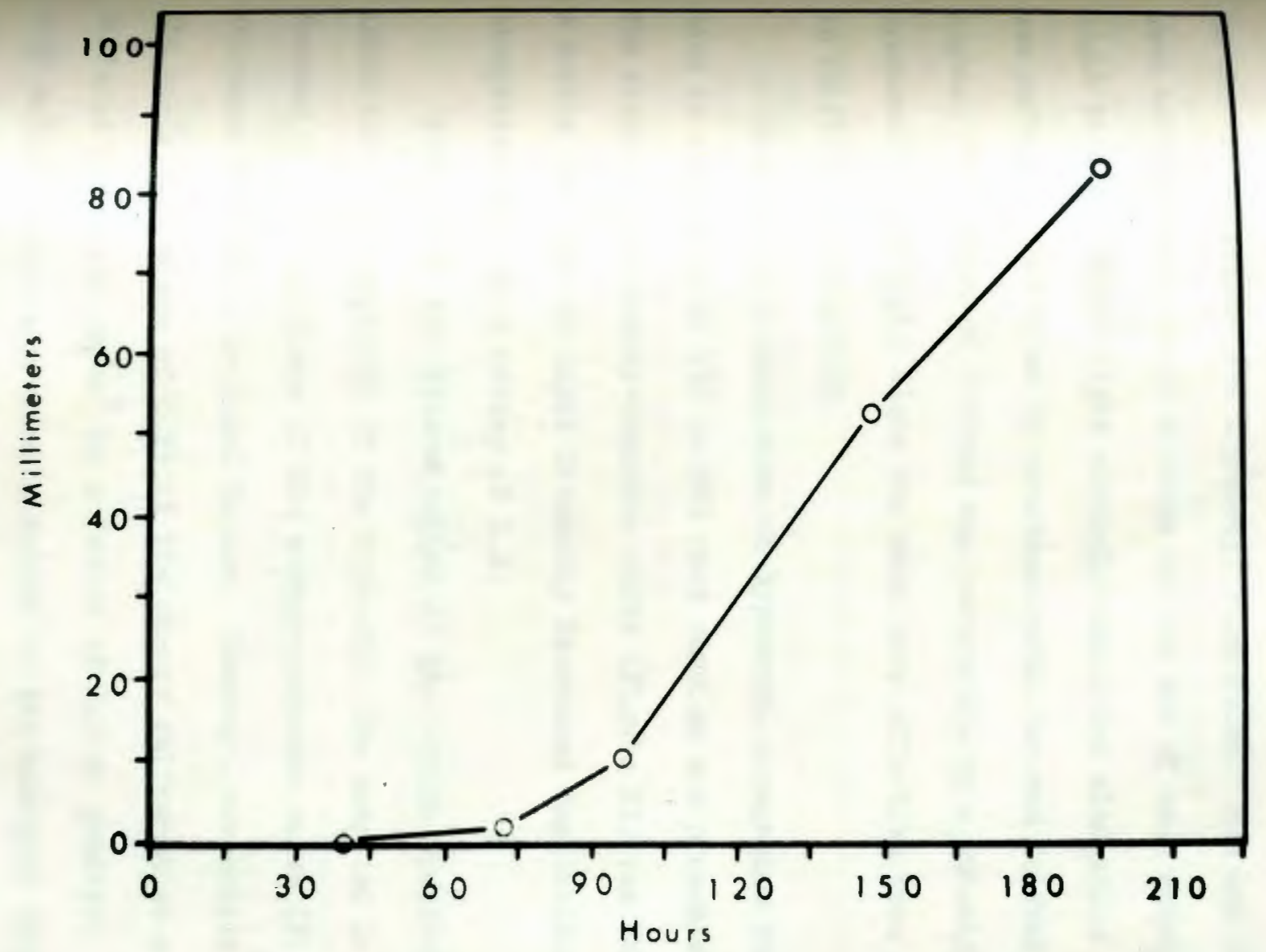

Figure 21. The Rate of Elongation of Impatiens Seedlings Grown in Darkness at $25^{\circ} \mathrm{C}$. 
arkness, repeated twice, was convenient and substantially inhibited hypoootyl longation. Table XXIV presents the results of treatments with red, far-red, and 400 foot candles of cool-white fluorescent light given on the above program for hypocotyl elongation. Red and far-red light were administered for 10 minutes at the end of each scheduled 2 hour Hight period. White light strongly inhibited elongation and its action was ofially inhibited by treatment with far-red following the white Light. The effect of far-red was reversible by a subsequent red light areatment. Red light alone was much more effective than far-red light in inhibiting elongation.

Data for the inhibition of hypocotyl elongation for light intensities in the range of 180 to 660 foot candles are presented in Table XXV. The slope of the energy-response curve (Figure 22) was found to be 0.29 . A 2-fold increase in light intensity increased the inhibition of langation only by a factor of 1.2 .

Results of the determination of the action spectrum for the Inhibition of elongation of the hypocotyl are compiled in Table XXVI. Racause of the low slope of the energy-response curve (Figure 22), energy delivered was not a critical factor. However, corrections were made on the basis of a slope of 0.29 if the energy delivered at any wavelength differed from $0.50 \mathrm{ntw} / \mathrm{cm}^{2}$ by a factor of 1.5 or greater. The value of $0.50 \mathrm{mw} / \mathrm{cm}^{2}$ is the approximate median of the energies delivered by the mious filters. Correction factors for energies differing from the median by less than a factor of 1.5 would be small so as to make only insignificant changes of the data. Data for the action spectrum of the inhibition of hypocotyl elongation are plotted in Figure 23. The curve 


\section{TA B I E X XIV}

EFFEGT OF RED, FAR-RED, AND FLUORESGERT LICGIT ${ }^{1}$

ON HYPOCOTYI BLONGATION?

preatment

dark 118 hrs.

dark 160 hrs.

Ilght alone

anr-red

red

light $+\mathrm{F}-\mathrm{R}$

Iight $+\mathrm{F}-\mathrm{R}+\mathrm{R}$
Irength mm

9.7

42.7

22.2

37.2

29.6

28.5

20.3
Flongation nm

0

33.0

12.5

27.5

19.9

18.8

10.6
Inhibition $\mathrm{mm}$

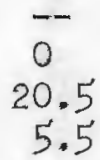

13.1

14.2

22.4

1. Iilght program $=2(2 \mathrm{hr}$. Iight $+4 \mathrm{hr}$. dark $+2 \mathrm{hr}$. 1ight $+16 \mathrm{hr}$. dark) Red or far-red given for $5 \mathrm{~min}$. at the end of each light period.

2. Values $=$ average of 30 seedlings

\section{A B I E $\mathrm{X} X \mathrm{X}$}

EFFECT OF DIFFERENT LEVELS OF FLUORESGENT IIGHT ON THE INHIBITION OF ELONGATION OF THE IMPATTENS HYPOCOTYL

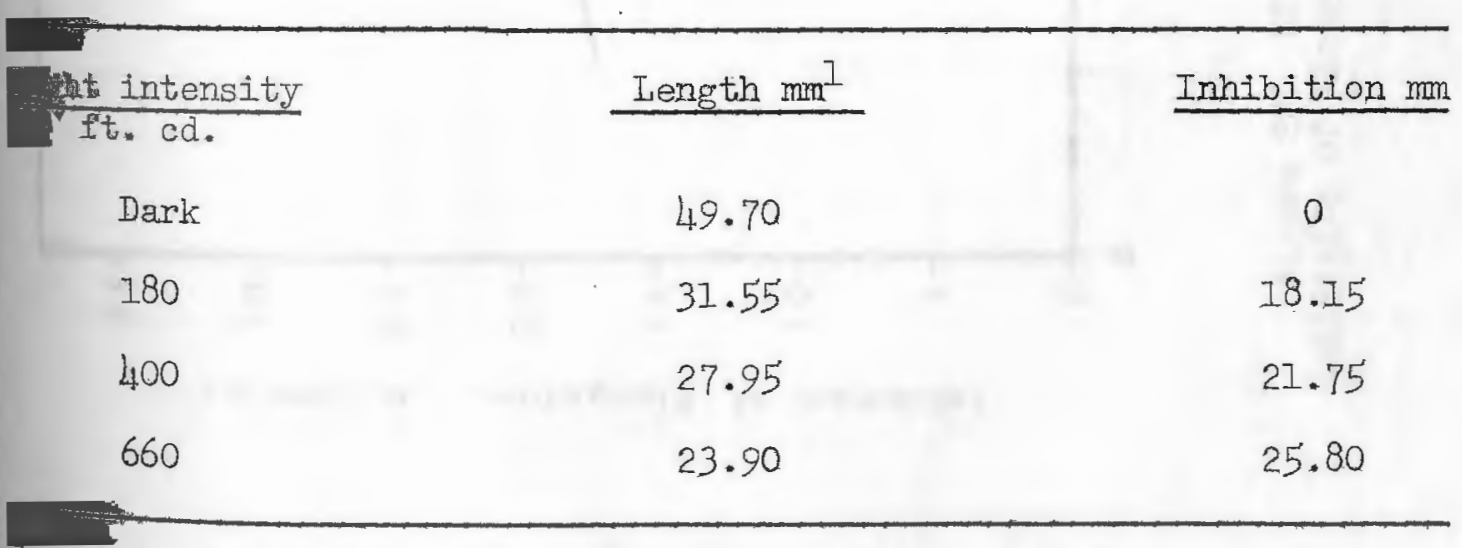

1. Fach value represents the average of 60 seedlings. 


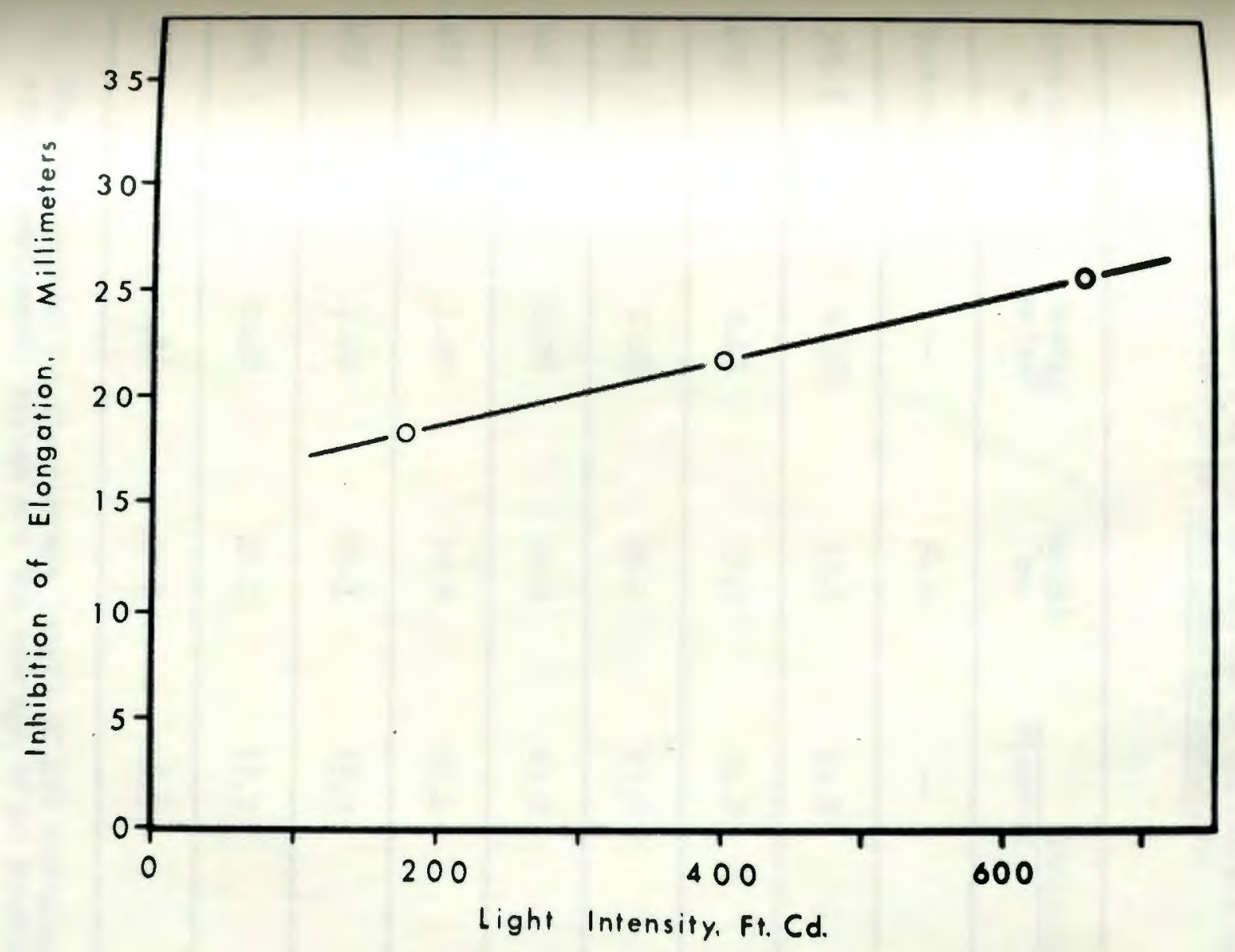

Figure 22. Effect of Different Levels of Fluorescent Light on the Inhibition of Elongation of the Impatiens Hypocotyl. 
ACTION SPEGTRUM FOR THE INHIBITION OF ETONGATION OF THE HYPOCOTYL OF IMPATIENS BALSAMINA L.

\begin{tabular}{|c|c|c|c|c|c|}
\hline \multirow{2}{*}{$\underset{\mathrm{mu}}{\text { Irradiation }}$} & \multirow{2}{*}{$\begin{array}{l}\text { Finergy } \\
\mathrm{mw} / \mathrm{cm}^{2}\end{array}$} & \multirow{2}{*}{$\begin{array}{l}\text { Length } \\
\text { mm }\end{array}$} & \multicolumn{3}{|c|}{ Inhibition $\mathrm{mm}$} \\
\hline & & & Observed & & orrected ${ }^{2}$ \\
\hline Gontrol ${ }^{1}$ & -- & 54.0 & -- & & - \\
\hline 386.5 & 0.18 & 39.5 & 14.5 & & 18.9 \\
\hline 405 & 0.49 & 29.8 & 24.2 & & 24.2 \\
\hline 425 & 0.56 & 26.2 & 27.8 & & 27.8 \\
\hline 441 & 0.78 & 30.2 & 23.8 & & 22.0 \\
\hline 463 & 1.00 & 30.6 & 23.4 & & 19.5 \\
\hline $483^{\circ}$ & 1.00 & 28.3 & 25.7 & & 21.4 \\
\hline 500 & 0.48 & 36.3 & 17.7 & & 17.7 \\
\hline 517 & 0.86 & 37.7 & 16.3 & & $I_{4} .8$ \\
\hline
\end{tabular}

1. The dark control is the average length of 150 seedlings. All other experimental values are the average of 40 seedlings.

2. See text, page 112 . 


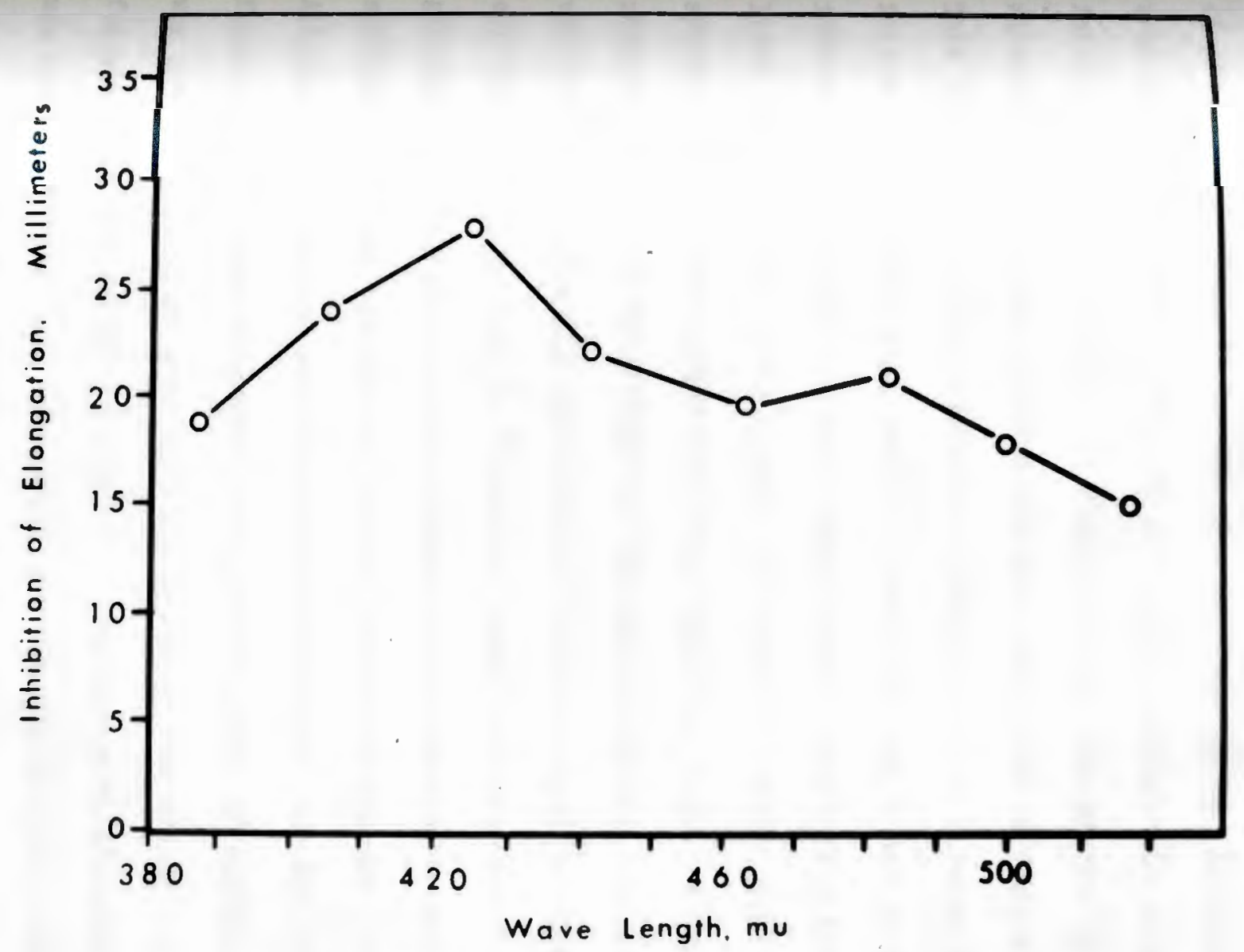

Figure 23. Action Spectrum for the Inhibition of Elongation of the Hypocotyl of Impatiens Balsamina L. 
was very similar to that for anthocyanin formation having a definite aximum at $425 \mathrm{mu}$.

In this same experiment observations were also made on the effects of the light treatments on the straightening of the hypocotyl arch. The arch remained closed in the 160 hour dark control. No effects of red or ar-red Iight used alone were observed while the arches of seedlings receiving fluorescent light alone were partially to completely opened. This latter effect was completely inhibited by 10 minutes of far-red allowing the white light period. Red light was found to reverse the Inhibiting effect of far-red to give results comparable to fluorescent light alone. Table XXVII (page 118) presents results for the action pectrum of the straightening of the hypocotyl arch. Since no energyresponse curve was determined for the straightening of the arch the values were arbitrarily corrected as in the elongation experiments. The corrected data, plotted in Figure 24, show that the action spectrum is gerally similar to the action spectra for elongation and anthocyanin whthesis in that the most effective region was between 405 and $463 \mathrm{mu}$. Although the apparent maximum at $441 \mathrm{mu}$ differs from the $425 \mathrm{mu}$ maximum found for the other responses, the precise point of maximum effectiveness was not determined as precisely as in the action spectra for anthocyanin Formation and hypocotyl elongation. Complete straightening of the arches was not achieved at any wavelength and the differences between values in the region of maximum response were small. There seems to be little doubt, however, that the region of 400 to $450 \mathrm{mu}$ is the most effective, ince the irradiation energies of this region were all less than those 
T A B L E Z X V I I

ACTION SPECTRUM FOR THE STRAIGHTENING OF THE HYPOCOTYL ARCH OF IMPATIENS BAISAMINA L.

\begin{tabular}{|c|c|c|c|c|}
\hline \multirow{2}{*}{$\underset{\mathrm{mu}}{\text { Irradiation }}$} & \multirow{2}{*}{$\begin{array}{l}\text { Energy } \\
\text { niw } / \mathrm{cm}^{2}\end{array}$} & \multirow{2}{*}{$\begin{array}{l}\text { Angle } \\
\text { Index }\end{array}$} & \multicolumn{2}{|r|}{ Increase } \\
\hline & & & observed & Gorrected \\
\hline control ${ }^{1}$ & -- & 1.59 & - & $-\infty$ \\
\hline 386.5 & 0.18 & 2.80 & 1.21 & 1.57 \\
\hline 403 & 0.49 & 3.35 & 1.76 & 1.76 \\
\hline 425 & 0.56 & 3.27 & 1.68 & 1.68 \\
\hline$W_{11}$ & 0.78 & 3.70 & 2.11 & 1.92 \\
\hline 463 & 1.00 & 3.52 & 1.93 & 1.61 \\
\hline 483 & 1.00 & 3.12 & 1.53 & 1.28 \\
\hline 500 & 0.48 & 2.92 & 1.33 & 1.33 \\
\hline 517 & 0.86 & 2.99 & 1.40 & 1.27 \\
\hline
\end{tabular}

1. The dark control is the average length of 150 seedlings. All other experimental values are the average of 40 seedlings.

2. See text, page 40 .

3. See text, pages 117 and 112 . 


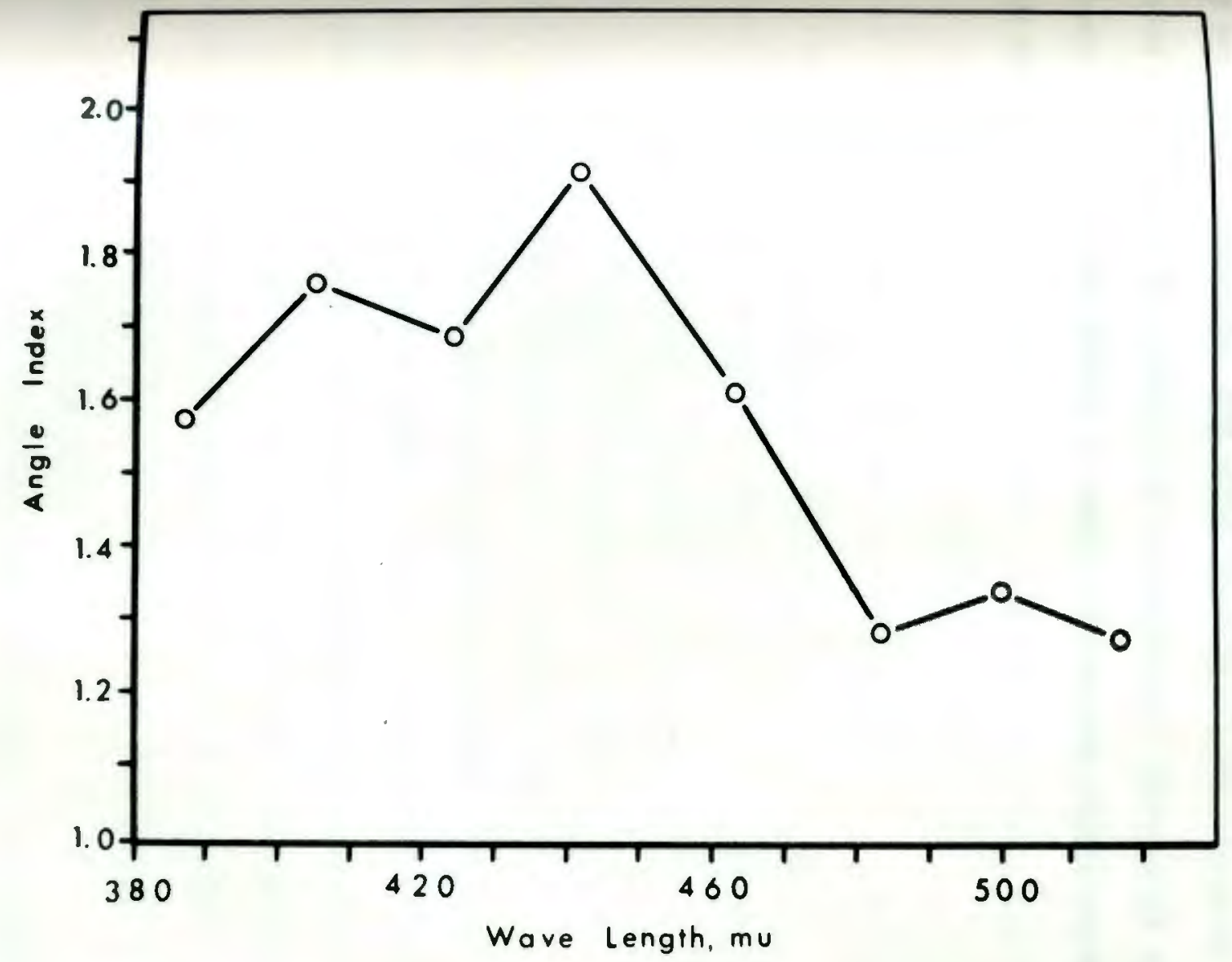

Figure 24. Action Spectrum for the Straightening of the Hypoootyl Arch of Impatiens Balsamina L. Angle index: see page 40 for explanation. 
delivered at the longer wavelengths, with the exception of $500 \mathrm{mu}$ (Table XXVII).

The photomorphogenic responses of anthocyanin synthesis, inhibition of hypocotyl elongation, and straightening of the hypocotyl arch were found to be under the control of phytochrome. Their high energy action pectra were similar having a region of maximum effectiveness between 400 and $450 \mathrm{mu}$. 
The abjective of this research was to attempt to show interrelationships between the development of morphological structures, (i.e. the Erelopment of roots and hairs) and a biochemical process (i.e. anthogjanin synthesis). Definite relationships have been shown to occur and Indicate possible mechanisms of endogenous and exogenous control of Mhocyanin synthesis and morphogenetic capacity. Anatomically the axis of the hypocotyl of Impatiens balsamina I. has been shown to present a radient of tissue types from meristematic at its upper end to highly differentiated and specialized types towards its basal end. Therefore the various physiological functions and responses as well as the morphoenetical manifestations observed in cultured hypocotyl segments can be pterpreted with reference to the basic structure and levels of Wferentiation of the tissues. Still another approach to the problem, IOphysical in nature, has shown that specific wavelengths of light are fective in causing and controlling both anthocyanin synthesis and the Phological processes of elongation and the straightening of the Fpocotyl arch which provided direct evidence for the primary action of light through a single mechanism.

Anatomical features of the rypocotyl will be discussed as they pertain to the other results of this research rather than as a separate unit, but certain findings are worthy of separate comment. A report by 
Resch (123) indicating that the hypodermis of Impatiens balsamina (Plate X) is 8 to $16 \mathrm{~N}$ in chromosome complement was of particular interest since Hrtually all anthocyanin formed in the hypocotyl of Impatiens seedlings wsed in this thesis was found in this tissue. Resch describes the aryloid condition as arising from an asynchronous type of amitosis with a gradual increase of chromosome material. All cells of the hypodermis were not pigmented in seedlings grown in the light by the author, but they varied from cells containing no pigment to very densely 1. Inmented cells. In the dark, where no anthocyanins were formed, a wimilar pattern of differential development of the hypodermis cells (Plates $X$ and $X I$ ) was noted. Such a striking correlation between llular morphology and anthocyanin content, and reported poljploidy would indicate that the three are closely related. However, on the basis of the results obtained here this question must remain open. This condition of the hypodermis would appear to provide an excellent oportunity to study the control of differentiation and anthocyanin Nhthesis on the cellular level.

The respiratory gradient along the axis of the kypocotyl provides further information upon which other results can be interpreted. The curves for respiration (Figures 1 and 2) conform closely to those btained by Brown and Broadbent (38a) in pea root. Plotted on a fresh weight basis, the respiratory gradient of the hypocotyl correlates Mosely with the area of the pseudomeristem in that the respiration rate drops sharply just below the pseudomeristem (Figure 2). However, on a per-cell basis Figure 2 shows that the maximum rate of respiration Dccurs at the 8 to $12 \mathrm{~mm}$ level which falls at the lower end of segment 1 
where the most rapid rate of cell elongation was found (Table VI). Segment I therefore has been shown to be both physiologieal y and matomically different from the rest of the hypocotyl because of its ristematic and elongating tissues which are responsible for the Featly elevated rate of respiration. The responses of segment 1 to the Earious chemical constituents of the medium were in general quite fifferent from the rest of the hypocotyl. Also segment 1 was always the first to show visible signs of anthocyanin during the course of an periment. The pigment appeared in the lower portion of the segment which would correspond to the rggion of elongation where respiration on a per cell basis is maximum (6). These results correlate well with the report of Paech and Eberhardt (112a) that the rate of anthocyanin mesth is maximum in germinating red cabbage seedlings during the period of maximum respiration.

The effects of glucose and sucrose on anthocyanin synthesis and growth were studied because there is some disparity on this point in the literature. Glucose was found to be more effective in prortoting anthocyanin synthesis (Table VIII) while sucrose supported better growth (Table VII) in the Impatiens hypocotyl. The most critical test of the tiliency of the sugars in promoting anthocyanin synthesis was in the dark grown cultures. Neither sugar was effective in supporting anthocyanin synthesis in segment 1 , but glucose gave a 2-to-3-fold increase in Hocyanin content over sucrose in segments 2 to 10 . In the light Weriments, none of the segments showed as much as a 2-fold difference in athocyanin content although glucose was clearly more effective. In 
magment 10 the two sugars were equally effective. Table VII shows that sucrose supported better raat formation in the segments below \#5 in bath the light and dark, but was only slightly more effective or equal to Grase in the upper segments. Bddy and Mapson (55) have shown that Iucose is most effective of a number of sugars in promoting anthocyanin whethesis in cress seodlings, while Thimann et al (146), and Straus (144) have shown that sucrose is most affective in Spirodela oligorrhiza and evitured corn endosperm tissue, respectively. However Thimann et al (146) has indicated that sucrose is used preferentially for anthocyanin arathesis while glucose is used for growth in Spirodela and Straus (144) finds sucrose most effective for bath pigment formation and growth of the corn endosperm. The results obtained under the conditions of the aperiments herein reported for the hypocotyl of Impatiens balsamina I. are unlike those of Thimann and Edmundson (146) for Spirodela, i.e., that gucrose is more effective for growth while glucose is more effective for the formation of anthocyanins. The conflicting reports in the literature wegether with the results obtainsd here indicate that information from one merimental object cannot be appli od to another and that little is definitively known about the rale of sugars in the process of anthocyanin synthesis. In the hypocotyl segments, the onset of pigmentation was more rapid with glucose in the upper segments but more rapid with sucrose in vegments nearer the base (6). In general sucrose appeared to bo more fectively utilized in the more highly differentiated tissue near the base of the hypocotyl. Such differences are a result of the tissue used for Merimentation rather than any direct role of the sugar being tested 
and this is probably an important factor not taken into account already in the literature. In attempting to interpret the literature concerning the effects of sugars on growth and anthocyanin formation, Bogorad (19) states: "The extensive current information on enzymatic reactions in sugar transformations appear to provide little comfort".

The most interesting results obtained from the treatment of the wpocotyl segments were obtained from experiments using the auxin, NAA. Daggestions made by Alston ( 1 ) concerning the mode of gene control of anthocyanin synthesis are supported by these results. He suggests that mothocyanin synthesis is gene controlled in two ways: ( 1 ) by the ability to produce a particular enzyme, or (2) through differences in the amount of enzyme, its distribution, time of appearance, and efficiency. Gene control of anthocyanin synthesis of the second type could be affected by altering the cellular environment so that important reactions in the bynthesis of anthocygnins may be favored or inhibited regardless of the proper enzymes being present. These genetic effects would be observed as the quantitative distribution of pigments in various organs or along the stem axis, the time of appearance of anthocyanins in a particular tissue, and the rate of pigment synthesis. In Impatiens, a series of genes is known to govern the distribution of anthocyanin pigments from the first node upward in the stem axis and even to the midribs of the I $(1)$. The hypocotyls used for the present studies when grown on a medium containing no NAA have been shown to have a specific quantitative 1. readually decreasing amounts in each subsequent segment toward the base 
of the hypocotyl (Figure 6). Since pigment appears first in segment I and proceeds step-wise toward the base (6), it would not appear that the rates of anthocyanin synthesis in the various segments differ greatly. A similar appearance and distribution of anthocyanins are found in the intact seedling grown in the light. This pattern of anthocyanin formation is under genetic control (1) and falls under the second type or indirect genetic control suggested by Alston. Increments of NAA added to the medium were found to generally increase anthocyanin synthesis (TPigure 5), but more important, NAA caused a shift in maximum anthocyanin gontent from segment 1 in the control, to segment 4 and 5 with $5.0 \times 10^{-8} \underline{M}$ NAA in the medium, and to segment 8 at the highest level of NAA (Figure 6). NAA also retarded the appearance of anthocyanins in the upper segments Wring the course of the experiments while the lower segments were effected only slightly. For example, anthocyanins appeared in segments 2 and 9 at the same time when subjected to $5.0 \times 10^{-6}$ NAA (Figures 3 and 4 ). Rates of anthocyanin synthesis in the lower segments were apparently greatly increased since segment 9 formed nearly twice the amount of thocyanin of segment 2 on the medium with $5.0 \times 10^{-6}$ NAA (Table XI) in about the same amount of time. Therefore, the hypocotyls grown on the two levels of NAA, and their control, may be looked upon as three mutants gimilar to the previously mentioned Impatiens plants in which the quantitative distribution of anthocyanins along the stem and jnto the Matioles and leaf midribs is controlled by an allelic series. The Wpothetical mutant hypocotyls differ in the rates of anthoeyanin ynthesis, the times of appearance of anthocyanins and the quantitative 
Histribution of anthocyanins along the axis of the hypocotyl, which uggests the shift of a physiological gradient favoring anthocyanin Wrathesis, towards the base of the hypocotyl. The control of anthocyanin vathesis then could be accomplished by a series of alleles affecting the endogenous levels of auxins in the hypocotyl. This concept is supported by the results of experiments using the antikaxin TIBA, which has been shown to effectively lower endogenous auxin levels (9, 10, 11). TIBA at a level of $5.0 \times 10^{-5}$ completely overcame the low level of NAA (5.0 X $10^{-8}$ MI) in the control to cause a quantitative distribution of thocyanin pigments along the axis of the hypocotyl which was identical to the hypocotyl segments where no NAA was added to the medium (Figure 8). When the same concentration of IIBA was interacted with the level of NAA which caused the greatest shift in the pattern of anthocyanin formation (5.0 $\times 10^{-6}$ ) results intermediate between no NAA and the highest level of NAA were obtained (Figure 9). Along with the anthocyanin responses, NAA enhanced both root and hair formation by the hypocotyl segments (Table IX) and these effects were likewise counteracted by TIBA (Table X and XVI, Figures 10 and II). Therefore if the three mutant varieties of Impatiens showing the different patterns of anthocyanin distribution were arailable, one would expect those hypocotyls forming greater amounts of Fathocyanins to also have a greater capacity to form adventitious roots and epidermal hairs. Just such a correlation between anthocyanin formation and rooting ability has recently been observed in cuttings of Acer rabrum and Eucalyptus camaldulensis by Bachelard and Stowe (1la). They found a direct correlation between the total amount of anthocjanin in the 
leaves and rooting ability of the cuttings. The auxin, indole butyric acid was found to increase the concentration of anthocyanin in the leaves, but not the total amount formed, which appeared to be an inherent preperty of an individual cutting. A possible interrelated system of root formation, anthocyanin synthesis, and leaf size is indicated by the report of Bachelard et al. Thus, it is quite possible that such apparentIy unrelated processes as anthocyanin synthesis, root formation and pidermal hair formation may be controlled simultaneously by factors (genetic or environmental) which influence the endogenous levels of axins in the hypocotyl.

GA was found to cause a marked increase in olongation of segment 1 in the light which was similar to the response of segment 1 cultured in the dark without GA. The meristematic tissues of segment 1 are responsiBle for its ability to elongate. Elongation per se appears to be navorable for the formation of both roots and anthocyanins. Root formation and anthocyanin synthesis in segment 1 was inhibited with Fespect to the other segments of the hypocotyl in the dark without GA (Table VII and VIII) and in the light in the presence of GA (Table X and XII).

In general, all the compounds tested affected both growth and whocyanin synthesis in the same way. That is, an enhancement or Inhibition of anthocyanin formation was usually accompanied by'a Gorresponding response in rooting and/or hair formation.

Thimann and Radner (148) have reported that in Spirodela, Rb replaced the light requirement for anthocyanin synthesis and enhanced anthocyanin 
formation in the light. He concluded that anthocyanin formation in Spirodela is directly dependent upon Rb synthesis. In the Impatiens Nopocotyl $\mathrm{Rb}$ was found to actually inhibit anthocyanin formation in the dark and also inhibit root and hair formation in segment I (Table XV). The growth of the lower segments of the hypocotyl was not noticeably affected (Table XV), When used in combination with $\mathrm{Bz}$ in the light, $\mathrm{Rb}$ arerely inhibited all activities of the hypocotyl and was lethal to most of the Iower segments (Table XVI and XVII). In agreement with the results obtained by the author, Straus (143) has shown that $\mathrm{Rb}$ inhibited anthocyanin synthesis in cultured corn endasperm tissue.

The purine analogues, $\mathrm{Bz}$ and $\mathrm{Aza}$, used individually and $\mathrm{Bz}$ used in combination with NAA effectively separated the growth responses (root and hair formation) from each other and from anthocyanin synthesis. It is finteresting to note that these responses were uncoupled only through the use of metabolic inhibitors ( $\mathrm{Bz}$ and $\mathrm{Aza}$ ) and not by compounds such as the sugars, auxins, or other chemicals which would be expected to act as factors known to occur naturally in plant tissues. Both Bz and Aza effectively inhibited growth and anthocyanin synthesis in all segments of the hypocotyl except \#I (Table XIII). The results of the inhibition of anthocyanin formation in segments 2 to 10 by the purine analogues agree well with the report of Thimann and Radner (149), but in segment 1 only $\mathrm{Bz}$ was effective in preventing anthocyanin formation while Aza had no appreciable effect. Although Aza did not inhibit anthocyanin synthesis in segment 1 , it strongly inhibited root formation and $\mathrm{Bz}$ in this case had little effect. These results suggest that Bz and Aza act at different 
points in the processes of anthocyanin synthesis and root formation. Both points in the two processes are apparently labile in the more highly differentiated tissues of the segments below segment 1 , while the $\mathrm{Bz}$ labile events in the case of root formation and the Aza labile steps in anthocyanin synthesis are absent or somehow protected in the undifferentiated tissue of segment 1 . The relationship between the level of differentiation of a tissue and the sensitivity of anthocyanin synthesis to Aza was further supported by the observation that the anthocyanin was formed well up into the hypocotyl arch (the region of the pseudomeristem) when Aza was present in the medium. Straus (143) has reported that Aza caused a slight enhancement of anthocyanin formation in corn endosperm. It would seem that the cultured corn endosperm would more nearly approximate the condition of the meristematic tissue of segment 1 rather than the mature Spirodela plants used by Thimann et al (146 to 149). Since anthocyanin synthesis and root formation can be selectively inhibited in segment 1 , but cannot in the lower segments of the hypocotyl, it appears that the processes are at first quite independent and become integrated as the tissue matures. It would be interesting to investigate the effect of $\mathrm{Bz}$ and $\mathrm{Aza}$ on the correlation between total anthocyanin formed in the leaves and the roating ability of Acer and Eucalyptus cuttings reported by Bachelard and Stowe (1la). That Aza acts as a potent inhibitor of anthocyanin synthesis in the mature tissue of the hypocotyl and has no effect on the wifferentiated pseudomeristem area, offers a likely explanation for the conflicting results of Straus (143) and Thimann and Radner (149). The mature Spirodela plants which Thimann and Radner used were severely Inhibited by Aza as was anthocyanin synthesis in the mature segments of 
the hypocotyl, while Aza did not affect anthocyanin synthesis in the ndifferentiated corn endosperm tissue of Straus and the pseudomeristem of the Impatiens hypocotyl. It appears that the effectiveness of Aza in inhibiting anthocyanin synthesis is dependent on the state of efferentiation of the tissue.

The interaction of $\mathrm{Bz}$ and NAA (Table XVI) was found to affect nthocyanin syathesis, root formation, and hair formation in different and apparentIy unrelated ways: (1) both anthocyanin synthesis (Figure 13) and the appearence of anthocyanins (Figure 12) in the segments was inhibited below the level attained with either compound used alone, (TabIes XIII and IX) (2) hair formation (Figure I4) was higher than that with the compounds themselves, and (3) root formation in segment 1 (Figure 15) was depressed while in the remainder of the segments intermediate mambers of roots were formed. Earlier in this discussion it was indicated that growth and differentiation, and anthocyanin synthesis in the hypoeotyl of Impatiens balsamina I. were closely related and that they could be simultaneously controlled by a single factor such as the level of auxins in the tissues. The effects of the purine analogues and their Whactions with NAA suggest that a coordinated response of both growth and differentiation, and anthocyanin synthesis is dependent on an unaltered purine metabolism in the tissue.

Thus far the discussion has been limited primarily to the onsideration of endogenous factors and relationships inherent in the Impatiens hypocotyl which could be involved in the auto-regulation of growth and differentiation, and anthocyanin synthesis under constant vironmental conditions. It has been suggested that morphogenesis and 
enthocyanin formation are closely associated phenomena, an idea which is supported in the literature $(6,11 a, 94)$ and that the morphogenetical processes of root and hair formation, and the biochemical process of anthocyanin synthesis are controlled simultaneously by the endogenous levels of auxin in the hypocotyl.

In general the morphogenesis of higher plants has been studied through the observation of responses induced by external stimuli. The major avenues of advance have been through the study of the action of light and chemicals as stimuli. Progress has been most rapid in the study of action spectra of photo-rosponses of plants such as flowering, internode elongation, and anthocyanin synthesis.

In the Impatiens hypoootyl, anthocyanin synthesis, inhibition of longation, and the straightening of the hypocotyl arch are under the influence of two photoprocesses. The first photoreaction requires high intensities and has an action maxima in the blue region of the visible wpectrum. The second photoreaction is the low energy photoreversible phytochrome system. In discussing the physiology of the photomorphogenic roactions, a separation must be made between the high energy and the low energy reactions. The high energy action spectra (Figures 20, 23 and 24) are very similar for all three responses studied indicating that the same photoreceptor is involved. These findings agree with those of Mohr (105), who found that the high energy action spectra for anthocyanin synthesis and hypocotyl elongation in Sinapsis alba I. were the same. Mohr also suggested that a single photoreceptor was acting for both responses, however the action maximum occurred at $710 \mathrm{mu}$, which is widely different from that in Impatiens (425 mu). Both anthocyanin synthesis 
and the inhibition of hypocotyl elongation was found to be under the phatoreversible control of phytochrome (Tables XXII and XXIV), but Mohr Foported that only anthocyanin synthesis was under phytochrome control in Sinapsis. This may have been due to the long periods of irradiation used by Mohr, since phytochrome control of anthocyanin in Impatiens is lost after long periods of light (Figure 16 and Table XVIII). The high energy action-spectra for anthoeganin synthesis in several other plants have been found to have prominent maxima in the red end of the spectrum with minor activities in the blue portion (132, 133). Downs (52) has recently determined the action spectrum for anthocyanin synthesis in milo edlings and found the action maximum to occur in the region of 470 to $480 \mathrm{mu}$ with no appreciable effect in the red part of the spectrum. Milo remains as the only example of an action spectrum for anthocyanin synthesis which closely approximates that of Impatiens. In bath the milo and in Impatiens a clear separation of the high energy blue photoreaction and the red, far-red reaction (phytochrome) was accomplishad.

Various suggestions have been made regarding the nature of the high energy reaction and its relation with the low energy phytochrome system. Downs (52) suggests that the high energy photoreaction causes the synthesis of a product essential for anthocyanin synthesis while phytochrome controls a later reaction in the pathway. From this it follows that if the proper "product" were already present in the plant the high energy photoreaction would not be necessary and the response could be controlled by the low energy phytochrome reaction alone. The magnitude of the response would be limited by the amount of product in reserve. 
This pattern is illustrated to different degrees in the responses of elongation and anthocyanir synthesis of the Impatiens hypocotyl (Tables IXV and XX). Figure 17 shows that anthocyanin does not respond linearly to light intensity as it would be expected to if substrates were not Iimiting (Gurve A in Figure 17). In Figure 18 it can be noted that mthocyanin synthesis responds sharply to very low light intensities but levels off quickly, presumably when reserve substrates are exhatsted. Apparentiy a threshold of light intensity must be exceeded in order to mply anthocyanin precursors so that the maximum rate of synthesis may again be achieved (Figure 19). Thus two photoreactions are clarly defined. The first (Figare 18), which is saturated at 30 foot candles, is thought to be the low energy red, far-red system which allows anthoeyanins to be formed from pre-existing substrates in the etiolated hypocotyl. The second photoreaction (Figure 19), which does not become saturated until above 1000 foot candles, is the high energy blue-light reaction (Figure 20) which drives reactions providing suitable substrates for futher anthocyanin synthesis. Table XXIV indicates that elongation of the hypocotyl may be controlled by the red, far-red system alone and is not nearly as dependent upon the high energy photoreaction as is anthocyanin synthesis. Maximum inhibition of hypocotyl elongation could only be achieved when relatively high level fluorescent irradiation was used which supplied the blue light necessary for the high energy photoreaction (Figure 23).

Contrary to the results of Klein et al (94a) and Withrow et al (169a) using bean seedlings, the hypocotyl arch of Impatiens was unresponsive to red or far-red light unless a previous period of high level blue 
light or fluorescent light was used. Klein et al (94a) found that only a few minutes of red light was necessary to cause the bean hypocotyl arch to open. Even repeated 10 minute exposures to red light (3 times per day) for several days caused no measurable opening of the hypocotyl arch in Impatiens. Excised bean arches were found to respond best to light and the action of the red light could be corapletely inhibited by auxin (IAA). This is in harmony with the findings of Galston et al (67) that eirradiation with red light reduced the sensitivity of pea epicotyls to treatment with auxin. Recently workers have shown that red light induces the formation of a flavonoid type auxin inkibitor in pea seedlings (64, 65, 107, 137). Assuming that auxin activity is controlled in the bean and Impatiens seedlings by photoreactions sinilar to that reported for the pea epicotyl, several factors could be responsible for the high energy blue-light requirement in Impatiens which is apparently absent in the photocontrol of the opening of the hypocotyl arch in the bean. Since the flavonoid auxin inhibitors would be formed from the same basic precursors as anthocyanins, it would not seem unlikely that their synthesis would depend upon the same high energy light requirement that is necessary for anthocyarin synthesis in the Impatiens hypocotyl. Fang et al (57a) has reported that relatively high intensities of fluorescent Ilght (exact intensities were unspecified) increased the rate of the oxidative destruction of IAA by corn and pea seedlings. Red light alone is reported to produce products which inhibit IAA oxidase (I07). Therefore if the levels of endogenous anxin were high a period of high Intensity irradiation would be necessary to remove IAA by oxidative 
destruction until the endogenous levels of auxin were low enough for the inhibitors induced by red light to be effective.

The photoreactions thus far mentioned may be divided into two general groups: (1) Those where the response may be controlled to a large extent by the red, far-red photoreversible system alone and are enhanced by high energy irradiation, and (2) those where the response is wholly dependent upon a period of high energy irradiation but are under the photoreversible control of the red, far-red system. Photoinhibition of elongation of the Impatiens hypocotyl is an example of the first type of reaction while anthocyanin synthesis and the straightening of the hypocotyl arch are examples of the second type.

To reiterate a previous statement, the high energy photo-reaction, which has its action maxima in the blue portion of the spectrum for the responses studied in Impatiens (Figures 20, 23 and 24) and the low energy

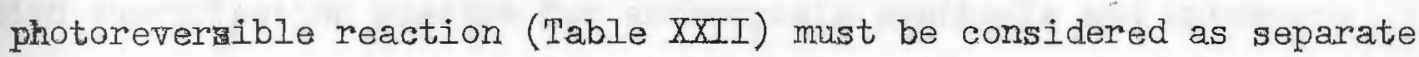
functions. The high energy reaction is thought of as driving endergonic reactions leading to the formation of substrates or causing the proper balance of physiological factors, such as auxins, necessary for the response-expression. The phytochrome (red, far-red) system apparently controls subsequent reactions in the biochemistry of the responseexpression which are not dependent upon an external energy source. At present, no specific biochemical reactions are known that are under the Influence of the photomorphogenic system, but work is currently in progress to uncover light-dependent reactions in the pathway of anthocyanin synthesis (130). Possible physiological mechanisms for the photomorphogenic system must remain speculative. However, a model system 
which could be subjected to experimental test can be constructed from information in the literature and the findings in this thesis.

Although the phytochrome reaction was initiælly written as an oxidation-reduction process, it is now believed to involve only the phytochrome molecule with no cofactors $(23,77)$. Hence, the low energy plotoreversible reaction is written as the following:

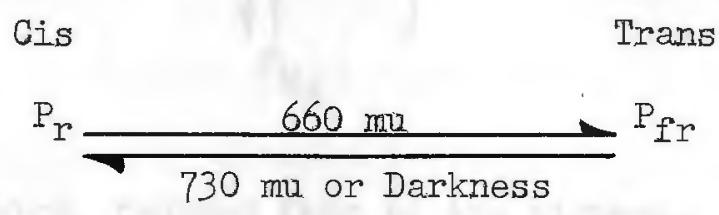

The cis-trans isomeration is indicated as the two possible forms of the pigment $(76,81)$. The absorption of phytochrome indicates that the prosthetic group may be a polyen (23) such as the chromatophore of certain phycocyanins, which is a bilitriene mesobiliverdin (112). The high energy action spectra for anthocyanin synthesis and internade elongation (105, 132, 133) which have their action maxima in the red portion of the spectrum indicate that the continuous excitation of phytochrome $i n$ either form $\left(\mathrm{P}_{\mathrm{r}}\right.$ or $\left.\mathrm{P}_{\mathrm{fr}}\right)$ may mediate the primary reactions. This ancept has been thoroughly developed by Hendricks and Borthwick $(78,79)$ and Hendricks, Toole, Toole, and Borthwick (80). If the proposals of Hendricks et al are $\mathrm{valid}$, then the action spectra for anthocyanin gynthesis in milo (52) and Impatiens (Figure 20) and the action spectra for elongation and arch straightening in the hypocotyl of Impatiens (Tigures 23 and 24), all of which have their action maxima in the blue, indicate that continuous excitation of phytochrome may also occur at shorter wavelengths. This is not contrary to absorption spectra data 
for phytochrome preparations (19a). A more "complete" photoreceptive system could then be represented as the following:

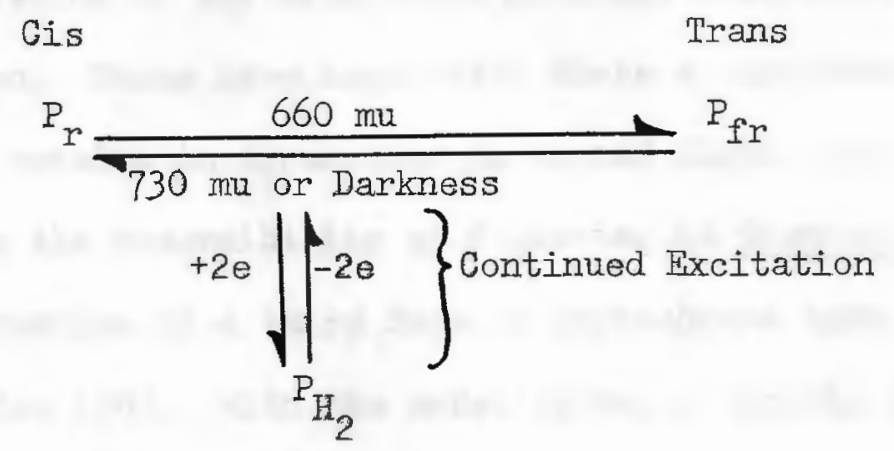

$\mathrm{P}_{\mathrm{H}_{2}}$ represents a third, reduced form of the pigment. It may arise from either the cis or trans isomer since the reduction of a bilitriene such as is proposed (76) would eliminate the possibility of isomerism. The high energy action maxima for anthocyanin synthesis and elongation occur at various wavelengths in the red (near $660 \mathrm{~mm}$ ) and far-red (near $730 \mathrm{mu}$ ) as well as in the blue ( 400 to $500 \mathrm{mu}$ ). This is quite reasonable since the product $\mathrm{P}_{\mathrm{H} 2}$ is the same regardless if it arises from $\mathrm{P}_{\mathrm{fr}}$ or $\mathrm{P}_{\mathrm{r}}$. The action spectrum for anthocyanin synthesis in the hypocotyl of Impatiens as determined with the interference filter light source (Figure 20) Indicates an action maximum at $425 \mathrm{mu}$, but the curve obtained from the spectrograph irradiations (Figure 20) indicates that the actual maximum occurs at somewhat shorter wavelengths, falling between 410 and $420 \mathrm{mu}$. This apparent discrepancy could not be resolved since no interference filters transmitting light between 405 and 425 mu were available. The Indication that the actual action maximum for anthocyanin synthesis occurs in the region of 410 to $420 \mathrm{mu}$ is important since it closely agrees with a reported absorption peak of phytochrome occuring at $415 \mathrm{mu}$ (19a). These 
data further support the idea that phytochrome participates directly in the high energy reaction and that a form of the pigment such as $\mathrm{P}_{\mathrm{H} 2}$ may arise from irradiation of any wavelength provided that sufficient radiant energy is absorbed. Cases have been noted where a continued exposure to far-red light results in a response as to red light, (44, 53, 108). Recent studies on the reversibility of flowering in Chenopodium have indicated the formation of a third form of phytochrome upon continued far-red irradiation (90). With the model above, a variety of wavelengths falling near the absorption maxima of either $\mathrm{P}_{\mathrm{r}}$ or $\mathrm{P}_{\mathrm{fr}}$ could cause the formation of $\mathrm{P}_{\mathrm{H} 2}$. The absence of both oxidized forms of the pigment could cause the "red effect" with continued far-red irradiation.

The model system consists of a photoreversible pigment (phytochrome) existing in one of two isomeric forms $\left(\mathrm{P}_{\mathrm{r}}\right.$ or $\left.\mathrm{P}_{f r}\right)$ and a third reduced form $\left(\mathrm{P}_{\mathrm{H} 2}\right)$ which can be derived from either of the two isomers as a result of high energy irradiation from the visible spectrum. The reduced form may arise from any portion of a broad band either in the red (600 to $750 \mathrm{mu}$ ) or in the blue (400 to $500 \mathrm{mu}$ ). Action spectra of the low energy photoreversible reaction, on the other hand, have in all cases been found to be the same and coincide with the absorption spectra of $P_{r}$ and $P_{f r}$ in the red end of the spectrum (24).

Although phytochrome has been linked to numerous plant responses, it is unknown how this apparently simple photoreversible reaction is linked to the physiology of the plant (23). It has been suggested that the far-red absorbing form $\left(P_{f r}\right)$ of phytochrome is an active enzyme associated with the metabolic fate of acyl coenzyme compounds (24, 131). 
Evidence for this proposal is inconclusive and it is difficult to envision a single enzyme having such varied effects and precise control over a number of processes of plant growth and development.

It has been shown recently that the synthesis of proteins and enzymes are under the control of the low energy phytochrore reaction (5, 102, 104). Marcus (102) demonstrated that the formation of a TPN dependent triosephosphate dehydrogenase in dark grown bean leaves is reversibly controlled by the low energy red, far-red reaction. Mego and Jagendorf (104) have recently shown that the growth of bean chloroplasts is induced by short exposures to red light (2 minutes per day) in otherwise dark grown plants. The effect was reversible with far-red treatment. Proteins were formed to the level of the mature ehloroplast, but the low energy reaction was capable of convarting only preaxisting protochlorophyll to chlorophyll. The development of the structure, shape and ahlorophyll content of mature chloroplasts was dependent on long periods of high level irradiation. Of impartance in the work of Marcus, Mego and Jagendorf is that proteins (presumably enzymes) are synthesiged in response to the formation of $P_{f r}$ by red light with a negligible input of radiant energy. By this method, enzymes are formed which mediate the reactions leading to a particular response. However, if the response which is controlled by the red, far-red system through protein synthesis requires the synthesis of certain precursors such as protochlorophyll or redueed coenzymes (TPNH 2 far example), the response will not be displayed unless they are present. The high energy reaction functions to provide the proper precursors and cofactors. A third form of the pigment (such as $\mathrm{P}_{\mathrm{H} 2}$ for instance) could very easily transfer electrons to yield energy and/or 
proper substrates. Mego and Jagendorf ( 104 ) have clearly shown these two phases in chloroplast development. This separation has been shown earlier by the Beltsville group in several photoresponses of plants and the same pattern is apparent in the photoresponses of the Impatiens hypocotyl studied in this research. The fact that sugars will alleviate the high energy irradiance requirement for anthocyanin synthesis $(6,146,147)$, and for the display of photoreversibility of stem elongation (14, 54) implicates the high energy reaction in the energetics of the cell. Further evidence for the participation of the high energy form of the pigment ( $\mathrm{PH}_{\mathrm{H} 2}$ ) can be found in the work of Siegelman and Hendricks (131). They found that apple skins floating on sucrose solutions in the dark produced alcohol and aldehydes. If ght suppressed the synthesis of these products in a manner similar to the suppression of fermentation by oxygen. ApparentIy the irradiation facilitated the removal of electrons from the system, to molecular oxygen with (1) the concomittant release of energy, (2) utilization of acetate and (3) anthocyanin production. The role of the high energy reaction in the utilization of acetate and acyl coenzyme A compounds has been suggested in numerous publications from the Beltsville laboratory $(23,24,78,79,80,105,133)$. From this discussion the previous model could be extended as follaws: 


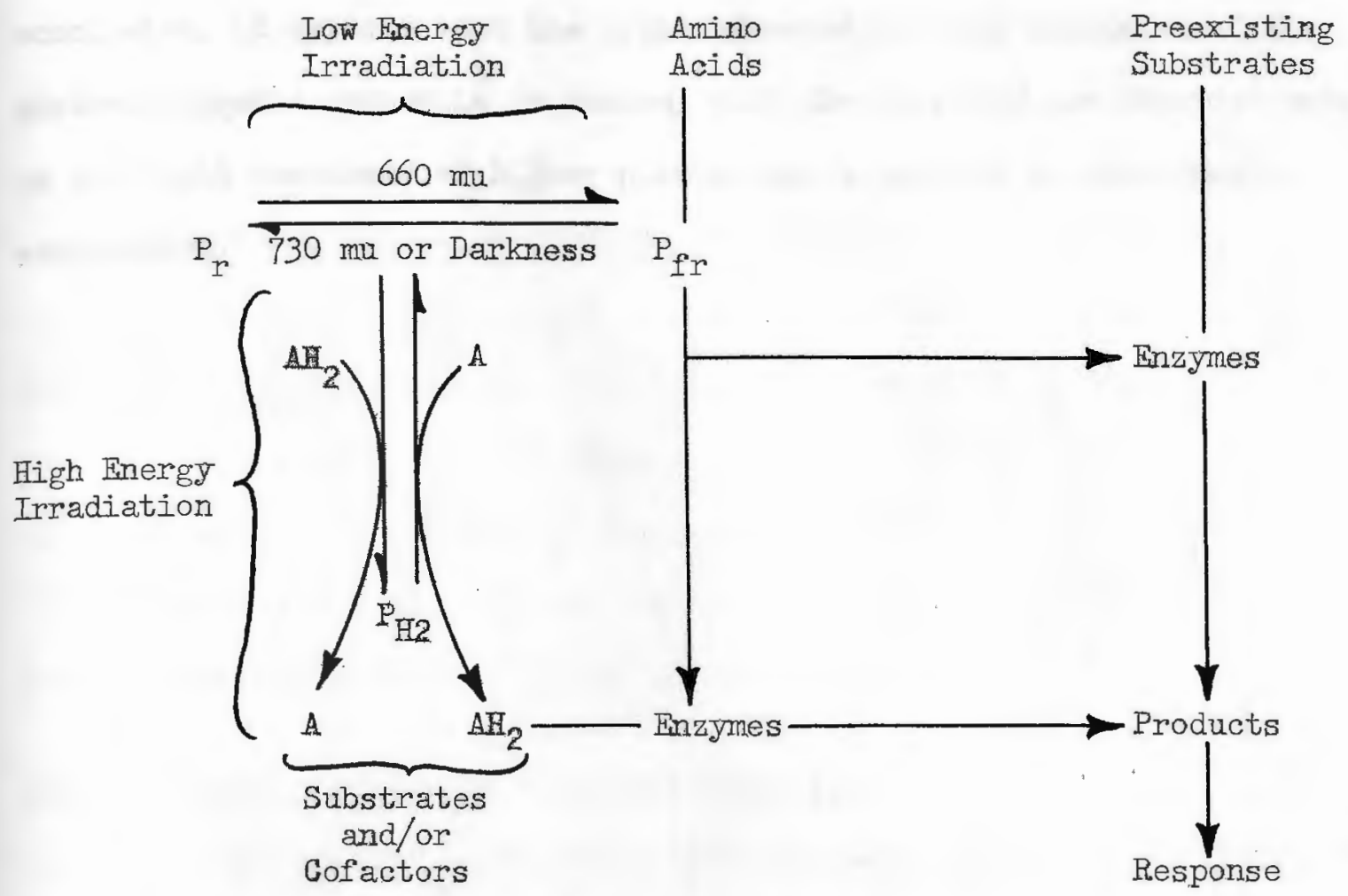

Further evidence which implies that the phytochrome system is active in some phase of protein synthesis is that pyrimidines strongly influence photoinduction of flowering in Xanthium (125, 126). Recently, it has been shown, through the use of $\mathrm{c}^{\text {Ih }}$ - labelled 5-fluorouracil, that RNA synthesis may be the process essential to photoperiodic induction of flowering in Xanthium (22). The above model allows for the formation of products mediated by enzymes which are dependent on the formation of $\mathrm{P}_{\mathrm{fr}}$ through the action of $660 \mathrm{mu}$ red light. Far-red light (730 mu) inhibits protein synthesis by converting $\mathrm{P}_{\mathrm{fr}}$ to $\mathrm{P}_{\mathrm{r}}$, thereby making the system photoreversible. The formation of products within the proposed system which are casually related to the observed response, may or may not have a high energy requirement depending on the existence suitable substrates. In 
conclusion, it appears that the proposed model for the mechanism of the photomorphogenic system is in harmony with the observations thus far made on the light responses of higher plants and is subject to experimental examination. 


\section{H $A P E R \quad V I$}

$S U M M A Y$

Factors affecting anthocyanin synthesis and morphogenesis of the hypocotyl of Impatiens balsamina I. were investigated. Anatomy of the etiolated Impatiens hypocotyl was studied and respiration rates along the axis of the hypocotyl were determined. Factors affecting anthocyanin synthesis and morphogenesis which were studied fall into two groups:

(1) chemicals which are reported to affect growth and differentiation or anthocyanin synthesis and (2) the effects of light.

\section{Anatomy and Respiration Rates of the Hypocotyl}

1. The anatomy of the etiolated Impatiens hypocatyl, including the arrangemnt and occurrence of the primary tissues is described. Growth, i.e. elongation, of the dark grown hypocotyl arose from the contribution of new cells by the pseudomeristem in the hypocotyl arch, and the region of cell elongation immediately below the hypocotyl arch. Anthocyanin synthesis was limited nearly exclusively to the hypodermis, a highly differentiated single layer of cells directly beneath the epldermis.

2. Simple hairs similar to root hairs were formed from epidermal cells of the hypocatyl. Adventitous roots arose from 4 small zones of pericycle tissue located at the points of the tetrarch xylem pattern of the hypocotyl.

3. Highest rates of respiration occurred in the region of the pseudomeristem when calculated on a fresh weight basis. On a per cell 
basis the pseudomeristem exhibited minimal respiration and the maximum rate occurred in the region of cell elongation.

\section{Ghemical Factors Affecting Anthocyanin Synthesis and Morphogenesis}

1. The effects of the following types of compounds on the formation of roots, hairs, and anthocyanin pigments in segmented hypocotyls grown in sterile culture were studied: (1) the sugars, glucose and sucrose, (2) the growth substances, Naphthalene acetic acid (NAA), Triiodabenzoic acid (TIBA) and Gibberellic acid (GA), (3) compounds effecting anthocyanin synthesis, Azaguanine (Aza), Benzimidazole (Bz) and Riboflavin (Rb).

2. Both sucrose and glucose supported good growth and anthocyanin formation in the hypocotyl segments, glucose being more effective in supporting anthocyanin synthesis than sucrose in both the light and dark while sucrose supported better growth. Neither sugar was effective in causing anthocyanin synthesis in segment 1 in the dark.

3. Increments of NAA in the medium caused a coordinated increase in hair production, root formation, and anthocyanin synthesis. A shift in the point of maximum anthocyanin synthesis from segment 1 in the control to segment 8 in hypocotyls treated with NAA was observed.

4. TIBA inhibited both growth and anthocyanin synthesis in the hypocotyl segments and acted as a direct antaganist of NAA.

5. GA acted primarily on segment 1 of the hypocotyl. Under the influence of $\mathrm{GA}$, segment $I$, in the light, elongated considerably which was accompanied by a reduction in rooting and anthocyanin synthesis. A similar pattern of growth and anthocyanin formation was noted when segment I was cultured in darkness without GA. Hair formation was not significantly 
affected by GA.

6. Both the purine analogues, Bz and Aza, effectively inhibited hair formation in all segments of the hypocotyl and inhibited rooting and anthocyanin synthesis in segments 2 to 10 . In segment 1 Bz inhibited anthocyanin synthesis and had little effect on rooting while Aza acted in the opposite manner. In segments 2 to $10 \mathrm{Aza}$ was about 100-fold more effective in inhibiting anthocyanin synthesis than Bz, but was nearly without effect in segment $I$.

7. In hypocotyl segments cultured in the dark, $\mathrm{Rb}$ inhibited anthocyanin synthesis generally and inhibited root and hair formation in segment 1 . In the light, the interaction of $\mathrm{Rb}$ and $\mathrm{Bz}$ severely inhibited all observed activities of the hypocotyl segments and was lethal to many of the lower segments.

8. Interaction of $\mathrm{Bz}$ and NAA had synergistic effects in inhibiting anthocyanin synthesis and in enhancing hair production in the hypocotyl segments. NAA counteracted the inhibition of rooting by Bz in segments 6 to 10, while NAA acted synergistically with Bz to inhibit rooting in segment 1 .

9. Results are discussed in relation to literature concerning the effects of chemicals on growth and differentiation and anthocyanin synthesis, and theories on the endogenous regulation of the appearance of anthocyanin pigments in plant tissues.

Responses of the Hypocotyl to Light

I. High energy action spectra for anthocyanin synthesis, inhibition of hypocotyl elongation, and straightening of the hypocotyl arch in 
the region of 400 to $500 \mathrm{mu}$ were determined. These responses were also shown to be under the control of the low energy, photoreversible red far-red system, i.e. phytochrome.

2. Action spectra for anthocyanin synthesis and inhibition of hypocotyl elongation were found to be identical, having an action maximum in the vicinity of $425 \mathrm{mu}$. Straightening of the hypocotyl arch had an action maximum at 4 li $\mathrm{mu}$.

3. Anthocyanin synthesis and straightening of the arch were obligate for high energy irradiation, but elongation could be controlled to a large extent through the low energy red and far-red irradiation alone. Inhibition of elongation was enhanced by high energy blue light.

4. All responses investigated, anthocyanin synthesis inhibition of hypocotyl elongation and straightening of the hypocotyl arch were under the ultimate control of the low energy phytochrome reaction.

5. Direct evidence was obtained for the simultaneous control of the biochemical process of anthocyanin synthesis and the morphogenetic processes of hypocotyl elongation and straightening of the hypocotyl arch through a single system.

6. Results are discussed in relation to current Iiterature concerning photomorphogenesis of plants. It is suggested that a single photoreceptor for the high energy irradiation is active in mediating the responses studied and that the photoreceptor is the phytachrome molecule itself. A model photomorphogenic system is proposed. 
1. Alston, R. E., 1959. Physiology and the inheritance of anthocyanin pattern. Genetica 30: 261-277.

2. 1958. Effect of light on leucoanthocyanin synthesis in Impatiens balsamina. Botan. Gaz. 120(2): 99-101.

3. 1958. Leucoanthocyanin synthesis in dark grown seedlings of Impatiens balsamina. Am. J. Botany 45: 289-294.

4. inheritance of flower color in Impatiens balsamina. Genetics 43: $35-47$.

5. Appleman, D. and Pyfrom, H. T., 1955. Changes in catalase activity and other responses induced in plants by red and blue light. Plant Physiol. 30(6): 543-549.

6. Arnold, A. and Alston, R. E., 1961. Certain Properties of hypocotyl of Impatiens balsamina reflecting physiological complexity. Plant Physiol : 36(5): 650-656.

7. Arthur, J. M., 1936. Radiation and anthocyanin pigments. In: Biological Effects of Radiation, B. M. Duggar Ed., vol. II, pp. 1109-1118, McGrar Hill, New York.

8. Asen, S. and Hamner, C. I., 1953. Effect of growth regulating compounds on development of basal shoots of greenhouse roses. Botan. Gaz. 115: 86-89.

9. Audus, L. J., 1959. Plant Growth Substances Leonard Hill (Books) Itd., London.

10. , and Thresh, R., 1956. The effects of synthetic growth regulator treatments on the level of free endogenous growth substances in plants. Ann. Botany N. S. 20(79): $439-459$.

11. and 1956. The effects of synthetic growth substances in the level of endogenous auxins in plants. In: The Chemistry and Mode of Action of Plant Growth Substances. Wain and Wightman, Eds. Butterworths, London, pp. $248-252$.

112. Bachelard, E. P. and Stowe, B. B., 1962. A possible link between root initiation and anthocyanin formation. Nature 194: 209-210.

12. Batalin, A., 1871. Uber die Wirkung des Lichtes auf die Enwicklung der Blatter. Botan. Z. 29: 669-686. 
13. Bentley, J. A., 1958. The naturally-oceurring auxins and inhibitors. Ann. Rev. Plant Physiol. 9:47-80.

14. Bertsch, W. F. and Hillman, W. S., 1961. The photoinhibition of growth in etiolated stem segments I. Growth caused by sugars in Pisum. Am. J. Botany 48(6): 504-517.

15. Bindlos, E. A., 1942. A developmental analysis of cell length as related to stem length. Am. J. Botany 29: 179-188 (1942).

16. Birch, A. J. and Donovan, F. W., 1953. Studies in relation to biosynthesis. I. Some possible routes to derivatives of oreinol and phloroglucinol. Aust. J. Chem. 6:360-368.

17. Birth, G. S., 1960. Agricultural applications of the dual-monochromator spectrophotometer. Ag. Fing. 4I(7): 432-435.

18. Blank, $F_{*}, 1947$. The anthocyanin pigments of plants. Botan. Rev. 13: $241-317$.

19. Bogorad, I., 1958. The Biogenesls of flavonoids, Ann. Rer. Plant Physiol. 9: 477-448.

19a. Bonner, B. A., 1961. Properties of phytochrome from peas. Plant Physiol. Suppl. 36: xli1i.

20. Bonner, J., 1949. Further experiments on flowering in Xanthium. Botan. Gaz. 110: 625-627.

21. and Thurlow, J., 1949. Inhibition of photoperiodic induction in Xanthium by applied auxin. Botan. Gaz. 110: 613624 .

22. and Zeevaart, A. D., 1962. Ribonucleic acid synthesis in the bud an essential component of floral induction in Xanthium. Plant Physial. 37(1): 43-49.

23. Borthwick, H, A. and Hendricks, S. B., 1961. Effects of radiation on growth and development. Handbuch der Pflanzen Physiol. 16: $299-300$.

24. and $132: 1223-1 \overline{228}$. 1960. Photoperiodism in plants. Science

25. and Parker, M. W., 1938. Photoperiodic perception in Biloxi soybeans. Botan. Gaz. 100: 374-387.

26. Hendricks, S. B. and Parker, M. W., 1952. The reaction cantrolling floral initiation. Proc. Natl. Acad, Sci. 38(11): $929-934$. 
27.

and 1948. Action spectrum for photoperiadio control of floral initiation of a long day plant, Wintrex barley (Hordeum vulgare). Botan. Gaz. 110: 103-118.

28. Toole, E. H., and Toole, V. K., 1954. Action of light on lettuce seed germination. Botan. Gaz. 115(3): $205-225$.

29. Parker, M. W., Toole, E. H. and Toole, V. K., 1952. 'A reversible photoreaction controlling seed germination. Proc. Natl. Acad. Sci. 38(8): 662-666.

30. Bouillenne, R. and Bouillenno-Walrand, M., 1947. Determination des facteurs de la rhigogenese. Acad. Roy. Belgique Cl. Sci. 33: $790-806$.

31. and 1939. Teneur en auxines des plantules et hypocotyls inanities d' Impatiens balsamina $I$. en rapport avec $I^{\prime}$ organogenesis des racines. Acad. Belgique Bull. Gl. Sci. $(5 / 8): 473-490$.

32. and F.A. Went, 1933. Recherches experimentales sur la neoformation des racines. Ann. Jard. Bot., Buitenzorg 43: 25-202.

33. Brian, P. W., 1959. Effects of gibberellins on plant growth and development. Biol. Rev. Cambridge Phil. Soc. 34: 37-84.

34. 1957. The effects of some microbial metabolic products on plant growth. Symp. Soc. Exptl. Biol. 9: 166-182.

35. Grove, J.F. and MacMillan, J., 1960. The gibberellins. Progr. in Chem. Org. Nat. Prods., 18: 350-433.

36.

, Heming, H. G., and Lowe, D., 1960. Inhibition of rooting of cuttings by gibbersllic acid. Ann. Botany 24(96): $407-419$.

37. gibberellio acid on shoot growth of cupid sweet peas. Physiol, Plantarum 12: 15-29.

38. and Radley, M., 1957. A physiologieal comparison of gibberellic acid with some auxins. Physiol. Plantamum 8 : 899-912.

38a. Brown, R. and D. Broadbent, 1950. The development of cells in the growing zones of the root. J. ExptI. Botan. 1: 249-263.

39. Bunning, E. and Mohr, H., 1955. Das Aktionsspektrum des Lichteinflusses auf die Keimung von Farnsporen. Naturwiss. 42: 212. 
40. Butler, W. I., Norris, K. H., Siegelman, H. W. and Hendricks, S. B., 1959. Detection, assay, and preliminary purification of the pigment cantrolling photoresponsive development of plants. Proc. NatI. Acad. Sci. 45(12): 1703-1708.

41. , Siegelman, H. W., and Hendricks, S. B., 1961. Some Photochemical properties of playtochrome. Plant Physiol. Suppl. 36: xlii-x>iii.

42. Caspary, R., 1861. Bulliardia Aquatica D. C. Schr. Kgl. physic. okonom Ges. Koningsberg 1: 66-91.

43. Cathey, H. M., 1959. Gibberellins in horticulture, A preliminary review. Natl. Hort. Mag. 38: 215-231.

44. and Borthwick, H. A., 1957. Photoreversibility of floral initiation in Chrysanthemum. Botan. Gaz. 119: 71-76.

45. Chauveaud, G., 1917. L'apperiel conducteur des plentes vasculaires et les phases prtncipales de son evolution. Ann. Sci. Nat. Bot., Ser. 9, 13: 113 .

46. Compton, R. H., 1912. Theories of the anatomical transition from root to stem. New Phytol. 11: 13-25.

47. Crocker, W., 1936. Fiffect of the visible spectrum upon the germination of seeds and fruits. In: Biological Effects of Radiation,

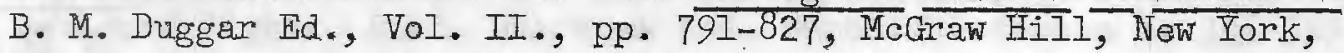

48. Davis, D.W., I. A. Taylor, and R. P. Ash, 1958. Impatiens balsamina The inheritance of flower colors. Genetics $43(1): 16-34$.

49. Denffer, D. V* and Grundier, H., 1950. Jber wuchsstoffinduzierte Bluhhermung bei Langtagpflanzen. Biol. Zentr. 69: 272-282.

50. De Ropp, R. S., 1951. The growth capacity of the sunflower hypocotyl. Plant Physiol. 26(4): 778-783.

51. DeWaard, J. and Roodenburg, J. W., 1948. Premature flawer bud initiation in tomato seedlings caused by 2,3,5-trilodobenzoic acid. Koninkl. Nederland. Akad. Wetenschap., Proc. 51: 248-251.

52. Downs, R. J., 196I. Photocontrol of anthocyanin synthesis in dark grown milo seedlings. Plant Physiol. Suppl. 36 x xili.

53. 1956. Photoraversibility of flawer Initiation. Plant Physiol. 31: 279-284.

54. , Hendricks, S. B., and Borthwick, H. A., 1957. Photoreversible control of elongation of Pinto beans and other plants under normal conditions of growth. Botan. Gaz. 118(4): 199-208. 
55. Bddy, B*, and Mapson, L., 1951. Some factors affecting anthocyanin synthesis in cress seodlings. Biochem. J. 49: 694-699.

56. Fsau, K., 1953. Plant Anatomy. Willey and Sons, New York.

57. Evenari, M., 1956. Seed gormination, In: Radiation Biology, A. Hollaender Ed., VQI. III, pp. 519-549, McGraw Hil1, New York.

57a. Fang, S. C., Theisen, P. and Butts, J. S., 1959. Metabolic studies of applied indoleacetic acid l-Gli in plant tissues as affected by light and 2,4D treatment. Plant Physiol. 34: 26-32.

58. Fawcett, G. H., 1961. Indole auxins. Ann. Rev. Plant Physiol. 12: $345-368$.

59. Flint, L. H., 1936. The action of radiation of specific wavelengths in relation to the germination of light sensitive lettuce seed. Compt. Rend. Assoc. Internatl. Ess. Sem., no. 1.

60. and McAlister, E. D., 1935. Wavolengths of radiation in the visible spectrum inhibiting the germination of light sensitive lettuce seed. Smith. Misc. Goll. 94(5): 1-11.

61. Funke, G. I., 1938. Proeven over photoperiadiateit by verschillend gekl aurd Iight. Biol. Jaarboek Nat. Genoot. Dodoneae 5: 404424 .

62. 1937. Proeven over photoperiadiateit by verschillend gekl wurd Iight. Biol. Jaarboek Nat. Genoot. Dodaneae 4: 345-359.

63. ㄴ. 1936. Proeven over photoperiodiateit by verschillend gekleurd light. Biol. Jaarboek Nat. Genoot. Dodonaea 3: 225-261.

64. Furuya, M. and Galston, A. W., 1961. Fiffect of in vitro pretncubation with cofactors on the activity of the indoleacetic acid oxidase of peas. Physiol. Plantarium I4: 750-766.

65. , and Stawe, B. B., 1961. Isolation of cofactors and inhibitors of indoleacetic acid axidase from pea plants. Plant Physiol. Suppl. 36: xlviti.

66. Galston, A. W., 1947. The effect of 2,3,5-trilodobengoic acid on the growth and flowering of soya beans. Am. J. Botany 34: 356360 .

67. and Baker, R. S., 1953. Studies on the physiology of light action: $V$. Photoinduative alteration of auxin metabolism in etiolated peas. Am. J. Botany 40: 512-516.

68. and Purves, W. K., 1960. The mechanism of action of auxin.Ann. Rev. Plant Physiol. 11: 239-276. 
69. , Baker, R. S. and King, J.W., 1953. Benzimidazole and the geometry of csll growth. Physiol. Plantarum 6: 863 72.

70. Garner, W. W. and Allard, H. H., 1923. Further studies in photoporiodism, the response of the plant to relative length of day and night. J. Agr. Research 23: 87I-920.

71. day and night and other factors of the environment on growth and reproduction in plants. J. Agr. Research 18: 553-606.

72. Goldacre, P. I., Griston, A. W., Weintraub, R. L., 1953. The effect of substituted phenols on the activity of the indoleacetic acid oxidase of peas. Arch. Biochem. Biophys. 43: 358-373.

73. Goodwin, R. H, and Taves, C., 1950. The effect of coumarin derivatives on the growth of Avena roots. Am. J. Botany 37: 224-3I.

74. Gordon, S. A., Paleg, I. G., 1961. Formation of auxin from tryptophan through action of polyphenols. Plant Physiol. 36: 838-845.

75. Hagen, C. W., 1959. Influence of genes controling flower color on relative quantities of anthocyanins and flavonols in petals of Impatiens balsamina. Geneties 44: 787-793.

76. Hendricks, S. B., 196I. Personal conv.

77. factor determining photoperiodism in plants. Cold Spring Harbor Symp. Quant. Biol. 25: $245-248$.

78. development by the simultaneous excitations of two interconvertable pigments. Proc. Natl. Acad. Sci. 45(3): 344-349.

79. and , 1959. Photocontrol of plant development by the simutaneous excitation of two interconvertable pigmats II. Theory and control of anthocyanin synthesis. Botan, Gaz. $120(4): 187-193$.

80. Toole, E. H., Toole, V. K. and Borthwick, H. A., 1959. Photocontrol of plant development by the simultaneous excitations of two interconvertable pigments. III Control of seed germination and axis elongation. Botan. Gaz. 121: 1-8.

81. and Borthwick, H. A., 1954. Photoresponsive growth. In: Aspects of Synthesis and Order in Growth, 13th Symposium of the Saciety for the Study of Development and Growth. Dorothea Rudnick Ed., Princeton U. Press, Princeton, N. J. pp. 149-169. 
82. Hil7man, W. S., 1955. The action of benzimidazole on Lemna minor. Plant Physiol. 30: 535-542.

83. and Galston, A. W., 1957. Inductive control of indoleacetic acid axidase activity by red and near infrared light. Plant Physiol. 32: 129-135.

84. Hygen, G., 1948. Fotoperiodiske reaksjoner bos alger. Blyttia I: $1-6$.

85. Johansen, D. A., 1940. Plant Microtechnique. McGraw Hill, New York.

86. Johnston, F. S., 1936. Sun Rays and plant life. Smith. Repart for 1936, pp. 353-371.

87. 1934. Phototropic sensitivity in relation to wavelength. Smitit Misc. Col1. 92: 1-17.

88. , 1934. Phototropigm: A spealfic growth response to light. Smith. Ann. Report of 1934, pp. 313-323.

89. Kandeler, R., 1960. Uber die Lichtabhangigkeit der Anthocyanbildung. Flor: 149: 487-519.

90. Kasperbauer, M. J., 1962. Unpublished data.

91. Kato, J., 1958. Studies on the physiological effect of gibberellin. II. On the interaction of glbberallin with auxins and growthinhibitors. Physiol Plantarum 11: 10-15.

92. Katunskij, V, M., 1937. Dependence of photopertodic reactions of plants on the spectral composition of light. Comp. Rend. (Doklady) Acad. Sci. U.S.S.R. 15: 509-512.

93. Kaufman, P. B. and Katz, J. M., 1961. Growth of node-internode segments of Avena sativa under red and far-red light regimes. Plant Physiol. Suppl. 36: x7i.

94. Klein, A. 0. and Hagen, C. W., Jr., 1961. Anthocyanjin production in detached petals of Impatiens balsamina I. Plant Physiol. 36(I): $1-9$.

94a. Klein, W. H., Withrow, R. B. and Elstad, V. B., 1956. Response of the hypocotyl hook of bean seedlings to radiant energy and other factors. Plant Physiol. 31: 289-294.

95. Kleshnin, A. F., 1943. On the role of spectral compasition of light in photoperiodic reaction. Compt. Rend. (Doklady) Acad. Sci. U.S.S.R. $40: 208-211$.

96. Klingensmith, M. J., 1961. The effect of Benzimidazole on cation uptake by plant roots. Am. J. Botany 48(8): 711-716. 
97. Laetsch, W. M. and Briggs, W. R., 1961. Photomorphogenetic responses of the sporling of the water fern, Marsilea vestita. Am. J. Botany 48(No. 6. Part 2): 529 .

98. Lang, A., 1956. Stem elongation in a rosette plant induced by gibberellic acid. Naturwiss. 43: 257-258.

99. 1956. Induction of flower formation in biennial Hyoscyamus by treatment with gibberellin. Naturwiss. 43: 284285.

100. Lang, S., 1929. Uber den Einfluss weissen and roten Lichtes auf die Entrucklung des Mesokotyls bei Haferkeimling. Jahrb. Wiss. Bot. 71 : $1-25$.

101. Leopold, A. C. and Guernsey, F. S., 1953. A theory of auxin action involving coenzyme-A. Proc. Natl. Acad. Sci. (U.S.) 39: 1105기기.

102. Marcus, A., 1960. Photocontrol of formation of red kinney bean leaf triphosphopyridine nucleotide linked triosephosphate dehydrogenase. Plant Physiol. 35: 126-128.

103. McCorquodale, D. J., and Ducan, R. E., 1957. Plant growth inhibitions by certain imidazole compounds and their preventions with metal ions. Am. J. Botany $44(8): 716-723$.

104. Mego, J. L. and Jagendorf, A. T., 1961. Effect of light on growth of Black Valentine bean plastids. Biochem. Biophys. Acta 53: $237-254$.

105. Mohr, H., 1957. Der Einfluss monochromatischer Strahlung auf das Langenwachstum des Hypocotyls und auf die Anthocyanbildung bei Keimlingen von Sinapsis alba $L$. ( = Brassica alba Boiss.) Planta 49: $389-405$.

106. and Pichler, I., 1960. Der Einfluss hellroter und dunkelroter Strahlung auf die geotropische Reaktion der Keimlinge von Sinapsis alba I. Planta. 55: 57-66.

107. Mumford, F. E., Smith, D. H. and Castle, J. E., 1961. An inhibitor of indoleacetic acid oxidase from pea tips. Plant Physiol. $36(6): 752-756$.

108. Nakayama, S., Borthwick, H. A. and Hendricks, S. B., 1960. Failure of photoreversible control of flowering in Pharbitis nil. Botan. Gaz. 121: 237-243.

109. Nance, J.F., 1958. Effects of indoleacetic acid on the utilization of acetate 1-Cl4 by pea stem slices. Plant Physiol. 33: 93-98. 
110. Noel, R., 1951. Contribution a l'etud de la rhizogenesis. Neoformation des racines dans les fragments de hypocotyles d'Impatiens balsamina L. cultives in "Vitro". Arch. Inst. Bot., Univ. of Tiiege, Belgique 21: 1-164.

111. balsamina I. Lejunia $14:$ 33-36.

112, 'O hEocha, Colm, 1960. Chemical studies of phycoerythrins and phycocyanins. In: Comparative Biochemistry of Photoreactive Systems, Symposia on Comp. Biol. Vol. I. Mary Belle Allen, Ed., Academic Press, N.Y. pp. 181-203.

112a. Paech, K. and Eberhardt, F., 1952. Untersuchungen zur Biosynthese der Anthocyane. Z. Naturforsch. 7b: 664-670.

113. Parker, M. W., Hendricks, S. B. and Borthwick, H. A., 1950. Action spectrum for the photoperiodic control of floral initiation of the long-day plant Hyocyamus niger, Botan. Gaz. 111: 242-252.

114. —_ _ and Scully, N. J., 1946. Action spectrum for the photoperiodic control of floral initiation of short-day plants. Botan. Gaz. 108: 1-26.

115 .

and , 1945. Action spectrum for the photoperiodic control of floral initiation in Biloxi Soybean. Science 102: 152-155.

116. Perlis, I. B., Nance, J. F., 1956. IAA and the utilization of radioactive pyruvate and acetate by wheat roots. Plant Physiol. $31: 451-455$.

117. Person, C., Samborsky, D. J. and Forsyth, F.R., 1957. Eiffect of benzimidazole on detached wheat leaves. Nature 180: 1294-1295.

118. Phinney, B. 0., and West, C. A., 1960. Gibberellins as native plant growth regulators. Ann. Rev. Plant Physiol. 11: 411-436.

119. Prat, H., 1951. Histophysiological gradients and plant organogenesis Botan. Rev, 17(10): 693-746.

120. genesis. Botan. Rev. 14: 603-643.

121. Purves, W. K. and Hillman, W. S., 1959. Experimental separation of gibberellin and auxin actions in etiolated pea epicotyl sections. Physiol. Plantarum 12: 786-798.

122. Razumov, V.I., 1933. The significance of the qualitative composition of light in photoperiodical response. Bull. Appl. Botany, Genet. and Plant Breeding, III. Phys. Biochem. and Anat. Plants 3: $217-251$. 
123. Resch, A., 1952. Untersuchen uber Kerndifferzierung in Periferen Zellschicten der Sprossachse eineger Hlutenpflanzen. Chromosoma $5(3): 296-316$.

124. Resuhr, B., 1939. Bietrage zur Lichtkeimung von Amaranthus caudatus L. and Phacelia tanacetifolia Benth. Planta $\overline{30: 471-50} 6$.

125. Salisbury, F. B. and Boner, J., 1960. Inhibition of photoperiodic induetion by 5-fluorouracil. Plant Physiol. 35: 173-177.

126. and 1958. Fiffects of uracil dertvatives on flowering of Xanthium. Plant Physiol. Suppl. 33: xxv.

127. Samborski, D. J., Forsyth, F. R. and Person, G., 1958. Metabolic changes in detached wheat leaves floated on benzimidazole and the effect of these changes on rust reaction. Can. J. Botany 36 : 591-601

127a. Sass, J. E., 1951. Botanical Microtechnique. Iowa State Gollege Press, Ames.

128. Schraudolf, H. and Reinert, J., 1959. Interaction of plant growth regulators in regeneration processes. Nature $184: 465-466$.

129. Siegel, S. M. and Grlston, A. W., 1953. Experimental coupling of indoleacetic acid to pea root protein in vivo and in vitro. Proc. Nat. Acad. Sei. (J.S.) 39: 1111-1118.

130. Siegelman, H.W., 1962. Personal communication, March, 1962.

131. __ and Hendricks, S. B., 1958. Photocontrol of alcohol, aldehyde, and anthocyanin production in apple skin. Plant Physiol. 33(6): 409-413.

132. and , 1958. Photocontrol of anthocyanin syntresis in apple skin. Plant Physiol. 33(3): 185-190.

133. and , 1957. Photocontrol of anthocyanin formation in turnip and red cabbage seedlings. Plant Physiol. $32(5): 393-398$.

134 . Firer, E. M., Butler, W. L., and Hendricks, S. B., 1961. purification of phytochrome. Plant Physiol. Suppl. 36: Partial xlii.

135. Simpson, G. M. and Wain, R. L., 1961. A relationship between gibberellic acid and light in the control of internode extension of dwarf peas (Pisum sativam). J. texptl. Botany 12: 207-216.

136. Sinnot, F. W. and R. Bloch, 1947. Division in vacuolate plant cells. Am. J. Botany 28: 225-232. 
137. Smith, D. H., Jr., Mumford, F. E., and Castle, J. E., 1961. Indoleacetic aeid oxidase inhibitor from etiolated pea epieotyls. Plant Physiol. Suppl. 36: xlvii.

138. Steward, F. 0. and Shantz, T. M., 1959. The chemical regulation of growth (some substances and extracts which induce growth and morphogenesis). Ann. Rev. Plant Physiol. 10: 379-404.

139. Stewart, N.W. and Cathey, H. M., 196I. Applied aspects of the gibberellins. Ann. Rev. Plant Physiol. 12: 369-394.

140. Stodola, F.H., 1958. Source Book on gibberellin, 1828-1957. Agr. Research Ser. U.S.D.A., Peoria, Ill.

I47. Stowe, B. B. and Yamaki, T., 1959. Gibberellins: Stimulants of plant growth. Science 129: 807-816.

142 . and Yamaki, T., 1957. The history and physiological action of the gibberellins. Ann. Rev. Plant Physiol. 8; $181-216$.

143. Straus, J., 1960. Anthocyanin synthesis in corn endosperm tissue cultures. II. Effect of certain inhibitory and stimulatory agents. Plant Physiol. 35(5): 645-650.

Ih⿲. 1959. Anthocyanin synthesis in corn endosperm tissue cultures. I. Identity of the pigments and general factors. Plant Physiol. 34: 536-54工.

145. Tavant, H., 1961. Action du photoperiodisme et de I'acide gibberellique sur le development du Begonia gracilis et du Begonia sergoerfloreas. Bull. Soc. d'History Nat. Doubs. 63 (2): $37-38$.

146. Thimann, K. and Edmundson, Y., 1951. The biogenesis of the anthocyanins. III. The role of sugars in anthocyanin formation. Arch Biochem. Biophys. 34: 305-323.

147. and , 1949. The biogenesis of the anthocyamins. I. General nutritional conditions leading to anthocyanin formation. Arch. Biochem. 22: 33-53.

148. and Radner, B., 1958. The biogenesls of anthocyanin. VI. The role of riboflavine. Arch. Biochem. Biophys. $74: 209-223$.

149. and , 1955. The biogenesis of anthocyanin. T. Fvidence for the mediation of pyrimidines in anthocyanin synthesis. Arch. Biochem. Biophys. 59: 511-525.

150. Thomas, E. N., 1914. Seed7ing anatomy of Ranales, Rhoedales, and Rosales. Ann. Botany 28: 695-733. 
151. 1907. A theory of the double leaf trace founded on seedling structure. New Phytol. 6: 77-91.

152. Toole, E. H., 1958. Effect of light on the germination of seeds. Proc. Natl. Res. Council Symp. on Plant and Animal Photoperiodism and Related Phenomena. R. B. Withrow ed., pp. 89-99.

153. ___ Hendricks, S. B., Borthwick, H. A. and Toole, V. K., 1956. Physiology of seed germination, Ann. Rev. Plant Physiol. 7: $299-324$.

154. Tronchet, J., 1961. Etude par chromotographic sur papier des flavonoides d'especes "refractaires" a un traitment gibberellique. Bull. Soc. d'Hist. Nat. Doubs. 63(2): 39-43.

155. , 1960. Etud par chromotographic sur papier des flavonoides deConvolvulus sepium dans les flagelles volubiles, les tiges rampantes devenues volubiles par traitement gibberellique. Bull. Soc. d'Hist. Nat. Doubs 62(4): 101-104.

156. Trumpf, C., 1924. Uber den Einfluss intermittierender Belichtung auf das Etiolement der Pflanzen. Bot. Archiv. 5: 381-410.

157. Underhill, E. W., Watkin, J. E. and Neish, A. C., 1957. Biosynthesis of quercitin in buckwheat. Part. I. Can. J. Biochem. Physiol. 35: $3219-3222$.

158. Vendrig, J. C., 1961. Caffeic acid, a substance with auxin activity found in extracts from Coleus rhenaltianus. Acta Bot. Neer. 10: $190-198$.

159. Vogt. E., 1915. Uber den Einfluss des Lichtes auf das Wachstum der Koleoptile von Avena sativa. ㄱ. Bot. 7: 193-271.

160. Voth, P. O. and Hamner, K. G., 1940. Responses of Marchantia polymorphia to nutrient supply and photoperiod. Botan. Gaz.

161. Wa.tkin, J. E., Underhill, E. W., and Neish, A. C., 1957. Biosynthesis of quercitin in buckwheat Part II. Can. J. Biochem. Physiol. 35: $229-237$.

162. Weijer, J., 1959. Studies on Impatiens balsamina I. I. The inheritance of flower colour and its bearing on the phenomenon of cumulative linked isomery. Genetica 29: 358-384.

163. Weintraub, R. L., Brown, J.W., Nickerson, J. C. and Taylor, K. N., 1952. Studies on the relation between molecular structure and physiological activity of plant growth regulators. I: Abscissioninducing activity. Botan. Gaz. 113: 348-362 . 
164. Wheeler, A.W., 1961. Effect of light quality on the growth and growth-substance content of plants. J. Exptl. Botany 12: 217225 .

165. White, P. R., 1943. A Handbook of Plant Tissue Culture, Cattell Press, Lancaster, Pa.

166. Wiegand, O. F. and Schrank, A., 1961. Effects of red light on avena coleoptile growth. Plant Physiol. Suppl. 36: xli.

167. Withrow, R. B. and Benedict, H. M., 1936. Photoperiodic responses of certain greenhouse annuals as influenced by intensity and wavelength of artificial light used to lengthen the daylight period. Plant Physiol. 1l: 225-249.

168. and Biebel, J. P., 1936. Photoperiodic response of certain long and short day plants to filtered radiation applied as a supplement to daylight. Plant Physiol. 11: 807-819.

169. , and Withrow, Alice P., 1940. The effect of various wave bands of supplementary radiation on the photoperiodic response of certain plants. Plant Physiol. 15: 609-624.

$169 a$. , Klein, W. H. and Elstad, V., 1957. Action spectra of photomorphogenic induction and its photoinactivation. Plant Physiol. 32: 453-462.

170. , Price, L. and Elstad, V., 1953. Influence of visible and near infrared radiant energy on organ development and pigment synthesis in bean and corn. Plant Physiol. $28(1): 1-14$.

171. Wittwer, S.H., and Bukovac, M. J., 1958. The effects of gibberellin on economic crops. Econ. Botany 12: 213-255.

172. Woodruff, R. E., and Crandall, P. C., 1958. The effect of several respiratory inhibitors on apples. Proc. Am. Hort. Soc. 7l: $26-31$.

173. Zimmerman, P.W. and Hitchcock, A. E., 1942. Substituted phenoxy and benzoic acid growth substances and the relation of structure to physiological activity. Contr. Boyce Thompson Inst. 12: 321343 . 